\title{
WestVirginiaUniversity
}

THE RESEARCH REPOSITORY @ WVU

Graduate Theses, Dissertations, and Problem Reports

2009

\section{Understanding the expression and implications of deceptive affectionate messages}

Sean M. Horan

West Virginia University

Follow this and additional works at: https://researchrepository.wvu.edu/etd

\section{Recommended Citation}

Horan, Sean M., "Understanding the expression and implications of deceptive affectionate messages" (2009). Graduate Theses, Dissertations, and Problem Reports. 2852.

https://researchrepository.wvu.edu/etd/2852

This Dissertation is protected by copyright and/or related rights. It has been brought to you by the The Research Repository @ WVU with permission from the rights-holder(s). You are free to use this Dissertation in any way that is permitted by the copyright and related rights legislation that applies to your use. For other uses you must obtain permission from the rights-holder(s) directly, unless additional rights are indicated by a Creative Commons license in the record and/ or on the work itself. This Dissertation has been accepted for inclusion in WVU Graduate Theses, Dissertations, and Problem Reports collection by an authorized administrator of The Research Repository @ WVU.

For more information, please contact researchrepository@mail.wvu.edu. 


\title{
Understanding the Expression and Implications of Deceptive Affectionate Messages
}

\author{
Sean M. Horan
}

Dissertation

\author{
Submitted to the Eberly College of Arts and Sciences \\ at \\ West Virginia University \\ in partial fulfillments of the degree requirements \\ for the degree of \\ Doctor of Philosophy \\ in \\ Communication Studies \\ Melanie Booth-Butterfield, Ph.D., Chair \\ Rebecca M. Chory, Ph.D. \\ Megan R. Dillow, Ph.D. \\ Matthew M. Martin, Ph.D. \\ Ann Bainbridge Frymier, Ed.D. \\ Department of Communication Studies \\ Morgantown, West Virginia \\ 2009
}

Keywords: Affection, blood pressure, deception, guilt, emotion, heart rate, rumination, shame 


\begin{abstract}
Understanding the Expression and Implications of Deceptive Affectionate Messages
\end{abstract}

Sean M. Horan

Affectionate messages are important in romantic relationships as they are linked to multiple emotional, physical, and relational benefits (e.g., Floyd, 2006a). When examining affection, it is important to distinguish that feelings of affection and the communication of affection are two unique processes that theorists argue covary. Yet, deception researchers have found that individuals routinely lie to their non-married romantic partners about their feelings (DePaulo \& Kasy, 1998; DePaulo, Kashy, Kirkendol, Wyer, \& Epstein, 1996). This dissertation, composed of two studies, examined how individuals in non-married romantic relationships communicated deceptive affection and the implications of such messages. Study one used a week long diary method in which participants recorded instances of deceptive affection and rumination. Results indicated that individuals communicated approximately three deceptive affectionate messages (DAMs) to their partners in a week, and the type of DAM was related to rumination. These messages were most often used to conceal negative feelings and expressed for prosocial reasons. Study two was an experiment that examined the emotional (guilt and shame) and physiological (heart rate and blood pressure) implications of expressing DAMs to romantic partners. A writing method was used where participants wrote for 20 minutes about either a DAM, honest affection, or plans with friends (control). Results indicated that the writing method did not result in any physiological changes. Deceptive motives did not influence deceivers' feelings of guilt and shame. Together, deceptive affection appears to be a message that partners routinely communicate to one another resulting in minimal emotional and physiological implications. 


\section{Table of Contents}

ABSTRACT. .ii

ACKNOWLEDGEMENTS................................................ vi

CHAPTER 1: INTRODUCTION..........................................

Affection.........................................................

Rationale.......................................................... 2

Affection Exchange Theory........................................6 6

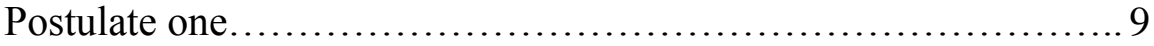

Postulate two.................................................. 9

Postulate three............................................... 10

Postulate four.............................................. 13

Postulate five............................................... 14

Deception......................................................... 16

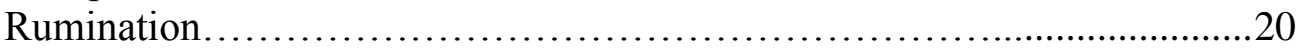

Affection and physiological responses.............................. 22

Emotional responses............................................... 25

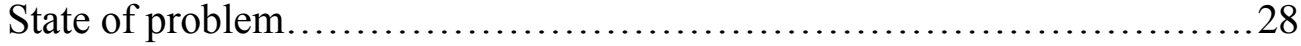

Study one................................................. 28

Research question one...............................28

Research question two-a............................ 29

Research question two-b.............................29

Research question three.............................. 29

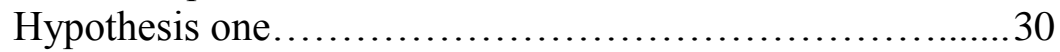

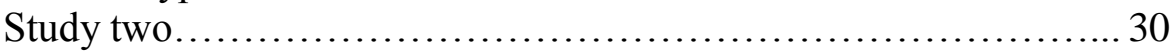

Hypothesis one-a.................................... 31

Hypothesis one-b.................................. 31

Research question one-a.................................... 32

Research question one-b............................ 32

Research question two-a............................... 32

Research question two-b............................. 32

Hypothesis two..................................... 33

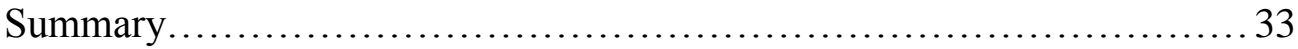

CHAPTER II: METHOD ................................................ 34

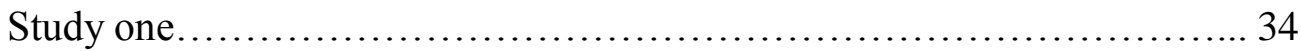

Participants............................................... 36

Procedure and instrumentation...................................... 37

Phase one: Introduction and training........................... 38

Phase two: Seven-day diary ................................. 44

Phase three: Submission and additional measures..................44

Understanding participant mortality ......................... 47 


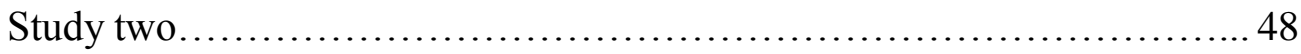

Participants.................................................. 48

Procedure and instrumentation................................ 50

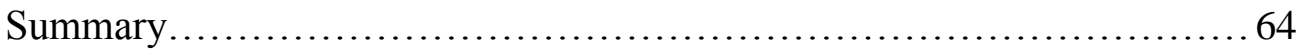

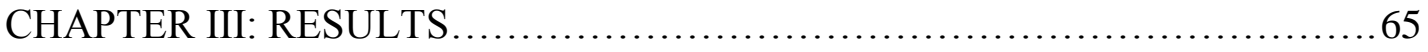

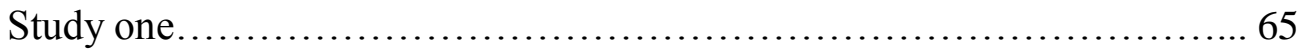

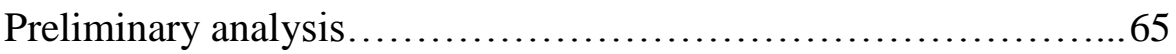

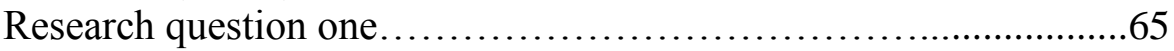

Analyzing research questions two and three......................67

Research question two-a....................................... 68

Research question two-b.................................. 71

Research question three...................................... 72

Hypothesis one ............................................. 76

Post-hoc analysis............................................ 77

Summary ....................................................... 79

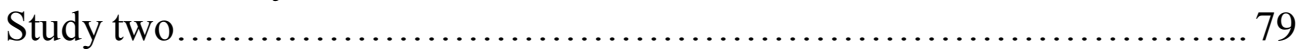

Preliminary analysis.......................................... 79

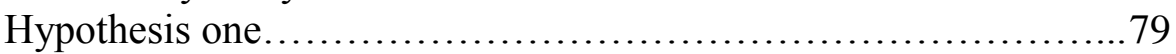

Research question one...................................... 80

Research question two......................................... 81

Hypothesis two ............................................ 82

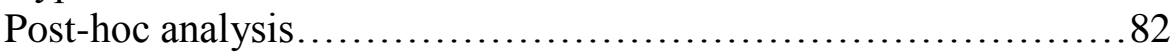

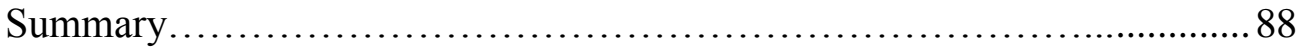

CHAPTER IV: DISCUSSION................................................. 90

Deceptive affectionate messages..................................... 91

Feelings, messages, and deceptive affection............................ 93

Motives for deceptive affection....................................... 96

Deceptive affection and physiological responses........................ 99

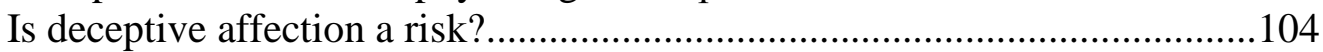

Implications..................................................... 107

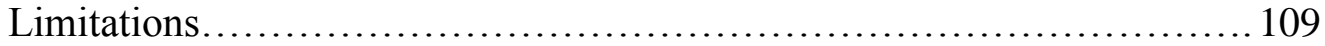

Future Research.................................................... 112

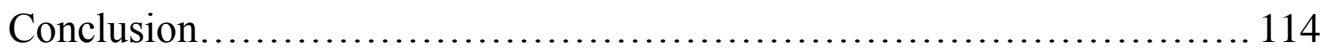

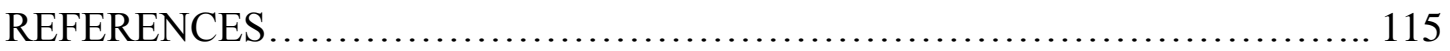

\section{APPENDICES}

A Outline of study one training................................ 130

B Study one materials.......................................... 133

C Writing instrument for study two.................................

D Guilt and shame measures.................................... 147

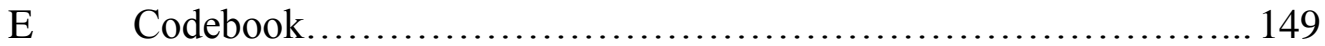




\section{LIST OF TABLES AND FIGURES}

Figure 1. Summary of instruments completed in study one..................... 35

Table 1. Study one descriptive statistics............................... 45

Figure 2. Summary of study two design.................................. 49

Table 2. Study two descriptive statistics................................ 52

Table 3. Descriptive statistics for physiological measures at time one for men.....54

Table 4. Descriptive statistics for physiological measures at time one for women...55

Table 5. Men's physiological statistics for deception condition at time two.........58

Table 6. Women's physiological statistics for deception condition at time two...... 59

Table 7. Men's physiological statistics for honest condition at time two............60

Table 8. Women's physiological statistics for honest condition at time two....... 61

Table 9. Men's physiological statistics for the control condition at time two........62

Table 10. Women's physiological statistics for the control condition at time two...63

Table 11. Feelings that are the subject of deceptive affection...................69

Table 12. Affectionate messages employed to convey deception................. 73

Table 13. Motives for deceptive affectionate messages...................... 75

Table 14. Men's physiological descriptive statistics for guilt based on motive..... 83

Table 15. Women's physiological descriptive statistics for guilt based on motive... 84

Table 16. Descriptive statistics for guilt based on motive $\ldots \ldots \ldots \ldots \ldots \ldots \ldots \ldots \ldots 6$

Table 17. Descriptive statistics for shame based on motive..................... 87 


\section{ACKNOWLEDGEMENTS}

Foremost, I would like to thank my advisor Melanie Booth-Butterfield.

Throughout my time at West Virginia you have challenged me and maintained difficult, yet fair, expectations that made me a better student and improved my research skills. I also want to thank you for the opportunity to work as your Editorial Assistant for Communication Education, for helping fund this dissertation, and for agreeing to advise a project on affectionate communication. Most importantly, thank you for believing in me. I have really enjoyed our relationship and look forward to working with you in the future. You are an excellent mentor.

Second, I would like to thank the members of my on campus committee: Rebecca Chory, Megan Dillow, and Matt Martin. I had all of you in class before and enjoyed hearing about your perspectives of the field. I have completed original research projects with each of you, and I appreciate the fact that you each let me research areas I was interested in. I also thank you for your feedback, as you all have helped me grow as a researcher. Thanking my committee would be incomplete without extending special gratitude to my external committee member, Ann Bainbridge Frymier. Ann, you have been a great mentor over the years and I appreciate all of the professional and personal advice you have offered.

Third, I would like to thank those who offered support throughout this journey. To my research assistant and COMM 100 TA, Colleen, thank you for all of your help with the administrative duties associated with this research. A special thanks to all of my close friends who offered support, especially Alan, Brandi, Kerry, and my fellow WVU 
graduate students. Importantly, thank you to Marian Houser and Tim Mottet who encouraged me to go to WVU.

Finally, I would like to thank my family for their consistent support over the years. Mom and Dad, I know you thought I'd never graduate high school, so I guess the joke is on you. Seriously though, I greatly appreciate all of the support, guidance, and laughs you have offered over the years. I also thank you for your unique ways, as they have given me hundreds of stories to use while I teach. To my brother Tom, thanks for visiting Morgantown and buying me stuff I could not afford. Finally, to all of my Aunts, Uncles, and cousins, especially Kelly, Marie, Al, Dawn, Barbie, Jerry, Lisa, Vicki, Chrissy, Dan, Matt, Amy, and Mikey (and the list does go on), thanks for always being a source of laughter and friendship. 


\section{Chapter 1}

Introduction

Affectionate messages are important memorable messages in romantic relationships (Booth-Butterfield \& Trotta, 1994; Owen, 1987). Speaking to their importance is research indicating that married couples reported affectionate communication to be the most significant interaction that impacted their relationship (Dainton, 1998). Dissatisfaction with affection was

cited as a main reason that couples seek therapy (Doss, Simpson, \& Christensen, 2004), and a 13 year study of married couples revealed that a decline in affectionate communication discriminated between divorced and stably married couples (Huston, Caughlin, Houts, Smith, \& George, 2002). Although the study of affection's impact on romantic relationships has largely focused on married couples, recent work suggests affection is equally important in non-marital romantic relationships. Self-report data of a sample in which more than $80 \%$ of respondents were not married indicated that highly affectionate individuals were more likely to be in a romantic relationship (Floyd, Hesse et al, 2005) and maintain higher levels of satisfaction (Floyd, 2002; Floyd, Hesse et al., 2005). Collectively, the previous studies demonstrate the significance of affectionate communication in romantic relationships.

Since affection is important in romantic relationships, social scientists have attempted to classify this phenomenon. Affection has been categorized as a basic interpersonal need (Schutz, 1958), a communication motive (Rubin, Perse, \& Barbato, 1988), and a relational maintenance behavior (Guerrero \& Bachman, 2006). Recently, in an effort to further understand affectionate communication, Floyd (2001, 2006a) proposed a comprehensive set of predictions about affectionate communication in the form of Affection Exchange Theory (AET). Grounded in an evolutionary perspective, AET (Floyd, 2001, 2006a) considers affectionate communication to be 
an adaptive behavior that leads to long term survival of human beings. Theoretically, affectionate communicators are viewed as being privileged compared to their less affectionate counterparts. Consistent with the argument that affection is a basic relational resource, past studies indicate that individuals identify affection as an important and valued characteristics in a potential mate (Brann, Horan, \& Sidelinger, 2008; Buss \& Barnes, 1986; Hansen, 1977). This suggests that individuals engaged in the mate selection process have an implicit awareness of the importance of affection, namely that such communication improves physiological functioning and positively influences relational qualities (e.g., Floyd, 2006a). Accordingly, AET predicts that affectionate communicators should be perceived as more attractive partners who are able to form quality romantic relationships. If these romantic relationships result in procreation, these attractive mates should be affectionate parents who regularly communicate such messages to their children. Combined, this long term pattern of affectionate communication should result in adult children who, when engaged in the mate selection process, will be attractive potential romantic partners, thus affording these adult children more reproductive opportunities. Accordingly, AET views affectionate messages to be pivotal in the mate selection and pro-creation process, as well as in the rearing of children (Floyd, 2006a).

\section{Rationale}

When discussing affection it is important to distinguish between feelings of affection and communicating affection. Feeling affection "involves feeling warmth and fondness toward someone" (Andersen \& Guerrero, 1998, p. 59), whereas affectionate communication is composed of messages that convey these "feelings of fondness, support, and love" (Floyd, 2006b, p. 47). As such, affectionate communication should represent the outward expression of one's internal feelings of affection-yet are these two experiences always consistent? Within 
romantic relationships, it is unlikely that partners are always completely honest about every feeling they experience. For example, an individual may feel tired, frustrated, or little desire to express affection yes still express romantic partner affection. Individuals may express affection that is inconsistent with their actual feelings of affection for a number of reasons. Potential motives for these deceptive messages include protecting their partner's feelings, saving their own face, manipulation, or simply following through with a relational ritual to strengthen pair bonds. This reasoning suggests that feelings of affection and expressions of affection may not always be consistent. Expressions of affection that a source does not genuinely experience may impact the quality of the relationship and the nature of the communication between partners. For instance, if this deception were discovered, partners could experience a decline in overall relationship quality. If these messages go undetected, the source may experience stress or guilt about the deception or, conversely, satisfaction that his/her goal was accomplished. Thus, although the frequency of and manner in which individuals express inauthentic affection is unknown, such messages likely occur in romantic relationships and have the potential to influence communicators.

In an attempt to clarify the relationship between feelings of affection and the communication of affectionate, AET's second postulate predicts that "Affectionate feelings and affectionate expressions are distinct experiences that often, but need not, covary" (Floyd, 2006a, p. 163). Although this postulate argues that affectionate messages and feelings often covary, it also acknowledges that affectionate messages and feelings can differ. Prior deception research revealed that deception is common and, indeed, people do lie about feelings in close relationships (DePaulo, Kashy, Kirkendol, Wyer, \& Epstein, 1996). In a week long diary study including traditionally aged college students and adults, DePaulo et al. (1996) revealed that 
deceptive messages were commonly communicated to romantic partners and participants reported feelings were the most frequent topic of deceptive communication. Examples of these lies included falsifying an emotion a source did not actually experience and expressions of enhanced feelings of liking toward someone/something.

Combining AET and deception research by DePaulo et al. (1996), the aim of this dissertation is to systematically examine deceptive affection in romantic relationships. Deceptive affection can occur in one of two ways. First, it can occur when individuals withhold feelings of affection they genuinely feel. This constitutes deception because a source is withholding information and, instead of expressing their genuine affection, a source elects to convey a different message. Second, deceptive affection can occur when an individual expresses deceptive affectionate messages (DAMs), considered as overt expressions of affection that are not consistent with a source's internal feelings of affection or non-affection. These messages are deceptive because they represent situations in which communicators use affectionate messages to mask their true feelings. Considering these types of deceptive affection together, the focus of this dissertation is on DAMs rather than instances in which communicators withhold affection. These DAMs constitute a specific type of romantic partner deception and, consistent with traditional deception research, both the valence and motive for deceptive affection vary and likely influence relational factors. Accordingly, in an effort to understand these inauthentic expressions of affection, this dissertation has two goals. As prior research has not systematically studied these inauthentic expressions of affection the first goal of this dissertation is to understand the frequency of, topics of, and motives for expressing deceptive affection messages (DAMs). Second, this dissertation seeks to examine the effects of expressing DAMs on the source, namely 
in the form of rumination, emotional reactions (guilt and shame), and physiological reactions (changes in heart rate and blood pressure).

Affection Exchange Theory largely positions affection as a positive experience because it predicts a host of positive outcomes associated with affectionate communication. However, Floyd (2006a) cautions against assuming that affectionate communication only results in positive outcomes, and AET researchers frequently describe affectionate communication as "risky" because it could result in less than optimal outcomes (Floyd, 1997a, 1997b, 2001, 2006a; Floyd \& Voloudakis, 1999; Morman \& Floyd, 1998). Potential risks include rejection, a lack of reciprocation, or being manipulated. Although not a widely researched area, Messman and Mikesell (2000) offer an example of one relational complication associated with affection. They found that affection is one of seven areas over which relational partners routinely compete. That is, partners typically try to "out-do" or "keep up with one another" in the area of affection (p. 26). Although affection and conflict strategies have not specifically been examined, research has found relationships between certain relational competition areas and negative, distributive conflict strategies (Messman \& Mikesell, 2000). Another study identifying complications that can result when expressing affectionate communication relates to sibling communication. It was found that individuals anticipated more rumination when siblings disclosed a transgression and communicated affection compared to when siblings disclosed a transgression without affection (Horan \& Turner, 2009). Contrary to research indicating enhanced relational perceptions within the context of affectionate communication (e.g., Floyd, 2006a), the previous study highlights a situation in which affectionate communication may hurt perceptions in the form of negative rumination. Together, the previous studies begin to identify instances in which affectionate messages may fail to enhance relational and situational perceptions. 
Given that expressions of affection are described as potentially "risky," Floyd (2006a) called for researchers to examine the conditions under which sending or receiving affection could be hazardous. Consistent with Floyd's argument, it is argued that DAMs are risks for sources of deception. Most apparent is the risk of deception detection, potentially resulting in alterations of relational qualities and/or communication. However, even if the deceptive message goes undetected, a source may feel guilt or shame for communicating deception to his/her partner, may ruminate over such communication, and could experience physiological changes related to increased stress. The present research examines these possibilities as potential outcomes for expressing deceptive affection. Further, this research will begin to elucidate if deceptive affection is, in fact, a risk for communicators.

In order to fully understand the rationale for this dissertation, it is necessary to discuss foundational research. Because this dissertation is grounded in AET, the theory's postulates and related research will be reviewed.

\section{Affection Exchange Theory}

Affection Exchange Theory is rooted in evolutionary psychology, and as such, it is necessary to first understand this perspective before discussing AET. Evolutionary theory is principally concerned with understanding and "explaining the survival of the species via processes of natural selection" (Harvey \& Wenzel, 2006 p. 35). Using Darwin's Theory of Natural Selection (Darwin, 1859), the evolutionary perspective has been largely applied to understanding mate selection preferences and argues that men and women value traditional gender characteristics in the opposite sex (e.g., Buss 1985, 1988, 2006; Buss \& Barnes, 1986; Pines, 2001; Sprecher, Sullivan, \& Hatfield, 1994). Consequently, men value good looks and youth, both indicators of women's fertility. According to this perspective, these characteristics 
are attractive to men because they indicate enhanced opportunities for procreation. In opposition, evolutionary theorists argue that women are more invested in the mate selection process because they can only produce a limited number of offspring and are responsible for rearing those children. Evolutionary theorists argue that women are attracted to men who exhibit the potential to care for and protect a family, enhancing the chances that offspring will survive. Although these arguments are controversial to some (see, for example, Harvey \& Wenzel, 2006), these arguments have garnered support. Sprecher et al. (1994), for example, found that women preferred men who had economic potential, whereas men preferred youthful and attractive women.

The evolutionary focus on what is attractive in mates has directed researchers toward examining mate value - that is, the perceived worth attached to certain characteristics potential mates possess (Kugeares, 2002). Mate value has been used to explain differences in relational communication. Sidelinger and Booth-Butterfield (2007), for example, examined the perceived difference in resource value between two partners, termed mate value discrepancy, and how this influenced communication. They found that when individuals perceived their partner to be of higher mate value than they perceived themselves to be they reported a higher likelihood to forgive their partner's transgressions and a higher likelihood to experience jealousy. This suggests that mate value discrepancy influences relational communication. Given that affection has been identified as a valued characteristic in a potential mate (Brann et al., 2008; Buss \& Barnes, 1986; Hansen, 1977) and as a resource given in romantic relationships (Floyd, 2006a; Foa \& Foa, 1972), perceptions of another's affection potentially influences mate value discrepancy and subsequent communication. 
Mate value researchers and AET scholars both view affection as a beneficial resource in romantic relationships, arguing affection's main benefit is its direct link to procreation. However, prior research offers other, non-procreation based examples of how affectionate messages are important and beneficial in relationships. For instance, research indicates that parents' expressions of affection to children help prevent depression, neuroticism, and anxiety in children (Jorm, Dear, Rodgers, \& Christensen, 2003; Kerver, Van Son, \& De Groot, 1992). Within romantic relationships, affectionate messages are related to conflict resolution (Gulledge, Gulledge, \& Stahmann, 2003), physical health (e.g., Keicolt-Glaser \& Newton, 2001; Medalie, Strange, Zyanski, \& Goldbourt, 1992), relational satisfaction (Floyd, 2002; Floyd, Hesse et al., 2005; Gulledge et al., 2003; Horan \& Booth-Butterfield, in press), and commitment (Horan \& Booth-Butterfield, in press). Together, these studies identify a few of the non-procreation based benefits associated with affectionate communication, supporting AET and evolutionary theorists' contention that affection is a beneficial and valued resource in close relationships.

Affection Exchange Theory is argued to be both similar and unique from existing evolutionary theories. In terms of similarity, Floyd (2006a) acknowledges that some of the arguments proposed by AET can be found in other evolutionary research. For instance, both mate value research and AET argue that affection is a resource in relationships. However, AET is distinct from evolutionary psychology because it is not a direct application of the Theory of Natural Selection (Darwin, 1859) to explain affectionate communication. Rather, it is unique because it aims to "cast affectionate communication in adaptive terms and to begin to specify the biological and environmental factors through which it serves humans' most pressing evolutionary needs" (Floyd, 2006a, p. 160). Affection Exchange Theory details this process through five postulates which will be reviewed in the subsequent discussion. Throughout the 
theory summary, the term "affectionate communication" will be used to encompass both sending and receiving affection, because the theory argues there are benefits to both processes.

Postulate one. The first postulate of AET contends that "the need and capacity for affection are inborn" (Floyd, 2006a, p. 161). Accordingly, postulate one is consistent with Schutz's (1958) early claim that affection is a basic need. This postulate focuses on the internal need to give and to receive love and affection. Past research on communication motives may reflect a manifestation of this need. Rubin et al. (1988) identified affection as one motive for why people communicate. Later, Anderson and Martin (1995) found that competent communicators identified expressing affection as one of their primary motives.

Both developmental and non-developmental factors may impact one's need and capacity for affection. Family communication patterns, for example, are argued to be one source of variation in affection needs (Floyd \& Morman, 2000). Research revealed that fathers communicated more affection to sons than sons communicated to fathers (Floyd \& Morman, 2000, 2003). Further, a number of internal factors, ranging from self monitoring to Asperger's syndrome, have been speculated to impact one's need and capacity for affection (Floyd, 2006a). Recent research found that the developmental factor Alexithymia (e.g., a personality trait that impairs one's ability to recognize emotions and feelings; Sifneos, 1973), was related to a communicator's affectionate expressions because those who exhibited high levels of Alexithymia reported lower levels of giving and receiving affection (Hesse \& Floyd, 2008). In concert, AET's first postulate argues that individuals have an innate need to give and to receive affection, which can be impacted by a number of factors.

Postulate two. The theory's second postulate contends that "Affectionate feelings and affectionate expressions are distinct experiences that often, but need not, covary" (Floyd, 2006a, 
p. 163). As the focus of this dissertation is on DAMs, this postulate is most relevant to this inquiry. Affection Exchange Theory proposes that individuals can "modify" (p. 163) affectionate messages by way of display rules (Ekman \& Friesen, 1975). Ekman and Friesen offer five ways in which individuals can act deceptively with regard to their emotional displays. Individuals can inhibit (e.g., withhold affectionate feelings), simulate (e.g., communicate affection one is not genuinely feeling), intensify (e.g., convey enhanced feelings of affection), deintensify (e.g., convey diminished feelings of affection), or mask (e.g., communicate a different feeling than one's actual affection) affectionate feelings. Potentially, deceptive affection could occur in any of these forms.

In the context of deceptive affection, emerging research supports the argument that individuals do act deceptively with regard to affection using display rules (Hayes \& Metts, 2008) and that individuals do regularly communicate affection that is inconsistent with their internal feelings of affection (Floyd, Erbert et al., 2005, as cited in Floyd, 2006a). Because these studies constitute deception, they will be reviewed later during the discussion of deception.

Postulate three. The third postulate of AET argues that "affectionate communication is adaptive with respect to human viability and fertility" (Floyd, 2006a, p. 164). This claim is elaborated in detail through four sub-postulates.

Postulate three- $a$ argues that "affectionate communication serves the superordinate motivation for viability by promoting the establishment and maintenance of significant human pair bonds" (p. 165). Relational communication theorists (Floyd, 2006a; Foa \& Foa, 1972) consider affection to be a resource in romantic relationships and, as such, the communication of this resource enhances human pair bonds. This is important to relationships because it indicates to partners that one wishes to form a relationship and is able to meet a partner's needs (Floyd \& 
Morr, 2003). This partially explains previously reviewed research indicating the importance of affection in romantic relationships (e.g., Dainton, 1998; Doss et al., 2004). Three-a is supported by research in which individuals reported they were more satisfied and committed in their romantic relationships when they gave and received affection (Floyd, 2002; Floyd, Hesse et al., 2005; Horan \& Booth-Butterfield, in press). Although pair bonding typically refers to romantic relationships, AET argues, and research supports, the notion that affectionate communication enhances relational qualities in non-romantic familial relationships (Floyd \& Morman, 2000, 2001; Floyd \& Morr, 2003; Martin \& Anderson, 1995; Punyanunt-Carter, 2005). These enhanced relational bonds likely explain why highly affectionate individuals, overall, are more comfortable with closeness and have lower fears of intimacy (Floyd, 2002; Floyd, Hesse et al., 2005).

Postulate three-b contends that "affectionate communication serves the superordinate motivation for fertility by representing to potential mating partners that the communicator is a viable partner and fit potential parent" (Floyd, 2006a, p. 166). This postulate extends Darwin's (1859) idea of sexual selection through the introduction of potential parental fitness, which describes the perception of how fit a parent one would be. That is, as part of the mate selection process, individuals discern a potential partner's parenting ability. Thus, communicating affection would signal that one would be a potentially fit parent who is able to form a bond with a mate and a child. This further explains why affection is a valued mate characteristic (Brann et al., 2008; Buss \& Barnes, 1986; Hansen, 1977). Interestingly, AET argues that individuals need not be consciously aware of the affection they give or receive in order to garner its benefits.

Postulate three-c contends that "the relationship between affectionate communication and reproductive opportunity is stronger for women's mate selection than for men's" (Floyd, 2006a, p. 169). Mate selection research supports the argument that men and women seek out different 
criteria in potential mates. Trivers (1972) proposed these sex differences early on by arguing that women are more invested in the procreation process than men. Later research found that resources are an important mate value characteristic and that women identify these resources as important (e.g., Fletcher, Tither, O’Loughling, \& Overall, 2004). As affection is a relational resource (Floyd, 2006a; Foa \& Foa, 1972), women should be more attuned to a mate's affectionate communication when discriminating between potential partners. Extending these findings, AET predicts that men are more likely than women to convey affection to initiate sexual contact. Evolutionary theorists argue that women would be more persuaded by affection than men because affection would signal commitment and attachment, indicating that the male partner would remain in the woman's life to aid in the raising and protection of offspring (Buss, 1985, 1988). However, these findings may not apply when an individual is looking for a short term mate because both sexes value physical attraction during short term mate selection (Fletcher et al., 2004). Collectively, women and men appear to approach mate selection differently, but affection is an important resource in this process that may impact them differently.

Postulate three- $d$ predicts that "the experiences of feeling, communicating, and receiving affection covary with immunocompetence and regulatory physiological pathways for stress and reward" (Floyd, 2006a, p. 169). Essentially, sending or receiving affectionate messages is related to stress and reward responses. Multiple studies have indicated that affection enhances physiological functioning and stress responses (Floyd, 2002, 2006b; Floyd, Mikkelson, Hesse et al., 2007; Floyd, Mikkelson, Tafoya, Farinelli, La Valley, Judd, Davis et al., 2007; Floyd, Mikkelson, Tafoya, Farinelli, La Valley, Judd, Haynes et al., 2007). Self report data indicate that highly affectionate individuals report being less stressed (Floyd, 2002), and self reported expressed affection, while controlling for affection received, was related to lower levels of 
glycosylated hemoglobin, a stress-related factor (Floyd, Hesse, \& Haynes, 2007). Similarly, Schrodt, Ledbetter, and Ohrt (2007) found a negative relationship between parents' level of affection and adult children's self reported levels of stress.

Postulate four. The fourth postulate contends that "humans vary in their optimal tolerances for affection and affectionate behavior" (Floyd, 2006a, p. 171). This extends AET's first postulate because it introduces that individuals have a range of tolerance composed of two anchor points: need and desire. On the low end, individuals have a need for affection, representing an individual's least satisfactory amount of affection that they could receive. On the high end is one's desire for affection, representing an individual's maximum threshold of affection needed. Variations in the range of tolerance are attributed to developmental and nondevelopmental sources. Such factors include parental affection (Floyd, 2001b; Floyd \& Morman, 2000, 2003, 2005), attachment style (Floyd, 2002; Guerrero \& Bachman, 2006), mental health, and gender (Floyd, 2002). Based on the aforementioned factors, as well as other factors that remain to be identified, the width of one's range will fluctuate between people. Postulate four is elaborated through two subpostulates.

Postulate four-a predicts: "The experience, expression, and receipt of affection contribute to immunocompetence and regulatory pathways for reward and stress management when they occur within an individual's optimal range of tolerance" (Floyd, 2006a, p. 175). As three-d argues that affection covaries with physiological pathways to stress and reward, four-a extends this claim by arguing that affection enhances these responses as long as affection falls within a communicator's range of tolerance (Floyd, 2006a). Although research has not measured range of tolerance, support for this postulate is largely drawn from previous work supporting postulate three-d (e.g., Floyd, 2002, 2006a; Floyd, Mikkelson, Hesse et al., 2007; Floyd, Mikkelson, 
Tafoya, Farinelli, La Valley, Judd, Davis et al., 2007; Floyd, Mikkelson, Tafoya, Farinelli, La Valley, Judd, Haynes et al., 2007).

Postulate four- $b$ predicts that "affectionate communication to one's biological offspring enhances reproductive success by contributing to the health and viability of the offspring, so long as the affectionate behavior falls within the receiver's range of optimal tolerance" (Floyd, 2006a, p. 176). Theoretically, affection should enhance the body's responses to stressful situations, therefore, children of affectionate parents should be healthier and better able to respond to stress, resulting in increased health. This process should result in adult children that appear as more attractive mates to others, consequently improving their reproductive opportunities.

Affection Exchange Theory draws on the theory of Discriminative Parental Solicitude (Daly \& Wilson, 1980) to clarify that postulate four-b's prediction only pertains to one's biological children. Discriminative Parental Solicitude posits that parents invest more resources in children that they perceive have strong chances of reproducing. Thus, parents should share less of their resource of affection with non-biological children because if/when those children reproduce, they will not pass down the biological characteristics of the parents. This is supported by studies indicating that fathers communicated more affection to biological sons compared to step-sons (Floyd \& Morman, 2001, 2003) and to heterosexual versus homosexual sons (Floyd, 2001b; Floyd, Sargent, \& DiCorcia, 2004). Naturally, the previous studies examining different father-son relationships were likely impacted by mediating factors such as homophily between the parent and child and previous conflict; however those factors were not studied.

Postulate five. Postulate five of AET states that "conveying or receiving affectionate behaviors that violate one's range of optimal tolerance initiates noticeable sympathetic nervous system arousal and further initiates a cognitive appraisal of the same" (Floyd, 2006a, p. 179). 
Although this appears similar to Expectancy Violations Theory (EVT; Burgoon, 1978), AET is argued to be unique from EVT. When someone violates another's expectations of what normal behavior is, EVT predicts that the receiver engages in a cognitive appraisal process. In contrast, AET argues that when an individual's range of tolerance is violated the receiver's sympathetic nervous system (SNS) is aroused, not an initial cognitive sense making process. The SNS system is composed of many functions; including blood pressure, heart rate, and respiratory rate (see Floyd, 2004; Floyd, Haynes, \& Mikkelson, 2005). One's SNS system is activated during positive excitement and perceived threat. Affection Exchange Theory considers that the body views a range of tolerance violation as a threat, thus activating SNS changes. The key difference between the two theories is that EVT views violations as positive or negative, whereas AET considers all range of tolerance violations to be negative. Further, AET argues that one's cognitive sensemaking process is first based on their internal SNS arousal and second on the behavior.

Postulate five- $a$ reads: "A violation of the minimum threshold in the range of optimal tolerance constitutes a threat to viability" (Floyd, 2006a, p. 180). Further, postulate five- $b$ predicts that "a violation of the maximum threshold in the range of optimal tolerance initiates a physiological stress response that covaries in intensity with the probability that the violating behavior represents a threat to one's procreation success" (Floyd, 2006a, p. 181). Thus, violations are viewed as somewhat detrimental.

Summary. In sum, AET views affectionate communicate as a relational resource that is important in the mate selection process and later in the rearing of offspring. Affectionate messages that fall within a receiver's range of tolerance enhance a receiver's physiological reactions to stress. Importantly, it is not only the affection one receives, but the affection one expresses that also results in positive outcomes. The majority of the research examining AET has 
focused on family relationships, which differs from the direction of this dissertation which focuses on deceptive affection in romantic relationships. Inconsistencies between feelings and expressions of affection are considered to be deceptive; therefore, a review of deception follows.

\section{Deception}

Burgoon and Buller (1994) defined deception as an intentionally crafted message with the goal of creating false beliefs in the mind of a receiver. Given that honesty is both a relational expectation and a desired characteristic in a mate (Boon \& McLeod, 2001; Fishbein, Hennessy, Yzer, \& Curtis, 2004; Stewart, Stinnett, \& Rosenfeld, 2000), one may be tempted to think that deception occurs infrequently in romantic relationships. In fact, McCornack and Parks (1986) argued that we operate from a truth bias in relationships. That is, the closer we become to our romantic partners, the worse we become at detecting deception because relational closeness leads partners to assume honesty. Yet, research indicates that assumptions of honesty are not consistent with reality. Kashy and DePaulo (1996) described deception as an "everyday social interaction process" that "is a fact of social life rather than an extraordinary or unusual event" ( $p$. 1037). Supporting this argument, DePaulo and Kashy (1998) found that one in three interactions with a non-married romantic partner contained some deception. Interestingly, in their comparison of a variety of close relationship types, DePaulo and Kashy (1998) found deception was communicated the least often to spouses and children. The previous frequencies of deceptive messages indicate that non-married romantic couples are an appropriate population to study in the context of DAMs

Recall that AET's second postulate drew on display rules (Ekman \& Friesen, 1975) to argue that people can manipulate their affectionate messages by inhibiting, stimulating, intensifying, deintensifying, or masking affectionate feelings. For instance, an individual may 
console someone for having a rough day when, actually, the source of the consoling message may not genuinely feel supportive. Additionally, an individual may communicate deceptive affection in an effort to gain sexual contact.

Display rules are expectations for appropriate emotional expression, and consequently, can influence if, how, or when communicators express affection (Ekman \& Friesan, 1975). Consistent with this argument, Hayes and Metts (2008) reported that individuals do, in fact, manipulate affection via display rules. Thus, individuals have expressed affectionate messages when not genuinely experiencing affection. Relational research suggests that display rules may develop concurrently with relationships; specifically, individuals perceived emotional expression as more appropriate as the relationship developed (Strzyzewski, Buller, \& Aune, 1996). Those in later stages of relationships managed positive emotions less than negative emotions. Further, they found a curvilinear relationship between length of relationship and emotion management, such that individuals in earlier and later stages of relationships reported more management of negative emotions such as anger, fear, guilt, and frustration. Potentially, individuals may express DAMs to romantic partners as a means to mask such negative feelings.

Past affection work lends support to the display rule argument, revealing that individuals do maintain expectations about the appropriateness of affectionate expressions based on perceived contextual norms (Floyd, 1997a, 1997b; Floyd \& Morman, 1997). Floyd and Morman (1998), for example, found that respondents perceived it to be more appropriate to communicate affection to siblings compared to friends, indicating that the contextual norms of the sibling relationship influence sibling affection. Further, they found that individuals reported it was more appropriate to communicate affection in more emotionally intense situations. Consequently, an individual at a family wedding may feel the pressure to express affection to another family 
member that he/she is not actually feeling based on the norms of the context. Thus, the previous research offers examples of instances in which expectations could motivate the expression of deceptive affectionate messages. Possibly then, these contextual expectations could motivate the expression of DAMs.

Although DAMs have not been systematically researched, prior studies indicate that individuals do act deceptively with their affection. Erbert and Floyd (2004) found that individuals' face needs predicted perceptions that they had received inauthentic, manipulative affectionate messages. That is, respondents' negative face needs predicted their feelings of a negative face threat due to perceived manipulative affectionate communication. This suggests that individuals maintain an awareness that not all affectionate messages are honest. Later, and more advanced in scope, Floyd, Erbert et al. (2005, as cited in Floyd 2006a) drew on a sample of 1,032 people to examine inauthentic affection. Rather than a receiver approach, as adopted in Ebert and Floyd (2004), Floyd, Erbert et al. (2005) took a source approach, instructing participants to describe an instance in which they expressed manipulative affection. Manipulative affection was described as affectionate messages employed for an ulterior motive, specifically as "expressed affection that" participants "did not actually feel" rather than instances in which participants "reaffirmed genuine affection for a manipulative purpose" (Floyd, 2006a, p. 137). Based on this explanation, manipulative affection is similar to deceptive affection because they both involve dishonest affectionate expressions; yet, manipulative affection appears to be a subset of deceptive affection. Floyd, Ebert et al. (2005) found that $86 \%$ of their sample could recall a time when they communicated affection to manipulate another person, and more than half of respondents had done so in the previous 30 days. These messages were communicated for a number of motives in close relationships with friends and current or former romantic partners. 
These studies inform the study of deceptive affection because they highlight situations in which individuals act dishonestly with regard to affection.

Expressions of inauthentic affection constitute deception. In order to fully understand deception, researchers contend that it is imperative to examine the motive for deception (Buller \& Burgoon, 1994). Motives are “underlying reasons for deceiving” (Scholl \& O’Hair, 2005, p. 381) and are related to how individuals view deception and its acceptability (Buller \& Burgoon, 1994; Seiter, Bruschke, \& Bai, 2002).

O’Hair and Cody (1994) presented a synthesized typology of deceptive motives, arguing that there are two main ways to describe deceptive motives: valence and target. That is, deceptive motives can be described as aimed toward enhancing the relationship, the lie teller, or lie receiver (i.e., target), and as having either positive or negative goals (i.e., valence). Respondents in DePaulo et al.'s (1996) study reported telling more self-centered than other oriented-lies. Interestingly, when describing specific lies pertaining to feelings, respondents described those lies as more other-oriented aimed at benefiting the target. In a study of manipulative affection, the motives behind the inauthentic messages echoed past research in that they were self-centered, target-centered, and relationship-centered (Floyd, Erbert et al., 2005).

Together, research indicates that deception is motive driven and, consequently, individuals' expressions of deceptive affection should also be motive driven. Deception is considered a relational transgression (e.g., Metts \& Cupach, 2007) and this dissertation examines potential source implications of committing such a transgression. The specific outcomes are rumination, heart rate, blood pressure, guilt, and shame. Consistent with AET's argument that affectionate communication can be risky, the preceding outcomes are included in this dissertation as potential risks for sources. If expressing deceptive affection does result in 
rumination, guilt, shame, and physiological changes, then this dissertation will identify how affectionate communication can be hazardous for communicators. In order to fully understand how these previous factors may operate in the context of DAMs, it is first necessary to review prior research on these processes.

\section{Rumination}

One frequent response to relational transgressions is rumination (Cloven \& Roloff, 1991; Roloff, Soule, \& Carey, 2001), defined as "the tendency to experience intrusive thoughts, affects, and images about past events" (McCullough, 2001, p. 196). Rumination is largely studied as a response; that is, scholars examine how likely or often the receiver of the transgression or negative event ruminates about the situation. For example, individuals often ruminate in response to jealousy (Bevan \& Hale, 2006; Carson \& Cupach, 2000) or death (Abdel-Khalek, 1998).

Lying to one's romantic partner, regardless of the motive, violates expectations of honesty (Boon \& McLeod, 2001; Fishbein et al., 2004; Stewart et al., 2000) and can be considered a transgression. This suggests that deceivers may, potentially, experience adverse reactions following deception. Similarly, Knapp (2006) speculated that deceivers are bothered by their deceptive act, suggesting that source rumination may result from their deception. Yet, DePaulo et al. (1996) found that most respondents reported little distress before, during, and after deceptive communication. This suggests that little rumination may occur due to the frequent nature of deception. Recall that, in DePaulo et al.'s (1996) study, feelings were the most often cited topic of deception, these lies were told to benefit another person and, typically, were positive. This may explain why individuals experienced little distress. However, DePaulo et al.'s respondents rated interactions where they communicated deception as less pleasant and intimate, suggesting that, on some level, individuals were aware that their deceptive messages violated 
relational expectations. Potentially, these less than pleasant and intimate interactions could result in rumination and physiological changes. Indeed, for those individuals who did experience distress while communicating deception, their level of discomfort did not significantly decrease after the lie was communicated (DePaulo et al., 1996).

Source rumination is a potential outcome following DAMs; however, DePaulo et al.'s (1996) findings indicate that deceivers were not distressed following deception. This is likely due to the differing message and relationship focuses between this dissertation and their study. Their work focused on all deception in a variety of relationships, ranging from acquaintance to friend to romantic partner. Given that deception is so common, it is likely individuals do not ruminate over less intimate lies communicated in less close relationships, especially compared to DAMs communicated to romantic partners. The potential rumination after expressing deceptive affection could be due to cognitive dissonance (Festinger, 1957). Dissonance is the psychological discomfort an individual experiences when trying to reconcile two inconsistent thoughts. Deceptive affection involves two inconsistent thoughts: the thought of one's true feelings and the thought of the deceptive affection that is ultimately expressed. This inconsistency likely results in dissonance and could result in rumination. This dissonance argument was used recently to explain an AET study where siblings forecasted more rumination when a sibling transgression was disclosed in conjunction with an affectionate message compared to a transgression disclosure without affection (Horan \& Turner, 2009). The authors argued that respondents were bothered more by these two inconsistent cognitions, a transgression signaling relational distance and affection signaling relational closeness, and thus forecasted more rumination.

Ruminating about an event has a direct impact on a person's physiological response, with individuals who reported ruminating more over an interpersonal transgression exhibiting higher 
levels of cortisol, a stress related factor (McCullough, Osulak, Brandon, \& Akers, 2007).

Similarly, this dissertation examines the physiological implications of recalled expressions of deceptive affection.

\section{Affection and Physiological Responses}

Prior work on affectionate communication and formal predictions offered by AET contend that individuals experience physiological responses to expressed and received affection. Postulate three-d of AET, for example, argues that affection and affectionate communication enhance the physiological passages for stress and reward (Floyd, 2002, 2006a; 2006b; Floyd, Mikkelson, Hesse et al., 2007; Floyd, Mikkelson, Tafoya, Farinelli, La Valley, Judd, Davis et al., 2007; Floyd, Mikkelson, Tafoya, Farinelli, La Valley, Judd, Haynes et al., 2007). In an effort to test postulate three-d, researchers have examined affectionate communication in conjunction with a number of stress related factors, including cholesterol and cortisol. Floyd, Mikkelson, Hesse et al. (2007) found that individuals who wrote for 20 minutes weekly about their affectionate communication over a three week period experienced a significant decline in cholesterol.

A related factor, cortisol, has also been subject to study. Cortisol assists the body in developing responses to stress and is highest when one wakes up; however, consistently high levels of cortisol are damaging (see Floyd, Mikkelson, \& Hesse, 2008). Research indicates that those who are highly affectionate in general (Floyd, 2006b) and those who receive more affection from their spouses (Floyd \& Riforgiate, 2008) experience an overall morning-toevening decrease in cortisol. Since cortisol is released in response to stress, researchers have examined how affection influences responses to stress. Floyd, Mikkelson, Tafoya, Farinelli, La Valley, Judd, Davis et al. (2007) experimentally found that reported levels of received affection 
were negatively related to free cortisol levels after respondents were exposed to stress. In a related study, Floyd, Mikkelson, Tafoya, Farinelli, La Valley, Judd, Haynes et al. (2007) examined how writing about affection following exposure to stress impacted cortisol recovery toward baseline. Participants were exposed to multiple stressors, and multiple cortisol samples were taken. As expected, those in the affection group, compared to other conditions where participants thought about a loved one or wrote about the layout of their room, experienced enhanced responses to stress in the form of cortisol level recovery. Collectively, the coristol research indicates that both giving and receiving affection aids the body in responding to stress.

Cholesterol and cortisol are not the only physiological markers that have been theoretically and empirically linked to affectionate communication. Affection Exchange Theory's fifth postulate also focuses on the physiological responses to affection, arguing that expressing and receiving affection that breaches a communicator's range of tolerance causes arousal in a communicator's sympathetic nervous system (Floyd, 2006a). The SNS is composed of many functions; including blood pressure, heart rate, and respiratory rate (see Floyd, 2004; Floyd et al., 2008). One's SNS is activated during both positive excitement and perceived threat. Past research on another communication construct, communication apprehension (anxiety associated with actual or anticipated interaction, McCroskey, 1970), reveals that individuals do experience physiological responses when faced with a perceived threat in the form of communication (for a review, see Beatty \& Dobos, 1997). As just one example, BoothButterfield (1987) found that speakers with a high level of CA maintained higher heart rates during their speech whereas lower CA speakers exhibited increased heart rates initially but returned to baseline quickly. 
Expressing deceptive affection to a romantic partner is potentially threatening to communicators. Discovered deception could impact relational quality and communication, and non-discovered deception could result in a source feeling distressed post deception. Accordingly, this dissertation focuses on two SNS responses - heart rate and blood pressure- - because the SNS is activated in times of perceived threat. Research on authentic affectionate communication suggests that the SNS is activated during affectionate expressions. Floyd, Hesse, and Haynes (2007) examined how expressed affection related to resting heart rate and resting blood pressure. They found a negative relationship between self reported expressed affection and both systolic and diastolic blood pressure. Importantly, Floyd et al. controlled for reported affection received, suggesting that these SNS responses are attributable to affection communicated. However, Floyd et al. did not obtain the predicted negative relationship between heart rate and expressed affection, although the means were in the predicted inverse direction. They speculated that a lack of variability in their obtained heart rate scores between high and low affectionate communicators may have contributed to this nonsignificant finding. Floyd et al. encourage future heart rate research in the context of affectionate expressions as their research demonstrates a relationship between affectionate communication and blood pressure, an SNS response.

Since multiple studies indicate that people experience physiological responses when they send and receive affectionate messages, it is likely that they also experience physiological responses when they convey deceptive affectionate messages. Recall that cognitive dissonance (Festinger, 1957) was used to argue that rumination was likely post-DAM expression because of the two inconsistent thoughts involved with deceptive affection. The two inconsistent thoughts are one's actual feelings of affection and one's deceptive affectionate expression, which would result in dissonance. Similar to rumination, it is believed that this dissonance experienced 
following deceptive affection will influence physiological functioning. Early research on dissonance indicates that individuals do experience physiological responses in conjunction with dissonance. Brehm, Back, and Bogdonoff (1964) found that individuals who reported being hungry after fasting, yet still committed to fasting longer for compensation, exhibited minimal increase in fat mobilization, despite being hungry. That is, individuals who were hungry yet still committed to fast appeared physiologically, based on fat mobilization, as if they were not actually hungry. This research offers a link between psychological dissonance and physiological responses. As a result, the psychological discomfort caused by dissonance after expressing deceptive affection may also result in physiological responses, specifically in the form of heart rate and blood pressure changes.

Expressing deceptive affection is a risk for sources that will result in both rumination and physiological changes. In addition to those processes, the final potential negative outcome examined entails emotional reactions to deception.

\section{Emotional Responses}

Since DAMs represent deceptive messages about feelings, there are likely to be emotional reactions to this deception and Knapp (2006) speculated that deceivers are "troubled" by their act of deception (p. 520). Despite this, researchers contend that emotions are underresearched in the deception process (Horan \& Dillow, in press; McCornack \& Levine, 1990; Seiter \& Bruschke, 2007). Two potential emotional reactions to deceiving someone are guilt and shame. Guilt is defined as an "individual's unpleasant emotional state associated with possible objections to his or her actions, inaction, circumstances, or intentions" (Baumeister, Stillwell, \& Heatheron, 1995a, p. 245). Similarly, shame involves "painful scrutiny and negative evaluation of the entire self, with corresponding feelings of shrinking and being small" (Tangney, Wagner, 
Hill-Barlow, Marschall, \& Gramzow, 1996, p. 797). Guilt and shame are similar in that they are both self conscious emotions that result from human interaction (Andersen \& Guerrero, 1998). Both guilt and shame involve an uncomfortable emotional response, yet their focus differs. Guilt is an emotional response that is focused on a behavior, whereas shame is an emotional response focused on an individual (Lewis, 1971; Tangney, Wagner, \& Gramzow, 1992). In the context of deception, an individual would experience guilt in response to communicating deception, and shame would result if an individual views him-or-herself as a deceptive individual. Although both emotions appear to be important, guilt has been the subject of more research.

Feelings of guilt and shame have been correlated with other personality and emotional descriptions. For example, feelings of guilt were positively related to feelings of depression, insecurity, sadness, and helplessness and negatively related to feelings of comfort and competence (Jones \& Kluger, 1993). Those prone to consistently feeling guilty often report feeling regret, misery, resentment, loneliness, and dissatisfaction. Those prone to feeling shame report maladaptive responses to anger and hurt, including direct and indirect physical and verbal aggression (Tangney et al., 1996). Interestingly, those prone to feeling guilt do not report similar aggression results. Feelings of guilt and shame appear to be complex experiences related to other important emotional responses.

Guilt is argued to arise from interpersonal interactions and, largely, from transgressions (Baumeister et al., 1995a; McGraw, 1987; Smith, Webster, Parrot, \& Eyre, 2002). For instance, in a research study where participants were asked to describe instances where they felt guilt, most participants offered descriptions of interactions occurring in close relationships (Baumeister et al., 1995b). One's emotional reaction to transgressions can impact how one behaves and feels post-transgression. Communicatively, guilty individuals are more likely to be motivated to repair 
a situation whereas shamed individuals are more likely to withdraw (Lewis, 1971; Tangney et al., 1992). Both emotions involve distress and discomfort and elicit physiological changes, including increases in heart rate and body temperature (Scherer \& Wallbott, 1994).

Given that these emotions are often experienced in response to transgressions, some researchers have focused on understanding how guilt and shame operate in response to deception. Results of these studies indicated individuals experience these feelings in response to communicating deception (Horan \& Dillow, in press; Peterson, 1996; Seiter \& Bruschke, 2007; Tangney, 1992). Seiter and Bruschke (2007), for example, asked participants from American and Chinese cultures to imagine themselves in different deceptive situations and assessed their forecasted levels of guilt and shame. They found that both Chinese and American respondents expected to feel guilt and shame, indicating these emotions are active in response to expressing deception. Similarly, they found a negative relationship between emotional responses of guilt and shame and the probability of communicating deception.

Because individuals cite deception as a guilt and shame inducing event (Tangney, 1992), some scholars have focused on how message and relational dynamics influence guilt and shame. Peterson (1996) examined how different deceptive messages impacted feelings of guilt. She found participants reported feeling the least amount of guilt after failing at deception or communicating white lies compared to the other message types examined. Later, Horan and Dillow (in press) found that more committed and satisfied individuals reported feeling higher levels of guilt and shame following romantic partner deception as compared to less committed and less satisfied individuals. Yet, no differences in guilt and shame were obtained based on the type of deceptive message expressed. The discrepancy between Horan and Dillow (in press) and Peterson (1996) may be attributable to methodological differences. Peterson (1996) used 
hypothetical scenarios whereas Horan and Dillow (in press) asked respondents to recall and describe a recent time they communicated deception to their romantic partner. Nevertheless, this body of research indicates that guilt and shame are emotional reactions that do occur in response to deceptive communication, indicating they are active in the deceptive affection process.

\section{Statement of Problem}

In order to further understand DAMs, two studies were conducted. Because no prior research has systematically examined DAMs, the aim of the first study was to gain a detailed description of the frequency of, topics of, and motives for deceptive affection. Study one also examined feelings of rumination associated with these DAMs. The aim of the second study was to examine the physiological and emotional implications of expressing deceptive affection.

\section{Study One}

Study one seeks to understand the expression of deceptive affection as well as whether sources can recognize and describe such messages. Floyd, Erbert et al. (2004, as cited in Floyd, 2006a) reported that the majority of their respondents could describe a recent time they expressed manipulative affection. Given that manipulative affection involves the expression of inauthentic affection, it represents a subset of deceptive affection with a specific goal. Consistent with Floyd, Erbert et al.'s finding, this study argues that individuals do communicate deceptive affection; however, it is unknown whether communicators are cognizant of the fact that they convey these deceptive messages to their romantic partners. To test the basic argument that individuals are deceptive with their affection, research question one asks:

RQ1: Can communicators identify instances of deceptive affection?

Study one seeks to obtain a detailed description of how deceptive affection is communicated. That is, this study seeks to identify the feelings individuals routinely lie about to 
their partners and the types of affectionate messages that are used to communicate deception. Exploring how deceptive affection is communicated is beneficial because it will provide a depiction of these messages in close relationships. Accordingly, research question two asks: RQ2a: When communicating deceptive affection, what feelings are the subject of deception? RQ2b: When communicating deceptive affection, what affectionate messages are employed to convey deception?

In order to fully understand the deception process, it is important to examine the motive for the deceptive message (Buller \& Burgoon, 1994). Based on past work, it is probable that DAMs are motivated by both selfish and selfless reasons; yet these motives remain to be specifically identified. Possible positive reasons behind communicating DAMs could be face saving, consolation, conflict avoidance, support, and improving a partner's esteem or mood. Conversely, potential negative motives driving DAMs could be manipulation, topic avoidance, avoiding an uncomfortable situation, to receive affectionate communication, and to obtain or avoid sexual contact. Related to AET, understanding source motives for expressing deceptive affection will shed light on whether or not deceptive affection is a risk for receivers of affectionate messages. If a number of antisocial motives are discovered, then findings related to this research question will demonstrate how deceptive affection is risky for receivers. However, if mostly prosocial motives are discovered, then potentially deceptive affection is not a message receivers should be concerned about. Understanding the motives behind DAMs will offer a more complete picture of the DAM process and allow researchers to explore if the implications of DAMs differ based on motivation. Thus, research question three asks: RQ3: What are the motives for communicating deceptive affectionate messages? 
In an effort to begin to understand how affectionate communication can be risky for communicators, study one also examined rumination following expressions of deceptive affection. Rumination following the expression of DAMs is likely and represents a negative outcome for sources of DAMS; yet it is unlikely that one ruminates following every act of deceptive affection. The motive argument from Buller and Burgoon (1994) suggests that the reasons for deception play an important role in understanding potential rumination. Deceptive affectionate messages communicated to benefit one's partner, perhaps in the form of a nongenuine compliment on a rough day, would likely result in little rumination. However, deceiving a partner about feelings in order to gain or to avoid sexual contact would likely result in more rumination. Thus, the valence of the motive likely influences whether or not a source ruminates about their deceptive expression. Although Floyd (2006a) identified inauthentic affectionate messages as a risk to receivers, this study examines deceptive affection as a risk to sourcesnamely, sources risk experiencing rumination and negative affect as a result of communicating DAMs. Because motives are integral in understanding deception and subsequent implications (Buller \& Burgoon, 1994), it is believed that rumination will differ based on the motives for expressing DAMs. Deceptive affectionate messages motivated to provide support or console a source likely result in little rumination compared to DAMs aimed to manipulate one's partner. Thus, hypothesis one predicts:

H1: There will be differences in rumination based on the motive for communicating deceptive affectionate messages.

Study Two

The purpose of study two is to examine the source implications of expressing deceptive affection. It is believed that expressing DAMs should result in heart rate and blood pressure 
changes, because they are a part of the SNS system which is activated in times of perceived threat (e.g., Floyd et al., 2008). Recall that prior AET research examining honest affectionate messages indicates that merely writing about affectionate communication impacted cholesterol and cortisol (Floyd, Mikkelson, Hesse et al., 2007; Floyd, Mikkelson, Tafoya, Farinelli, La Valley, Judd, Haynes et al., 2007). Thus, adopting a similar writing method should reveal if DAMs influence a communicator's heart rate and blood pressure. Communicating deceptive affection to a romantic partner constitutes a threat to the source of the message - potentially in the form of deception detection, relational turbulence if detected, and possible relational termination. Even if not detected, the source of the message may ruminate about concern over detection or potential guilt, regret, or shame. Feelings of rumination, guilt, and shame are related to physiological changes (McCullough et al., 2007; Scherer \& Wallbott, 1994), suggesting that this risk should result in SNS responses. Based on this reasoning, prior affection research, and AET's formal prediction of physiological responses, the following hypotheses are proposed: H1a: Writing about deceptive affection will result in increased heart rate. H1b: Writing about deceptive affection will result in increased blood pressure.

Although AET and affection research indicate that the body experiences physiological responses to affection, it is unknown whether honest or deceptive affection elicits a stronger physiological response. Recall that the SNS is activated in times of perceived threat and reward. Due to the benefits associated with honest affection, affectionate messages may be viewed as a reward and, due to the potential risks associated with DAMs, deceptive affection may be viewed as a threat. As a result, the SNS may be similarly activated during both honest and deceptive affectionate expressions. Conversely, it is quite possible that honest and deceptive affectionate 
messages elicit dissimilar physiological responses. In order to explore these possibilities, research question one asks:

RQ1a: Are there significant heart rate differences between written recalls of honest and deceptive affectionate messages?

RQ1b: Are there significant blood pressure differences between written recalls of honest and deceptive affectionate messages?

As deception researchers have argued (Buller \& Burgoon 1994; Seiter et al., 2002; Schroll \& O’Hair, 2005), it is important that we understand the motives behind deceptive communication. It is possible that these motives could differentially impact one's physiological responses. Conversely, perhaps expressing deceptive affection, regardless of the motive, influences communicators' heart rate and blood pressure similarly. Consequently, research question two asks:

RQ2a: Are there heart rate differences based on the motive for deceptive affection?

RQ2b: Are there blood pressure differences based on the motive for deceptive affection?

The work of prior deception-based guilt and shame studies suggests that motives may play a role in understanding feelings of guilt and shame. Recall that, using actual recalled instances of deception, Horan and Dillow (in press) found no guilt or shame differences based on the type of lie communicated. Since the type of lie did not impact emotional responses, this supports Kashy and DePaulo's (1996) claim that deception is a "fact of life." Further, it speaks to Buller and Burgoon's (1994) argument that it is necessary to examine deceptive motives. Consistent with this argument, Seiter and Bruschke (2007) found differences in expected feelings of guilt and shame based on deceptive motive. Respondents indicated that they would feel less guilt and shame if they communicated deception to benefit another person compared to 
deception communicated for malice or self benefit. Given that prior works indicates guilt and shame differences based on deceptive motive, hypothesis two predicts:

$\mathrm{H} 2$ : There will be differences in feelings of guilt and shame based on the motive for recalled written deceptive affection.

\section{Summary}

The previously described dissertation is driven by two goals. First, this dissertation aims to learn more about how people communicate deceptive affection, and second, to learn about the implications of expressing such messages. This chapter explained the rationale for this study as well as previous research examining relevant phenomena. The next chapter explains the methodology used. 


\section{Chapter II}

\section{Method}

\section{Study One}

Study one aimed to gain an understanding of the deceptive affection process. As such, a three phase study was undertaken. This design was modeled after prior deception work conducted by DePaulo and colleagues (DePaulo et al., 1996; DePaulo \& Kashy, 1998; Kashy \& DePaulo, 1996). Phase one of the study consisted of an introduction to the study and training addressing how to complete phase two materials. During this phase, individuals completed demographic measures, a frequency of deception measure, frequency of affectionate communication measures, and a social desirability measure. Phase two of the study consisted of individuals maintaining a 7-day diary in which they described their deceptive affectionate messages and rumination each day. Finally, phase three consisted of a short follow up survey asking a variety of questions about partner deception. These phases, and associated measures, will be described in detail in the Procedures and Instrumentation section. Figure 1 maps the study one process.

Although all responses were confidential, data from this multi-phase study were associated so that participation in all three phases could be tracked. Responses were paired based on a respondent-generated unique identification number. This was a six digit number, with the first two composed of the participant's day of birth and the last four composed of the last four digits of the participant's phone number. Respondents were asked to list this number on all submitted materials. Two participants during phase three of the study provided an incorrect identification number that could not be matched to materials submitted during the first two phases; otherwise, all survey responses were successfully grouped. 
Figure 1

Summary of Instruments Completed in Study One

Phase Instrument (Author, year)

Phase one: Introduction, training, trait-like scales

Phase two: Seven day diary completion

Social Desirability (Andsager et al., 2006)

Frequency of Deception (Cole, 2001)

Modified Trait Affection Given and Received

(Floyd, 2002; Horan \& Booth-Butterfield, in press)

Demographic questions

Deception Record (created for this study)

Severity/impact question (created for this study)

Mulling Scale (Cloven \& Roloff, 2001)

Phase three: Submission and additional measures

Single item questions following up on the diary

(created for this study) 
Participants. In order to participate, potential volunteers were informed that they must be over 18 and currently in a self-defined romantic relationship for at least three months. The three month criterion has been imposed in prior AET-based romantic affection research, and it is believed that this timeline is sufficient for partners to develop relatively normative routines of affectionate interactions (Horan \& Booth-Butterfield, in press). To ensure participants had regular face-to-face interaction, long-distance relationships were excluded. Prior diary based deception research indicates that individuals communicate the most frequent deception to nonmarried dating partners, and the least deception to married romantic partners (DePaulo \& Kashy, 1998). Thus, in order to examine a population in which deceptive affection should actively occur, this study focused solely on non-married romantic partners. Participants were offered minimal course credit for their participation.

One hundred and ten volunteers (46 men and 64 women) were initially recruited from a large Mid-Atlantic University and completed phase one of the study. Later, 61 volunteers (25 men and 36 women) submitted the phase two diary. The final sample consisted of 57 participants (21 men, 34 women, 2 participants' sex unidentifiable based on incorrect identification numbers provided in phase three) who submitted materials for all three phases. These final participants ranged in age from 18-27 $(M=20.27, S D=2.09)$ and had been dating their relational partners for an average of 21.34 months $(S D=18.05)$. The majority of participants described their relationships as "seriously dating" (89.1\%; casually dating 9.1\%; other $1.8 \%)$. The majority of participants were Caucasian (87.4\%; Asian 3.6\%; Native American 1.8\%; Black/African American 1.8\%; Hispanic/Latino 1.8\%; and other 3.6\%). Two participants submitted phase three surveys with incorrect identification numbers, and as a result, their demographic data collected during the first phase of the study cannot be reported. Differences between the initial phase one 
sample and final sample that submitted materials during all three phases will be discussed after study one procedures and instrumentation are explained.

Procedure and Instrumentation. After obtaining IRB approval, volunteers were solicited from a variety of introductory communication courses. Courses in which volunteers were solicited were assigned at the discretion of the researcher's Department Research Coordinator. Potential volunteers were informed that participation in this study required three phases, including a phase one meeting that would last between 20-35 minutes. This method was modeled after deception research conducted by DePaulo and colleagues (DePaulo et al., 1996; DePaulo \& Kashy, 1998; Kashy \& DePaulo, 1996), although those researchers initially conducted a participant training session lasting 90 minutes as their phase one. Next, their participants recorded every act of deception communicated over a week long period, regardless of the deceptive target, constituting phase two of their study. Finally, their participants submitted diaries and completed follow up measures, constituting phase three of their study.

Similar to DePaulo and colleagues (DePaulo et al., 1996; DePaulo \& Kashy, 1998; Kashy \& DePaulo, 1996), a three-phase diary method was adopted for two reasons. First, narrowing the focus of their method allowed for answers to this study's research questions. Specifically, DePaulo and colleagues' diary method focused on all deception communicated in a variety of relationships. This study adopted a narrower focus, examining one message-deceptive affection - communicated in one type of intimate relationship. Second, this method was adopted because of the value that diary research affords. Charnia and Ickes (2006), for example, encourage diary research methodologies in relational studies because they are "an excellent way to track individuals over time" (p. 56). Support for this claim comes from McAuliffe, DiFranceiso, and Reed (2007), who examined response accuracy differences between survey and 
diary research methodologies. To that end, they conducted a three-month study including 493 adults. Volunteers submitted daily diaries of their sexual activity and, at the end of the study, completed surveys asking them to recall their sexual activity. McAuliffe et al. discovered a significant discrepancy between daily diaries and survey recollections, specifically finding that respondents typically over or under reported their sexual activity in surveys compared to diaries. This large scale longitudinal study demonstrates the accuracy of findings obtained using diary research, especially for those studies examining behaviors with potential social desirability concerns.

Phase one: Introduction and training. Participants were required to attend an introductory meeting. Multiple phase one meetings were conducted, ranging in length from 2035 minutes depending on how long it took participants to complete survey materials. The purposes of these meetings were to collect demographic information, explain the general goal of the research, provide informed consent, review participants' rights as human subjects, explain relevant concepts (i.e., deception, affection, and deceptive affection), and explain how individuals should complete the diary during phase two. No meeting had more than 10 people in attendance. Appendix A contains an outline of the phase one training content.

Before any content was introduced, participants were first asked to complete a series of questionnaires. These questionnaires were administered because they allow for a description of the participants and may explain differences in diary reporting. That is, individuals who feel the pressure of social desirability, for example, may report a lower number of DAMs compared to those who do not feel similar pressure. Individuals first completed a five item measure of social desirability (Andsager, Bernker, Choi, \& Torwel, 2006). This measure uses a response format ranging from 1 (never) to 5 (always) and item scores ranged from 2.80 to $4.60(M=3.94, S D=$ 
.34). Sample items included "I am courteous" and "I deliberately hurt others." Andsager et al. argued that many previous measures of social desirability are not unidimensional, and consequently, combined items from previous measures (Crowne \& Marlow, 1960; Helmreich \& Stapp, 1974; Holden \& Fekken, 1989) to create a unidimensional social desirability measure. This resulted, initially, in a 17-item measure that was, based on factor analyses, later reduced to a 5-item, single factor measure. Although this measure demonstrated acceptable reliability in their research (.70; Ansager et al.), it did not achieve an acceptable reliability in this study $(\alpha=.44)$ and, consequently, was not included in analysis. Table 1 reports the summed descriptive statistics, as opposed to the item descriptive statistics, for all scales described in this section. Next, participants completed Cole's (2001) deception measure, designed to "assess the extent to which people conceal information, mislead, and/or deceive their partner" (p. 114). For the first eight items, this measure uses a 7-point Likert type response format with responses ranging from 1 (strongly disagree) to 7 (strongly agree). The final item of this scale asks respondents to "estimate the number of times" participants lie to their partner during a week. All items are then summed to make one scale, and item scores ranged from 0.89 to $8.67(M=3.20$, $S D=1.31)$. Sample items include "I sometimes lie to my partner" and "I try to hide certain things that I have done from my partner." Cole's initial use of this measure lends partial support for the presence of truth biases, speaking to the instrument's validity. Particularly, in his study of romantic partner deception, he found that individuals reported communicating more deception to their partner than individuals thought their partners communicated to them. Previous reliability was .84 (Cole) and the present study obtained a Cronbach's alpha of .70 .

Finally, participants completed modified versions of the Trait Affection Given and Received Scales (Floyd, 2002). These measures were originally designed to capture the 
propensity for an individual to express and receive affection in a variety of relationships, but were later modified to capture the frequency of affectionate communication with one's romantic partner (Horan \& Booth-Butterfield, in press). Respondents rate their agreement with items using 1 (strongly disagree) to 7 (strongly agree). The affection given measure consists of ten items, and item scores ranged from 2.80 to $7.00(M=5.96, S D=.84)$. Sample items include "I am always telling my partner how much I care about him/her" and "When I feel affection for my partner, I usually express it.” The affection received measure consists of six items, and item scores ranged from 1.50 to $7.00(M=6.08, S D=.94)$. Sample items include "My partner hugs me quite a bit" and "My partner is always telling me that they like me, love me, or care about me." Prior research using these scales suggests that these self reports of given and receiving affection are valid. In Horan and Booth-Butterfield's (in press) research investigating romantic partner affection, male partners' reports of expressed affection were highly correlated with their female partners' reports of received affection. Similarly, male partners' reports of received affection were moderately correlated with their female partners' reports of expressed affection. Combined, these correlations suggest that these measures are accurate assessment tools of romantic partner affection. Both the affection given $(\alpha=.89)$ and received $(\alpha=.93)$ scales have been used reliably in past research (Horan \& Booth-Butterfield). The Cronbach's alpha for the affection given scale was .82 and the affection received scale was .94 . See Appendix B for a copy of all survey materials.

After all participants completed measures, the content portion of the meeting began. Participants were informed that the purpose of the study was to learn more about feelings, deception, and communication in relationships. The definition of deception offered by DePaulo et al. (1996) was used, explaining to participants that deception "occurs any time you 
intentionally try to mislead someone" (p. 981). Further, it was explained that deception contains both verbal and nonverbal components. To help safeguard against social desirability biases, it was emphasized that deception is common in romantic relationships, deception is not a good or bad thing, the researcher does not judge them for lying, and that all of their responses would be confidential. Next, based on Floyd's work (2006a), feelings of affection were explained. Feelings of affection were explained as feelings of liking, love, and fondness for one's partner and were distinguished from expressions of affection, which include verbal and nonverbal expressions of one's feelings of affection. Multiple examples of affectionate communication were offered, including hugs, kisses, sexual activity, telling your partner you love him/her, and telling your partner that you care about him/her.

After explaining these concepts, deceptive affectionate messages were explained as instances in which a source actively communicated affection to his/her romantic partner that he/she was not genuinely feeling. A myriad of examples were offered. One example included communicating affection while resolving a conflict; however, in this example, the source was not genuinely feeling affection for his/her partner. Another example included a source holding his/her partner's hand because a rival was expressing interest in his/her partner, not because the source was genuinely feeling affection. After each individual explanation of deception, affection, and deceptive affection, questions were solicited. Any confusion was clarified by the researcher until participants agreed they understood concepts.

After reviewing the previous content, the deception record was distributed and each page was reviewed (see Appendix B). The first page included a blank for participants to list a time of day that worked best for them to complete the journal. Although participants were encouraged to complete the journal immediately following the expression of a DAM, it was recognized that it 
was not always possible for participants to do so (e.g., one's partner is still present, the journal is not with the participant). Thus, encouraging participants to fit in daily time to complete this journal was stressed as a way to promote accurate descriptions and routine responding. Below this line was the contact information for the researcher. Throughout the training participants were encouraged to call or email the researcher with any questions or concerns; thus, the researcher's contact information was made immediately available to participants. No participants contacted the researcher with questions about how to complete diaries or to receive additional diary pages.

The second page of the journal contained two sections. First, most of the page included a review of the concepts addressed in the training session. Deception, affection, and deceptive affection definitions were reviewed and coupled with messages stressing the frequent nature of deception. A summary of journal directions was provided, and once again, the contact information of the researcher was listed. The final portion of this page prompted respondents to list the number of interactions they had with their romantic partner in a given day. Consistent with other social interaction research, interactions were defined as communication lasting longer than 10 minutes (DePaulo \& Kashy, 1998; Wheeler \& Nezlek, 1977).

The next page of the diary consisted of a one page document; participants were provided with 10 copies. Participants were instructed to complete this one page document as soon as possible following the expression of the DAM. At the top of the page, participants were asked to describe the date, time, and location of the interaction. Next, participants were prompted to answer three open-ended questions: What were you feeling (internal)?; What affection did you express (communicated verbally or nonverbally)?; Why did you choose to express something different than how you felt? These questions allowed for detailed descriptions of specific 
feelings that are the subject of deceptive affection, the affectionate messages employed during this deceptive process, and the motivates for the deception.

Participants were instructed, following the description of each DAM, to complete two brief questionnaires. First, a one item measure gauged severity/impact of deception by asking respondents "If discovered, how much do you think this deceptive message would impact your relationship?" Participants responded to this using a 5-point Likert scale format with 1 (no impact) to 5 ( a huge impact). Item scores ranged from 1 to $4(M=1.91, S D=.91)$.

Finally, participants completed a five-item forecasted rumination measure (Cloven \& Roloff, 1991). Their Mulling Scale uses a 7-point semantic differential format. Sample bipolar pairs included "I would worry much about the lie/I would not worry much about the lie" and "I would never think about this lie/I would think about this lie all the time." In their original use of this measure, Cloven and Roloff argued for its validity based on their obtained correlations between rumination and related experiences including the extent to which an individual's thoughts focused on identifying the source of a problem, efforts directed at finding a solution to a problem, and an individual's emotional response to problem. Although the scale has been used reliably in past research (Cloven \& Roloff, 1991; Horan \& Turner, 2009), the scale was not reliable ( $\alpha=.64)$ using the original five items. However, when the second item ("Thoughts of the lie would/would not interfere a lot with my daily activity") was removed, the four item scale was reliable $(\alpha=.90)$. In this study, item scores ranged from 1.00 to $6.00(M=2.05, S D=1.18)$, with higher scores reflecting greater feelings of forecasted rumination.

At the close of the meeting three points were stressed. First, participants were encouraged to complete the diary entries as completely and as honestly as possible. Consistent with the work of DePaulo and colleagues (DePaulo et al., 1996; DePaulo \& Kashy, 1998; Kashy 
\& DePaulo, 1996), participants were told that if they were unsure if something constituted a lie, they should record it. Second, participants were encouraged to call or email the researcher with any questions they have. Third, participants were instructed that if they needed additional pages, they should contact the researcher; however, no participant requested additional diary materials.

Phase two: Seven-day diary. The deception record was modeled upon the work of DePaulo and colleagues (DePaulo et al., 1996; DePaulo \& Kashy, 1998; Kashy \& DePaulo, 1996), which was adapted from the Rochester Interaction Record (Wheeler \& Nezlek, 1977). This modified deception record was explained in the previous section detailing the training of participants as to how to complete this record.

Midway through phase two the researcher emailed participants. This email reminded participants to maintain the deception record, invited questions, and informed them of when the researcher would be in his office to collect survey materials. Similarly, on the seventh day of phase two, a reminder email was sent out reminding participants to submit survey materials. If none of the collection times were viable options for participants, the researcher encouraged participants to set up an appointment with the researcher. After a brief time period, if participants did not submit materials, they were once again contacted by email and encouraged to submit materials.

Phase three: Submission and additional measures. On the eighth day, after the seven day diary was complete, participants were encouraged to submit their diaries and complete additional measures. The overall purpose of the final survey was to obtain data that would help characterize the communication recorded over the previous week. The first two questions were designed as another gauge of rumination; that is, to discover if participants actually did spend time 
Table 1

Study one descriptive statistics

\begin{tabular}{lcccccc}
\hline & Minimum & Maximum & $M$ & $S D$ & $\alpha$ \\
& & & & & \\
\hline Social Desirability & 14.00 & 23.00 & 19.68 & 1.69 & .44 \\
Frequency of Deception & 8.00 & 78.00 & 28.83 & 1.76 & .70 \\
Affection Given & 28.00 & 70.00 & 59.58 & 8.43 & .82 \\
Affection Received & 9.00 & 42.00 & 36.49 & 5.62 & .94 \\
Severity & 1.00 & 4.00 & 1.91 & .91 & N/A \\
Rumination & 4.00 & 24.00 & 8.21 & 4.79 & .90 \\
& & & & & \\
\hline
\end{tabular}


cognitively reflecting on their expressions of deceptive affection. The initial two questions were designed to gauge why individuals ruminated on an influential DAM. Thus, the first question asked participants to describe the instance of deceptive affection they thought about the most. This question was designed so that respondents would have their most influential act of deceptive affection in mind. Based on this description, the next question asked: "How often did you think about that deceptive affection you communicated?" Individuals categorized their responses as either not often (31.6\%), somewhat often (54.4\%), often (10.5\%), or very often (3.5\%). To discover why participants spent time ruminating more over one influential DAM, participants were then asked "why did you think of this instance of deceptive affection the most?"

The next question asked "Did your partner ever find out that you lied about your affection? If yes, how did he/she react?" The purpose of this question was to discover if individuals are skilled at masking their DAMs and to discover partner reactions to discovered DAMs. Ten participants responded "yes" to this question: five participants explained their partners reacted negatively and three respondents reported their partners did "not really care," "laughed it off," or were not "too upset." The final two respondents did not list reactions to discovered DAMs.

In order to understand those instances in which no DAMs were communicated, the following question was posed: "If you chose not to communicate deceptive affection to your romantic partner at all this week, why did you make that choice?"

Finally, quantitative questions were posed that measured deception and relational dynamics. First, participants were asked how typical the pattern of communication they had with their partner was over the previous seven days (7.0\% described it as not typical; $33.3 \%$ described 
it at somewhat typical; $42.1 \%$ described it as typical; and $17.5 \%$ described it as very typical). Next, they were also asked how successful they thought they were at deception $(8.8 \%$ described themselves as not successful; $38.6 \%$ described themselves as somewhat successful; $43.9 \%$ described themselves as successful; 8.8\% described themselves as very successful). Further, they were asked how their frequency of deception compared to other people their age in relationships (17.5\% responded as much as they do; $71.9 \%$ responded as less than they do; $1.8 \%$ responded as more than they do; and $8.8 \%$ responded as undecided). Combined, these responses suggest that most diary respondents believe they are skilled deceivers who reported on a week of interactions that appear to be relatively characteristic of their overall relational communication.

Fifty six individuals reported that, upon turning in their survey materials, they were still dating their romantic partner. When asked if deceptive affection played a role in the termination of the one relationship, the participant reported that it did not.

Understanding participant mortality. To examine the possibility that the initial sample and final sample may differ based on individual characteristics, analyses were conducted examining potential differences on the previously discussed phase one measures. Given the small mortality rate between phases two and three $(n=4)$, analyses focused on differences between those who completed just the first phase $(n=53)$ and those who completed all three phases $(n=$ 57). There were no significant differences between those who completed phase one and phase three on the amount of affection communicated to one's romantic partner (turned in all three phases $M=5.94, S D=.84$, did not turn in all three phases $M=5.98, S D=.84, t(108)=-.23, p=$ .82 ) or the amount of affection received (turned in all three phases $M=6.15, S D=.87$, did not turn in all three phases $M=6.01, S D=1.00, t(108)=.71, p=.48)$. However, an independent samples $t$-test did reveal that those who completed all three phases communicated significantly 
less romantic partner deception $(M=2.92, S D=1.12)$ compared to those who did not complete all three phases $(M=3.45, S D=1.43, t(108)=-2.34, p=.02)$. Consequently, diary respondents in this sample reported that, overall, they communicate less romantic partner deception than those participants who did not submit diaries.

Study Two

The goal of the second study was to examine the emotional and physiological responses to expressing DAMs. This was accomplished using a writing intervention modeled after work by Pennebaker and colleagues (e.g., Pennebaker \& Beall, 1986; Pennebaker \& Colder-Sharp, 1990; Pennebaker, Kiecolt-Glaser, \& Glaser, 1988). Participants individually signed up and attended an appointment with the researcher. During their appointment, they first completed pre-test measures assessing social desirability, frequency of deception, and health markers. Then, participants were asked to sit quietly for 10 minutes so that a resting heart rate and blood pressure assessment could be taken. Next, they wrote for 20 minutes about an affection or nonaffection related topic, based on random assignment. Upon completion, a second physiological assessment was taken followed by measures assessing emotional responses and demographics. This procedure, and associated measures, will be explained in detail in the forthcoming sections. Figure 2 summarizes this process.

Participants. After obtaining IRB approval, participants were solicited from introductory communication courses. Courses in which the researcher solicited volunteers were assigned at the discretion of the Department Research Coordinator and differed from the courses solicited in the first study. To participate, individuals had to be over 18 years of age and currently in a self defined romantic relationship for at least three months. Similar to the first study, long distance and married couples were excluded. The rationale behind this criteria was explained within the 
Figure 2

Summary of Study Two Design

Phase

Behavior and/or Instrument (Author, year)

Participants arrive and complete pre-test measures

Complete consent form

Frequency of deception (Cole, 2001)

Social Desirability (Andsager et al., 2006)

Resting period

Physiological assessment: Time one

Writing intervention

Sit quietly for 10 minutes to achieve a baseline heart rate and blood pressure (Floyd, Mikkelson Tafoya, Farinelli, LaValley, Judd, Davis et al., 2007)

Researcher assesses blood pressure and heart rate using the Omron HEM-650 (Floyd, Mikkelson Tafoya, Farinelli, LaValley, Judd, Davis et al., 2007)

Based on random assignment, participants write for 20 minutes about a deceptive affectionate message, honest affectionate message, or a time they made plans with friends (modified after Floyd, Mikkelson, Tafoya, Farinellia, LaValley, Judd, Haynes et al., 2007)

Physiological assessment: Time two

Researcher assesses blood pressure and heart rate using the Omron HEM-650 (Floyd, Mikkelson Tafoya, Farinelli, LaValley, Judd, Davis et al., 2007)

Follow-up measures

Modified measures of guilt and shame (deceptive affection condition only; Horan \& Dillow, in press; Tangney et al., 1989)

Demographic items 
first study's method. Potential volunteers were informed that they would have to sign up for an appointment, participation would require between 35-50 minutes of their time, and non-invasive measures of blood pressure and heart rate would be taken. They were told that the purpose of the research was to learn more about affectionate communication in romantic relationships. They received minimal course credit for their participation.

One hundred individuals volunteered to participate; however, due to one participant failing to conform to the experimental manipulation, a sample of 99 was used in analyses (42 men and 57 women). Participants aged ranged from 18 to $28(M=20.54, S D=1.70)$. The majority of participants were White/Caucasian (88.9\%; 2.0\% Asian; 4.0\% Black/African American, 2.0\% Hispanic/Latino, and 3.0\% other). Eleven participants described their relationships as casually dating (11.1\%), 85 as seriously dating (85.9\%), and 11 as engaged to be married (3.0\%). Individuals reported that they had been in a relationship anywhere from 3-73 months $(M=19.26, S D=14.36)$.

Procedure and instrumentation. The method used for this study was modeled on affectionate writing recalls in Floyd, Mikkelson et al. (2007), which is a variation on writing interventions by Pennebaker and colleagues (e.g., Pennebaker \& Beall, 1986; Pennebaker \& Colder-Sharp, 1990; Pennebaker et al., 1988). Pennebaker's program of research has demonstrated that writing about traumatic events was related to health factors, indicating this method has utility in studies that examine physiological responses. This method has been used successfully in past affection research measuring cholesterol (Floyd, Mikkelson et al., 2007).

When participants arrived at the laboratory, they read over and signed a consent form detailing their rights as human subjects and explaining the voluntary nature of the research. Next, they completed measures assessing factors that could potentially explain variability in their 
responses. Similar to the first study, Cole's frequency of deception measure was used. Item scores ranged from .89 to $5.79(M=2.89, S D=1.25)$ and this measure was reliable $(\alpha=.87)$. Next, participants completed the same social desirability measure from the first study (Andsager et al., 2006). Item scores ranged from 3 to $4.80(M=4.02, S D=.39)$ and this measure was again unreliable $(\alpha=.47)$. Consequently, social desirability was not included in any analysis. Table 2 reports the summed descriptive statistics, as opposed to item descriptions, for the scales used in this study.

In order to describe the physical health of participants, descriptions of smoking behavior, alcohol and caffeine consumption, and frequency of physical activity were assessed. The majority of participants did not smoke (never smoked 72.7\%; not currently smoking $10.1 \%$; less than 1 pack per day $15.2 \%$; and 1-2 packs per day 2.0\%); however, most consumed caffeine daily (1-2 cups per day $86.8 \% ; 3-4$ cups a day $10.1 \% ; 5-6$ cups per day $2.0 \%$; and $7-8$ cups per day 1.0\%) and alcohol weekly (never drink alcohol 8.1\%; less than 1 drink per year 3.0\%; 1-2 drinks per month $23.2 \%$; 1-3 drinks per week 31.3\%; 3-6 drinks per week 23.2\%; 7-14 drinks per week $8.1 \%$; and 14 more drinks a week 3.0\%). Participants actively exercised weekly (never 4.0\%; 1-2 times per week $39.4 \%$; 3-6 time per week $48.5 \%$; and 7 or more times a week $8.1 \%$ ). Average aerobic activity lasted about 30 minutes (5-10 minutes 4.1\%; 10-15 minutes 4.1\%; 1530 minutes $21.4 \%$; $30-60$ minutes $51.0 \%$; 60 or more minutes $19.4 \%)$.

After completing these measures, participants were asked to sit quietly for 10 minutes. Prior work indicates that sitting quietly for 10 minutes allows for an accurate baseline physiological assessment (Floyd, Mikkelson, Tafoya, Farinelli, LaValley, Judd et al., 2007). Participants were asked not to complete homework, text message, or talk to anyone; rather, they were instructed that it was extremely important for them to sit quietly and relax, allowing for a 
Table 2

Study two descriptive statistics

\begin{tabular}{llccccc}
\hline & Minimum & Maximum & $M$ & $S D$ & $a$ \\
& & & & & \\
& & & & & & \\
\hline Social Desirability & 15.00 & 24.00 & 20.10 & 1.94 & .47 \\
Frequency of Deception & 8.00 & 52.00 & 25.97 & 11.22 & .87 \\
Guilt & 11.00 & 72.00 & 42.44 & 16.29 & .93 \\
Shame & 9.00 & 55.00 & 30.03 & 13.12 & .92 \\
& & & & & & \\
\hline
\end{tabular}


baseline resting heart rate. To encourage compliance with this request, participants were asked to keep everything they brought with them in a separate room, including cell phones. After sitting quietly for 10 minutes, a resting heart rate and blood pressure assessment was taken.

The Omron HEM-650 was used to measure physiological factors of heart rate and blood pressure. This apparatus assesses physiological factors using a participant's wrist, and digitally displays results. An older version of this tool, the HEM-630, has been utilized in prior affection research (Floyd, Mikkelson, Tafoya, Farinelli, LaValley, Judd, Haynes et al., 2007). In that affection study, the researchers reported a high correlation between manual heart rate assessments and the HEM-630's heart rate assessments $(r=.93)$. Omron (2007) reported that the blood pressure readings are accurate to within $\pm 2 \%$ and heart rate readings are accurate to with $\pm 5 \%$ of reading for the HEM- 650 . Normal healthy systolic blood pressure for adults averages at about $120 \mathrm{~mm} \mathrm{Hg}$ and diastolic blood pressure averages about $80 \mathrm{~mm} \mathrm{Hg} \mathrm{(e.g.,} \mathrm{Floyd} \mathrm{et} \mathrm{al.,}$ 2008). Healthy heart rates for women are about 70 beats per minute and 80 beats per minute for men (e.g., Floyd et al., 2008). Presently, for the entire sample, resting baseline systolic blood pressure ranged from 84.00 to $144.00(M=110.60, S D=10.49)$, diastolic blood pressure ranged from 46.00 to $90.00(M=68.08, S D=9.30)$, and heart rate ranged from 45 to $100(M=74.44$, $S D=10.92)$. Because prior work indicates that men and women have differing heart rate norms, Tables 3 and 4 report these physiological descriptive statistics by sex.

After a resting heart rate and blood pressure were taken, participants were asked to write for 20 minutes. This time frame was selected because it has been used in prior physiological research assessing the influence of affectionate writing (Floyd, Mikkelson et al., 2007). Based on random assignment, using a random number table, participants only wrote about one of three topics. The first condition, labeled deceptive affection $(n=34)$, asked respondents to describe a 
Table 3

Descriptive statistics for physiological measures at time 1 for men

\begin{tabular}{lcccc}
\hline & Minimum & Maximum & $M$ & $S D$ \\
& & & \\
Systolic blood pressure & 84.00 & 144.00 & 114.64 & 16.75 \\
Diastolic blood pressure & 46.00 & 88.00 & 68.50 & 9.83 \\
Heart rate & 45.00 & 100.00 & 71.45 & 12.72 \\
& & & & \\
\hline
\end{tabular}


Table 4

Descriptive statistics for physiological measures at time 1 for women

\begin{tabular}{lcccc}
\hline & Minimum & Maximum & $M$ & $S D$ \\
\hline Systolic blood pressure & 95.00 & 132.00 & 107.61 & 8.38 \\
Diastolic blood pressure & 51.00 & 90.00 & 67.77 & 8.95 \\
Heart rate & 58.00 & 96.00 & 76.65 & 8.86 \\
& & & & \\
\hline
\end{tabular}


recent memorable time they communicated affection to their romantic partner that they were not genuinely feeling. In this condition, participants were provided with definitions of deception, affection, and deceptive affection as well as numerous examples of deceptive affection. The second condition, labeled honest affection $(n=33)$, asked respondents to describe a recent memorable time they communicated affection to their romantic partner that they were genuinely feeling. In this condition, participants were provided with definitions of affection, affectionate communication, and numerous examples of authentic affection. In the third condition, labeled control $(n=32)$, participants were asked to describe a recent memorable time that they made plans with a non-romantic friend. Appendix $\mathrm{C}$ contains the detailed prompts.

To ensure that participants understood what was expected of them during the 20 minute time period, the researcher orally explained directions, as well as any related concepts (i.e., deception, affection, and deceptive affection). During this explanation, participants had a typed copy of the directions and related definitions. After the researcher finished explaining directions and any related concepts, questions were solicited from participants. When questions emerged, the researcher generated appropriate, non-leading responses and addressed the questions until participants stated they understood the expectations of the study. Questions were rare, and upon further discussion, all participants indicated they understood what was expected.

Participants were asked to be as descriptive as possible and to focus for 20 minutes while writing. To encourage participants to write for 20 minutes, the survey began with a number of questions asking them to describe the interaction, that is, questions asking the basic location, time, and premise of the interaction. Next, they were asked to describe the entire interaction in narrative format, as if they were describing the situation to their closest friend. The researcher encouraged participants that, if they had difficulty writing for 20 minutes, to extend the story and 
add more detail. Participants were informed that they were not evaluated based on grammar or spelling and that answers were completely confidential. All items were open-ended, with the exception of a multiple choice deceptive motive question used in the deceptive affection condition. This item asked participants to describe the motive for their deceptive affection as self protection $(n=2)$, partner protection $(n=9)$, relationship protection $(n=17)$, or other $(n=6)$.

At the conclusion of the 20 minute writing period, a second heart rate and blood pressure assessment was taken. Tables 5-10 report the descriptive statistics for these measures by condition and sex. Next, for those individuals in the control and honest affection conditions, they were then asked to complete a brief demographic survey. Demographic items asked about respondent sex, age, ethnicity, and length of relationship. For those in the deceptive affection condition, they were asked to complete measures of guilt and shame followed by the same brief demographic survey. Guilt and shame were measured using a modified version of the Test of Self Conscious Affect (Tangney, Wagner, \& Gramzow, 1989). This scale was originally designed to measure emotional responses to hypothetical events. The guilt and shame dimensions were recently modified and used in the context of romantic partner deception (Horan \& Dillow, in press). Using a 7-point Likert scale, with 1 (strongly disagree) and 7 (strongly agree), participants rated how much each statement accurately describes their feelings following romantic deception. Sample guilt items include "I regret that I lied to my relational partner" and "I should have known that telling lies to my partner is not acceptable." Sample shame items included "I felt disgusted at what I had done" and "I felt stupid after telling the lie." In the present study, guilt item scores ranged from 1.00 to $6.55(M=3.86, S D=1.48)$, and shame scores ranged from 1.00 to $6.11(M=3.34, S D=1.46)$. Horan and Dillow obtained alpha 
Table 5

Men's physiological statistics for deceptive affection condition at time 2

\begin{tabular}{lcccc}
\hline & Minimum & Maximum & $M$ & $S D$ \\
& & & \\
Systolic blood pressure & 92.00 & 132.00 & 110.26 & 10.76 \\
Diastolic blood pressure & 53.00 & 79.00 & 65.96 & 8.19 \\
Heart Rate & 50.00 & 100.00 & 71.63 & 11.68 \\
& & & & \\
\hline
\end{tabular}


Table 6

Women's physiological statistics for deceptive affection condition at time 2

\begin{tabular}{lcccc}
\hline & Minimum & Maximum & $M$ & $S D$ \\
& & & \\
\hline Systolic blood pressure & 95.00 & 129.00 & 109.73 & 8.64 \\
Diastolic blood pressure & 55.00 & 77.00 & 67.73 & 6.47 \\
Heart Rate & 63.00 & 87.00 & 73.80 & 6.79 \\
& & & & \\
\hline
\end{tabular}


Table 7

Men's physiological statistics for honest affection condition at time 2

\begin{tabular}{lcccc}
\hline & Minimum & Maximum & $M$ & $S D$ \\
& & & \\
\hline Systolic blood pressure & 98.00 & 152.00 & 117.46 & 14.15 \\
Diastolic blood pressure & 58.00 & 85.00 & 69.08 & 8.07 \\
Heart Rate & 21.00 & 92.00 & 69.46 & 20.04 \\
& & & & \\
\hline
\end{tabular}


Table 8

Women's physiological statistics for honest affection condition at time 2

\begin{tabular}{lcccc}
\hline & Minimum & Maximum & $M$ & $S D$ \\
& & & \\
\hline Systolic blood pressure & 91.00 & 132.00 & 110.35 & 10.21 \\
Diastolic blood pressure & 58.00 & 83.00 & 69.25 & 7.10 \\
Heart Rate & 63.00 & 88.00 & 76.95 & 7.02 \\
& & & & \\
\hline
\end{tabular}


Table 9

Men's physiological statistics for control condition at time 2

\begin{tabular}{lcccc}
\hline & Minimum & Maximum & $M$ & $S D$ \\
& & & \\
\hline Systolic blood pressure & 84.00 & 130.00 & 114.80 & 13.10 \\
Diastolic blood pressure & 52.00 & 82.00 & 70.70 & 8.26 \\
Heart Rate & 64.00 & 93.00 & 74.60 & 8.76 \\
& & & & \\
\hline
\end{tabular}


Table 10

Women's physiological statistics for control condition at time 2

\begin{tabular}{lcccc}
\hline & Minimum & Maximum & $M$ & $S D$ \\
& & & \\
\hline Systolic blood pressure & 95.00 & 176.00 & 111.32 & 17.23 \\
Diastolic blood pressure & 56.00 & 135.00 & 68.95 & 15.99 \\
Heart Rate & 54.00 & 90.00 & 76.18 & 8.61 \\
& & & & \\
\hline
\end{tabular}


reliabilities of .85 for guilt and .91 for shame. Similarly, both guilt $(\alpha=.93)$ and shame $(\alpha=.92)$ were reliable in this study. See Appendix D for the guilt and shame scale.

\section{Summary}

The purpose of this chapter was to detail the methodology used in this dissertation. This method was designed in order to understand how communicators express deceptive affection, and the potential source implications of these deceptive expressions. To that end, participants, procedures, and instrumentation were explained. Largely, study one data were collected using a qualitative methodology whereas data for study two were collected using a quantitative methodology. The next chapter explains the results of these studies. 


\section{Chapter III}

Results

\section{Study One}

Preliminary analysis. During phase one of the study $(N=57)$, participants completed measures assessing their romantic partner affection (Floyd, 2002; Horan \& Booth-Butterfield, in press) and deception (Cole, 2001). Consistent with the goal of further understanding the relationship among deception and affection, three Pearson correlations were conducted. These analyses revealed that frequency of romantic partner deception was negatively related to both expressed $(r=-.25, p=.008)$ and received affection $(r=-.32, p=.001)$. Affection given and received were positively related $(r=.25, p=.002)$.

Given that AET and evolutionary theorists predict sex differences in communication, three independent samples $t$-tests were conducted to examine potential sex differences in frequency of romantic partner deception, expressed affection, and received affection. These analyses revealed that men $(M=3.53, S D=1.35)$ reported significantly more deception than women $(M=2.97, S D=1.23 ; t(108)=2.23, p=.03)$, and women $(M=6.14, S D=.70)$ reported communicating more affection to partners than men $(M=5.71, S D=.96 ; t(77.55)=-2.57, p=$ .01 ). Reports of received affection did not differ based on sex (men $M=6.24, S D=.62$, women $M=5.98, S D=1.11, t(102.35)=1.52, p=.13)$.

Research question one. The first research question asked, at the most basic level, if individuals could identify instances of deceptive affection. Fifty seven diaries were submitted; however, only 51 included descriptions of deceptive affection. Of the six that did not include deceptive affection, three were excluded because participants explained that they did not communicate any deceptive affection to their romantic partner in the previous week. When 
looking at their phase three follow up question that asked "If you chose not to communicate deceptive affection to your romantic partner at all this week, why did you make that choice?" three offered responses explaining that they do not act deceptively toward their partner. The remaining three excluded journals provided descriptions of overall deception, but not deceptive affection. This occurrence can be explained by the participant training, in which participants were encouraged to record all instances that may constitute deceptive affection, even if they were unsure if their interaction fit the DAM conceptualization.

Fifty-one participants submitted diaries that included descriptions of deception that constituted DAMs. They offered 180 descriptions of DAMs, and DAM reporting ranged from 16 DAMs. Thus, individuals communicate an average of $3.30(S D=1.78)$ DAMs to their romantic partners weekly. In response to the first research question, individuals can identify enactments of DAMs.

The number of DAMs reported did not correlate with how long a deceiver knew his/her partner $(r=-.07, p=.63)$, how long a deceiver had been in a romantic relationship with his/her partner $(r=-.02, p=.90)$, frequency of deceptive communication $(r=-.16, p=.25)$, received romantic partner affection $(r=-.09, p=.49)$, or expressed romantic partner affection $(r=.13, p$ $=.37$ ). Similarly, the frequency of expressing DAMs did not differ based on sex (male $M=3.05$, $S D=1.49 ;$ female $M=3.47, S D=1.95 ; t(52)=-.86, p=.39)$. Nor were there differences in the frequency of expressing DAMs based on the type of relationship (casually dating $M=3.80, S D=$ 2.28; seriously dating $M=3.32, S D=1.74$; or other $M=1.50, S D=7.07 ; F(2,51)=1.23, p=$ .30), perceived success rate at communicating deception (not successful $M=1.50, S D=0.71$; somewhat successful $M=3.35, S D=2.11 ;$ successful $M=3.50, S D=1.47$; very successful $M=$ $3.50, S D=1.73 ; F(2,52)=.23, p=.79)$, or assessments of how "typical" the communication 
pattern with their romantic partner over the past 7 days was ( not typical $M=3.67, S D=2.08$;

somewhat typical $M=3.93, S D=2.25$; typical $M=3.14, S D=1.42$; very typical $M=2.78, S D=$ $1.48 ; F(3,53)=.79, p=.50)$.

Analyzing research questions two and three. The open ended nature of research questions two and three (i.e., the feelings that are subject of deception, affectionate messages used to deceive, and motives for deception) required qualitative analysis. All responses were analyzed using a grounded theory approach (Glaser \& Strauss, 1967) in order to discover themes that depict the deceptive affection process. Given that responses ranged in length from one word to multiple sentences, responses to each question were considered as a whole rather than treating individual words as the unit of analysis. The treatment of responses as whole units is consistent with prior qualitative research (e.g., Soliz, 2008). Initially, a process of open coding occurred in which codes were identified after reading individual responses (Strauss \& Corbin, 1998). Codes were consistently compared against themselves and, when necessary, new codes were created. When the coding scheme was deemed to be representative, the researcher employed this scheme to code all responses. Next, the researcher recruited a graduate student to work as a second coder. The researcher met with this coder and explained the differences between feelings and expressions of affection, and reviewed the coding scheme with the second coder. The second coder was instructed to list any additional codes she thought were necessary; however, she did not recommend the addition of any new codes. The coding scheme was used to identify recurring themes that categorized responses to each diary question. The specific codes used to organize responses, as well as inter-rater reliability, will be discussed during the responses to each research question. 
Research question 2-a. Research question 2-a asked what feelings were the subject of deception when communicating DAMs. Based on several preliminary readings of the data, and after consulting with an additional coder, a codebook was developed to initially organize the data. The codebook is available in appendix E, and the two coders achieved an acceptable interrater reliability ( $\pi=0.90 ; \mathrm{Scott}, 1955)$. Consequently, seven themes emerged that described the feelings that are the subject of deceptive affection. Table 11 summarizes these themes.

First, and the most common, was negative feelings $(n=136,72.7 \%)$. This theme describes instances in which communicators felt negatively either physically or emotionally. The feelings participants described routinely depicted some sort of negative affect directed toward one's romantic partner. Participants described, for example, feeling angry, jealous, "disgusted" by a partner's weight, and “irritated" by a partner's choices. For example, one participant described feeling "lonely, sad, left out, and irritated," yet explained that she said "I love you more than anything in the world." This category also included internal physical feelings such as feeling tired, sick, or hung over.

The second theme, desire for interaction $(n=15,8.6 \%)$, described situations in which participants felt like they did, or did not want to, interact with their romantic partner. For example, one participant described feeling "ignored" by his romantic partner and desired to spend more time with his partner. Conversely, another person described feeling like he "wanted to get off the phone so I could watch the...basketball game.” This participant explained he told his girlfriend he loved her to end the interaction.

The third theme, reflecting on a transgression $(n=10,5.3 \%)$, described situations in which participants reported experiencing feelings that pertained to a relational transgression the 
Table 11

Feelings that are the subject of deceptive affection (Research question 2a)

Feeling

Negative feelings

Desire for interaction

Reflecting on a transgression

Neutral/baseline

Sexual interest

Positive affect

Other

Total
Frequency

136

16

10

8

7

5

5

187
Percent of Total

$72.7 \%$

$8.6 \%$

$5.3 \%$

$4.3 \%$

$3.7 \%$

$2.7 \%$

$2.7 \%$

$100 \%$ 
source committed. One participant, for example, reported feeling bad after accidentally physically hurting his girlfriend while playing a video game. Another participant felt concerned that his relational partner "caught" him checking out a relational alternative. Others described feeling "guilt" and "regret." For instance, a participant explained his girlfriend caught him checking out another woman. In response to her asking what he was doing, he explained "I was thinking about how much I love you."

The fourth theme, neutral/baseline $(n=8,4.3 \%)$ included situations in which participants reported feeling no recognizable emotion. Within this theme multiple participants reported feeling "no emotions." For instance, one participant listed that he felt "nothing" but still told his partner "I love you."

The fifth theme, sexual interest $(n=7,3.7 \%)$, described situations in which participants felt the desire to have, or avoid, sexual activity. Within this theme, participants described the urge to have sex with their romantic partners. Conversely, others described no urge to have sex with their partners. One participant explained that he had no desire to have sex at the moment, but agreed to the sex explaining that "the guy isn't supposed to be the one to turn it down."

The sixth theme, positive affect $(n=5,2.7 \%)$, described situations in which participants felt good. Examples of this theme include feeling "relieved" or excited about taking a trip with a relational partner. For example, one participant explained feeling "excited" about seeing a play, yet minimized her excitement and expressed affection because if she "played it down, he'd cough up the cash when the lady at the ticket booth told him the price."

The final theme, other $(n=5,2.7 \%)$, includes instances in which participants described feelings that did not fit into the preceding themes (e.g., feeling "emotional.") or situation specific details that did not accurately list a discernable feeling (e.g., "I am a Christian and don't believe 
it's right to marry a non-Christian and she asked me if she didn't get saved would I still marry her?").

In response to research question 2-a, the following themes describe the subject of deceptive affection: negative feelings, desire for interaction, reflecting on a transgression, neutral/baseline, sexual interest, and positive affect. A chi square revealed that the frequency of these themes differs $\left(x^{2}(6, N=180)=514.94, p=.000\right)$.

Research question 2-b. Research question 2-b asked what affectionate messages are used when communicating deceptive affection. After several preliminary readings of the data, and after consulting with an additional coder, a codebook was developed to initially organize the data (see Appendix E). The two coders achieved an acceptable inter-rater reliability $(\pi=0.91$; Scott, 1955). Three themes, summarized in table 12 , emerged: verbal affection, nonverbal affection, and supportive affection. Verbal affection $(n=89,39.7 \%)$ consisted of verbal expressions of love and affection. Example descriptions participants offered included "I said "I love you," "I miss you," telling one's partner you think he/she "looked good," and verbally committing to having sex.

The second theme, nonverbal affection $(n=89,39.7 \%)$, included nonverbal expressions of affection. These included hugs, massages, holding hands, smiles, sex, kisses, putting an arm around the partner, and cuddling. Descriptions included "I put my arm around her and later my hand on her leg" and "gave him a back rub."

The third theme, supportive affection $(n=46,20.5 \%)$, included tangible and intangible acts of support. These included assuring someone about the relationship/future, pretending to be interested in a partner's story/interests/talents, and supportive acts such as cooking dinner. For example, some participants expressed to their partners, during discussions of marriage, that their 
partner was their future spouse. Still, other participants explained that they spent time with their partner despite maintaining a desire not to spend time with their partner. Finally, participants offered examples in which they cooked dinner for their partner, ran an errand for their partner, or gave their partner money.

In response to research question 2-b, participants report communicating deceptive affection through verbal, nonverbal, and supportive affectionate behaviors. A chi square revealed that the frequency of these themes differs $\left(x^{2}(2, N=177)=20.98, p=.000\right)$.

Research question three. Research question three asked what the motives were for expressing deceptive affection. Based on several preliminary readings of the data, and feedback from an additional coder, a codebook was developed to initially organize the data (see Appendix E). The two coders achieved an acceptable inter-rater reliability $(\pi=0.88$; Scott, 1955). Eight themes were subsequently identified, and are summarized in Table 13. The first theme, induce affect in partner $(n=69,33.9 \%)$, described situations where participants wanted to make their partners feel a certain way. Participants described situations where deceivers wanted their relational partners to feel positively. Examples of positive affect included making a partner feel good and avoiding hurting a partner's feelings. Participants described these instances as “to save face," "made her feel better," avoiding "getting her spirits down," and "I didn't want him to feel guilty." Yet, one ( $n=2$ lies, $.9 \%)$ person described using affection to make their partner feel "guilty" or "bad."

The second theme, avoidance $(n=39,19.2 \%)$, described motives for deceptive affection in which participants wanted to avoid a conflict, topic, or their partner. Although deceptive affection was expressed to avoid certain topics or spending time with one's partner, this motive 
Table 12

Affectionate messages employed to convey deception (Research question $2 b$ )

Message

Verbal Affection

Nonverbal Affection

Supportive Affection

Total
Frequency

89

89

46

224
Percent of Total

$39.7 \%$

$39.7 \%$

$20.5 \%$

$100 \%$ 
largely consisted of instances where deceptive affection was used as a means to avoid or defuse a conflict situation. Participants described expressing deceptive affection because they “didn’t want to start a fight" or they wanted to avoid "arguing."

The third theme, mask affect $(n=29,14.3 \%)$, describes situations in which participants expressed deceptive affection to minimize emotion. This motive largely included situations in which participants masked their negative emotion toward their partner or a situation. Participants often expressed deceptive affection to mask feeling "sad," "annoyed," or "angry." Yet, two participants did describe situations in which they masked positive affect. An example entry explained that a man expressed deceptive affection because he did not want his girlfriend "to think I was that into it."

The fourth theme, routine/reciprocation $(n=27,13.3 \%)$ described motives for deceptive affection as being either habitual or reciprocation based. For example, a participant explained that he/she expressed deceptive affection because "I just feel after we've been together for so long some of it is habit." Others described their deceptive affection was communicated to reciprocate their partners' expressions. Thus, although participants were not genuinely feeling affectionate, they still reciprocated their partners' affectionate messages.

The fifth theme, provide support $(n=13,6.4 \%)$, included deceptive affection communicated to show support. For instance, a participant explained that he/she communicated deceptive affection because he/she "wanted to show my support."

The sixth theme, communicate affiliation $(n=12,5.9 \%)$ depicted situations in which deceptive affection was expressed to show affiliation with one's romantic partner to relational rivals. For example, a participant described putting his arm around his girlfriend because he 
Table 13

Motives for deceptive affectionate messages (Research question 3)

Motive

To induce affect in partner

Avoidance

Mask affect

Routine/reciprocation

Provide support

Communicate affiliation

To receive affection

Other

Total
Frequency

69

39

29

27

13

12

4

10

203
Percent of Total

$33.9 \%$

$19.2 \%$

$14.3 \%$

$13.3 \%$

$6.4 \%$

$5.9 \%$

$2.0 \%$

$4.9 \%$

$100 \%$ 
"wanted to show that she was mine because other guys were looking at her." Another participant reported expressing deceptive affection to her boyfriend when they were walking past the place of employment of her boyfriend's former girlfriend.

The seventh theme, to receive affection $(n=4,2.0 \%)$, describes instances in which participants expressed deceptive affection in order to receive affection. Two participants reported that they were affectionate in order to have sex. Two others reported being affectionate in order to receive affection later. For example, a participant explained that she was affectionate because she would not want her boyfriend to "blow her off" later just because she not was not currently affectionate.

The final theme, other $(n=10,4.0 \%)$, included situations that did not fit into the previous motives. This included blank responses and situations in which participants provided unique situational information rather than information that actually explained why they communicated deceptive affection.

To summarize, in response to research question three, individuals express deceptive affection to induce affect in their partners, for avoidance, to mask affect, because it is routine/reciprocate affection, to provide support, to communicate affiliation, and to receive affection. A chi square revealed that the frequency of these themes differs $\left(x^{2}(7, N=180)=\right.$ $105.16, p=.000)$.

Hypothesis one. The first hypothesis predicted that there would be differences in rumination based on deceptive motive. Some deceptive affection entries described more than one deceptive motive, and in those cases, the most apparent motive was coded for the purpose of this analysis. A one way analysis of variance (ANOVA) did not reveal any significant differences in 
rumination based on deceptive motive $(F(7,171)=1.16, p=.33$, observed power $=.49)$. Hypothesis one was not supported.

Given that this finding was counter to predictions, and in an effort to further understand if rumination was an issue for sources of deceptive affection, potential rumination differences were analyzed using the remaining two open-ended diary questions. An ANOVA revealed no significant differences based on the feelings that were the subject of deceptive affection (negative feelings $M=2.08, S D=1.22$; sexual interest $M=1.75, S D=.52$; desire for interaction $M=1.82, S D=.87 ;$ neutral/baseline $M=1.56, S D=.79 ;$ reflecting on a transgression $M=2.80$, $S D=1.43 ;$ positive affect $M=2.30, S D 1.44$; other $M=1.40, S D=.58 ; \mathrm{F}(6,172)=1.37, p=$ .23 , observed power $=.52$ ). However, a second ANOVA did reveal differences in rumination based on the type of DAM communicated (verbal $M=2.18, S D=1.26$; nonverbal $M=1.79, S D$ $=1.01 ;$ supportive $M=2.44, S D=1.34 ; F(2,173)=4.09, p=.02$, observed power $=.72) . \mathrm{A}$ post hoc analysis (Tukey) revealed that individuals ruminated more following supportive deceptive affection $(M=2.44)$ compared to nonverbal deceptive affection $(M=1.79)$.

Post hoc analysis. This dissertation argues that deceptive affection is a risk to sources of such messages. As a way of further gauging if deceptive affection is a risk, two factors were analyzed: rumination and perceived impact of the DAM if discovered.

In an effort to further understand rumination, the phase three responses were analyzed. Recall that respondents identified which DAM they ruminated most about from the previous week. With this in mind, participants were asked why they thought about this deceptive act the most. The answer to this "why" question offers insight into the factors that influenced source rumination. Of the 57 phase three surveys, 16 responses to this question were eliminated either because participants did not communicate any DAMs during the diary period or, when reviewing 
their previous response to "which instance of deceptive affection did you think about the most," they provided descriptions of overall deception rather than deceptive affection. Using the same coding procedure used to analyze the diaries $(\pi=0.91$; Scott, 1955), six categories were identified that described "why" participants ruminated the most about a certain DAM. The first category was severity of the DAM $(n=11)$, in which participants described thinking the most about the DAM because of the intimate nature of affectionate communication. For example, one participant explained that "I feel that saying 'I love you' is a pretty big thing and it really shouldn't just be said in order to keep a fight from occurring." The second category was beliefs about deception $(n=8)$, in which participants described that they reflected on their DAM because they "shouldn't lie," they should be "honest," and/or should not deceive their relational partner. The third category, negative affect $(n=4)$, explained situations in which participants felt bad about this DAM, i.e., one person reported he/she felt "guilty." The fourth category was only one DAM reported $(n=3)$, in which participants reported they reflected the most on a certain DAM because they only reported one in their diary. The fifth category was fear of partner reaction $(n=3)$, in which participants described that their partners would be "upset" if they found about the deception. The final category was unclear/irrelevant response $(n=12)$, included responses in which participants did not offer a discernable reason why they focused on a certain DAM, and instead offered situation specific details relating to their motive for the DAM or relational communication. Based on these categories, it appears that participants reflected the most on one DAM they perceived to be most severe.

The second potential risk factor analyzed was the impact of the deceptive affection if it were discovered by a deceiver's partner. ANOVAs revealed that perceptions of impact/severity did not differ based on the feelings lied about $(F(6,100)=.48, p=.82$, observed power $=.19)$ or 
the motive for deceptive affection $(F(7,99)=.31, p=.94$, observed power $=.14)$. However, severity did differ based on the type affection communicated $(F(2,103)=3.09, p=.05$, observed power $=.58)$. A post hoc analysis (Tukey) revealed that participants perceived their verbal deceptive affection $(M=2.16)$ as more severe than their nonverbal deceptive affection $(M$ =1.7). Collectively, it appears that deceivers perceive that their verbal DAMs, if discovered, would be more detrimental to their relationships than their nonverbal DAMs.

\section{Study One Summary}

The purpose of study one was to understand how and why individuals communicate deceptive affection to their romantic partners. Results indicate that individuals do routinely communicate DAMs to their romantic partners using verbal, nonverbal, and supportive behaviors. Individuals express DAMs for a variety of positive motives (e.g., induce affect in partner) used to mask feelings. Rumination was examined as a potential risk for deceivers, and it appears that individuals do ruminate following DAM expression. This rumination varies based on the type of DAM expressed. Study two aimed to extend the rumination finding by systematically examining the source implications of DAMs.

Study Two

Preliminary analysis. In order to better understand the romantic partner deception in this sample $(N=99)$, an independent samples $t$-test was conducted to examine potential sex differences in the frequency of romantic partner deception. As with study one, the $t$-test was significant $(t(97=2.59, p=.01)$ indicating that men $(M=3.25, S D=1.22)$ reported communicating more deception to romantic partners compared to women $(M=2.62, S D=1.21)$.

Hypothesis one. The first hypothesis predicted that writing about deceptive affection would result in increased blood pressure and heart rate. A series of paired sample $t$-tests 
conducted on all participants in the deceptive affection condition revealed no significant differences between times 1 and 2 on measures of systolic blood pressure (time $1 M=110.65$, $S D=10.42$, time $2 M=110.03, S D=9.74, t(33)=.38, p=.70$ ), diastolic blood pressure (time 1 $M=66.71, S D=9.07$, time $2 M=66.74, S D=7.43, t(33)=-.03, p=.98)$, or heart rate (time 1 $M=72.29, S D=10.32$, time $2 M=72.59, S D=976, t(33)=-.36, p=.72)$.

Given that men and women have different average heart rates, and the evolutionary nature of AET, data were analyzed separately by sex. A series of paired samples $t$-tests revealed no significant differences in men's systolic blood pressure $(t(18)=1.48, p=.16)$, diastolic blood pressure $(t(18)=.54, p=.60)$, or heart rate $(t(18)=-1.37, p=.18)$ between times 1 and 2 . Likewise, a series of paired samples $t$-tests revealed no significant differences in women's systolic blood pressure $(t(14)=-1.17, p=.26)$, diastolic blood pressure $(t(14)=-.56, p=.58)$, or heart rate $(t(14)=.59, p=.56)$ between times 1 and 2 . Tables 5 and 6 display the time two means by sex. Hypothesis one was not supported.

Research question one. Research question one asked if there were significant blood pressure and heart rate differences between honest and deceptive affectionate messages. A series of ANOVAs analyzed potential differences between the deceptive affection, honest affection, and control conditions. These analyses also included the control condition to insure that any potential changes were attributable to the experimental manipulation. Results revealed no significant differences between the three conditions on systolic blood pressure (deceptive $M=$ 110.03, $S D=9.74$, honest $M=113.15, S D=12.22$, control $M=112.41, S D=15.93, F(2,96)=$ $.54, p=.13$, observed power $=.13$ ), diastolic blood pressure (deceptive $M=66.74, S D=7.43$, honest $M=69.18, S D=7.38$, control $M=69.50, S D=13.92, F(2,96)=.77, p=.47$, observed 
power $=.17$ ), or heart rate (deceptive $M=72.59, S D=9.76$, honest $M=74.00, S D=13.92$, control $M=75.69, S D=8.55, F(2,96)=.66, p=.52$, observed power $=.16)$.

When analyzing by sex, a series of ANOVAs for men indicated no significant differences between honest and deceptive affectionate messages on measures of systolic blood pressure $(F$ $(2,39)=1.36, p=.27$, observed power $=.28)$, diastolic blood pressure $(F(2,39)=1.26, p=.30$, observed power $=.26)$, or heart rate $(F(2,39)=.37, p=.70$, observed power $=.11)$ at time two. A series of ANOVAs produced the same results for female participants' measures of systolic blood pressure $(F(2,54)=.70, p=.93$, observed power $=.06)$, diastolic blood pressure $(F(2$, $54)=.08, p=.92$, observed power $=.06)$, and heart rate $(F(2,54)=.77, p=.47$, observed power $=.17$ ) at time two. Tables 5 through 10 display the time two means by sex.

Research question two. Research question two asked if there were physiological differences at time two based on the motive (i.e., self protection, partner protection, relational protection, or other) for deceptive affection. When examining the entire sample, an ANOVA failed to reveal any significant differences in systolic blood pressure $(F(2,31)=.06, p=.94$, observed power $=.58)$, diastolic blood pressure $(F(2,31)=.48, p=.95$, observed power $=.57)$, and heart rate $(F(2,31)=.33, p=.73$, observed power $=.12)$ based on motive for communicating deceptive affection. Similar results were obtain for men's systolic blood pressure $(F(2,16)=.04, p=.97$, observed power $=.06)$, diastolic blood pressure $(F(2,16)=.25, p=.78$ observed power $=.08)$, and heart rate based $(F(2,16)=.06, p=.94$, observed power $=.06)$ on the motive for communicating deceptive affection. Likewise, an ANOVA failed to reveal any significant differences in women's systolic blood pressure $(F(2,12)=.18, p=.84$, observed power $=.07)$, diastolic blood pressure $(F(2,12)=.35, p=.71$, observed power $=.09)$, and heart rate based $(F(2,12)=3.41, p=.07$, observed power $=.53)$ on the motive for communicating 
deceptive affection. In response to the research question, there were not differences in physiological responses based on the motive for communicating deceptive affection. Tables 14 and 15 report the physiological descriptive statistics by motive.

Hypothesis two. The second hypothesis predicted that there would be differences in feelings of guilt and shame based on the motive for expressing deceptive affection. When looking at the entire sample, an ANOVA failed to reveal any significant differences between feelings of guilt $(F(3,29)=.56, p=.64$, observed power $=.15)$ based on deceptive motive; however, feelings of shame did significantly differ based on motive $(F(3,30)=3.88, p=.02$, observed power $=.72)$. A post hoc analysis $($ Tukey) revealed that individuals reported less shame for the other motive $(M=.40)$ compare to the self protection motive $(M=.49)$. In order to understand if these emotional processes differed by sex, ANOVAs were conducted separately for men and women. For women, there were no significant differences in guilt $(F(3,10)=.33, p=$ .80 , observed power $=.94)$ and shame $(F(3,11)=.87, p=.48$, observed power $=.91)$ based on motive. Analyses for men indicated no differences in guilt based on motive $(F(3,15)=.67, p=$ .58 , observed power $=.16)$, however, feelings of shame did differ $(F(3,15)=4.64, p=.02$, observed power $=.45$ ). When the motives were broken down by sex for the previous analysis, one motive, self protection, resulted with a frequency of 1 . Thus, a post hoc analysis could not be conducted to discover where differences in shame emerged for men. When self protection was removed from the shame analysis for men, the ANOVA for shame was no longer significant ( $F$ $(2,16)=3.58, p=.052$, observed power $=.57)$. Tables 16 and 17 report the means for guilt and shame based on motive.

Post hoc analysis. Multiple studies indicate that affectionate communication relates to physiological responses (e.g., Floyd, 2006a). However, the obtained physiological results failed 
Table 14

Men's physiological descriptive statistics for guilt based on motive

\begin{tabular}{llll}
\hline & Systolic BP & Diastolic BP & Heart Rate \\
& Mean $(S D)$ & Mean $(S D)$ & Mean $(S D)$ \\
\hline Self protection & $118.00(\mathrm{~N} / \mathrm{A})$ & $78.00(\mathrm{~N} / \mathrm{A})$ & $76.00(\mathrm{~N} / \mathrm{A})$ \\
Partner protection & $111.00(4.32)$ & $65.75(8.69)$ & $73.50(21.06)$ \\
Relationship protection & $109.60(14.31)$ & $64.90(9.09)$ & $71.30(7.82)$ \\
Other & $109.25(6.18)$ & $65.75(5.12)$ & $69.50(13.20)$ \\
& & & \\
\hline
\end{tabular}

*N/A for standard deviations indicates that the motive only occurred once. 
Table 15

Women's physiological descriptive statistics for guilt based on motive

\begin{tabular}{llll}
\hline & Systolic BP & Diastolic BP & Heart Rate \\
& Mean $(S D)$ & Mean $(S D)$ & Mean $(S D)$ \\
\hline Self protection & $102.00(\mathrm{~N} / \mathrm{A})$ & $58.00(\mathrm{~N} / \mathrm{A})$ & $80.00(\mathrm{~N} / \mathrm{A})$ \\
Partner protection & $111.00(12.51)$ & $66.60(7.30)$ & $68.80(4.67)$ \\
Relationship protection & $110.00(7.34)$ & $69.29(6.16)$ & $77.72(6.16)$ \\
Other & $109.50(4.95)$ & $70.00(4.25)$ & $69.50(4.28)$ \\
& & & \\
\hline
\end{tabular}

*N/A for standard deviations indicates that the motive only occurred once. 
to replicate such a finding. Consequently, further analyses were conducted in order to understand the data. Since prior studies have not specifically distinguished between honest and deceptive affection, the two conditions were combined to examine potential differences between the affectionate communication conditions (deceptive and honest affection) and the control condition. A series of independent samples $t$-tests for the entire sample revealed no significant physiological changes for participants' measures of systolic blood pressure (affection $M=$ 111.57, $S D=11.06$, control $M=112.41, S D=15.93, t(97)=-.31, p=.76)$, diastolic blood pressure (affection $M=67.94, S D=7.45$, control $M=69.50, S D=13.92, t(97)=-.73, p=.47$ ), or heart rate (affection $M=73.28, S D=11.92$, control $M=75.69, S D=8.55, t(97)=-1.02, p=$ $.31)$.

When analyzing by sex, a series of independent samples $t$-tests revealed no significant physiological changes for men's measures of systolic blood pressure (affection $M=113.19, S D$ $=12.56$, control $M=114.80, S D=13.10, t(40)=-.35, p=.72)$, diastolic blood pressure (affection $M=67.22, S D=8.16$, control $M=70.70, S D=8.26, t(40)=-1.17, p=.25$ ), or heart rate (affection $M=70.75, S D=15.36$, control $M=74.60, S D=8.76, t(40)=.75, p=.46$ ). Similarly, a series of independent samples $t$-tests did not reveal differences in women's measures of systolic blood pressure (affection $M=110.09, S D=9.44$, control $M=111.32 S D=17.23, t$ $(55)=-.35, p=.73$ ), diastolic blood pressure (affection $M=68.60, S D=6.78$, control $M=$ 68.95, $S D=15.99, t(55)=-.17, p=.91)$ or heart rate $($ affection $M=75.60, S D=7.00$, control $M$ $=76.18, S D=8.61, t(55)=-.28, p=.78)$ between affectionate (deceptive and honest affection) and non-affectionate conditions.

Because participants' first physiological assessments have the potential to influence results, a multivariate analysis of variance was conducted to examine differences in time two 
Table 16

Descriptive statistics for guilt based on motive

\begin{tabular}{llll}
\hline & Men \& women & Men & Women \\
& Mean $(S D)$ & Mean $(S D)$ & Mean $(S D)$ \\
& & & \\
\hline Self protection & $4.27(2.19)$ & $5.81(\mathrm{~N} / \mathrm{A})^{*}$ & $.47(\mathrm{~N} / \mathrm{A})^{*}$ \\
Partner protection & $3.68(1.51)$ & $4.23(1.71)$ & $.47(.48)$ \\
Relationship protection & $3.63(1.69)$ & $3.83(1.64)$ & $.44(.02)$ \\
Other & $4.50(.66)$ & $4.59(.76)$ & $.38(.46)$ \\
& & & \\
\hline
\end{tabular}

*N/A for standard deviations indicates that the motive only occurred once. 
Table 17

Descriptive statistics for shame based on motive

\begin{tabular}{llll}
\hline & Men \& women & Men & Women \\
& Mean $(S D)$ & Mean $(S D)$ & Mean $(S D)$ \\
\hline Self protection & $.49(.03)$ & $2.72(\mathrm{~N} / \mathrm{A})^{*}$ & $.51(\mathrm{~N} / \mathrm{A})^{*}$ \\
Partner protection & $.46(.04)$ & $3.18(1.23)$ & $.45(.04)$ \\
Relationship protection & $.45(.03)$ & $3.23(1.86)$ & $.46(.04)$ \\
Other & $.40(.05)$ & $3.36(1.44)$ & $.44(.03)$ \\
& & & \\
\hline
\end{tabular}

*N/A for standard deviations indicates that the motive only occurred once. 
physiological assessments between conditions, while simultaneously controlling for time one physiological assessments. A MANCOVA examining time two physiological differences between conditions was not significant (Wilks' $\lambda=.98, F(6,182)=.29, p=.94$, observed power $=.12$ ). When analyzing by sex, the models were not significant for male (Wilks' $\lambda=.87, F(6$, $68)=.79, p=.58$, observed power $=.28)$ or female $($ Wilks' $\lambda=.95, F(6,98)=.39, p=.88$, observed power $=.16$ ) participants.

Subsequent analyses were conducted to further understand how guilt and shame related to deception. Thus, Pearson correlations were conducted between frequency of romantic partner deception and feelings of guilt and shame after their recall of a DAM. When examining men and women together, frequency of deception did not correlate with feelings of guilt $(r=-.32, p=$ $.19)$ and shame $(r=-.08, p=.66)$ after recalling a DAM. For women, the correlations between frequency of romantic partner deception and guilt $(r=.03, p=.93)$ and deception and shame $(r$ $=.10, p=.77$ ) were not significant post-deceptive affection. For men, the frequency of romantic partner deception was negatively related to feelings of guilt $(r=-.62, p=.003)$ and shame $(r=-.49, p=.03)$ post-deceptive affection.

\section{Summary}

The purpose of this chapter was to provide the qualitative and quantitative results of studies one and two. The results of the first study identify the feelings that are the subject of, messages used for, and motives for communicating DAMs. The obtained rumination and severity results in study one begin to elucidate ways in which communicating DAMs can be problematic for sources. Study two was designed to further examine the emotional and physiological risks of expressing DAMs; however, no significant differences were obtained using the written recall 
method. The subsequent section will discuss the findings in detail, their implications, as well potential limitations and directions for future research. 


\section{Chapter IV}

\section{Discussion}

Affectionate messages are important in romantic relationships as they are related to relational qualities (e.g., Horan \& Booth-Butterfield, in press) as well as physical (Keicolt-Glaser \& Newton, 2001; Medalie et al., 1992) and emotional health (Floyd, 2002). Interestingly, results of this dissertation indicated that relational partners communicate about three deceptive affectionate messages a week, which could be problematic for sources. This dissertation was undertaken to learn more about DAMs and the associated implications. Results of the first study revealed the feelings that are the subjects of DAMs, the affectionate messages used to express DAMs, the motives for deception, and how rumination functions in conjunction with deceptive affection. Results of the second study revealed that recalling deceptive or authentic affection did not influence physiological functioning and had minimal influence on feelings of guilt and shame.

Before discussing the results of the specific studies, it is first necessary to review the preliminary data in both studies which, consistent with the aim of this dissertation, begin to explicate the relationships among romantic partner deception and affection. In the first study, the frequency of romantic partner deception was negatively related to giving and receiving affection, and giving and receiving affection were positively related. Based on the evolutionary nature of AET data were analyzed individually by sex. Women reported expressing more affection to romantic partners than men reported, and in both studies one and two, men reported communicating more overall deception to romantic partners than women. These results suggest that women may express more affection in relationships and, conversely, men may be more deceptive. It should be noted that both the affection and deception findings were obtained using 
self report data. It is likely that responses were influenced by a social desirability bias which, due to the unreliable nature of the measure, is a possibility that could not be explored. The affection measures, however, may be more valid given prior work revealing correlations among self and partner reports of affectionate communication (Horan \& Booth-Butterfield, in press).

The forthcoming sections of this chapter will discuss the results. This chapter will first discuss deceptive affection in general, followed by a detailed discussion of the feelings, messages, and motives that are a part of this communicative process. Next, the discussion will address the physiological findings, as well as whether deceptive affection is considered a risk for deceivers. Finally, limitations, future research, practical and theoretical implications will be addressed.

\section{Deceptive Affectionate Messages}

Before systematically studying DAMs, it was first necessary to discover if individuals did express such messages to their romantic partners. The diary results indicate that individuals express approximately three DAMs to their romantic partners in a week. This is consistent with the work of Floyd, Erbert et al. (2005, as cited in Floyd, 2006a), who found that most individuals in their study could recall recently expressing inauthentic affectionate messages to manipulate a variety of targets in close relationships. This dissertation extends their work by 1) examining all acts of deceptive affection, not just those aimed at manipulation and 2) exclusively studying romantic relationships.

The finding that individuals express three DAMs a week to romantic partners is supported by past deception research. For example, Kashy and DePaulo (1996) depicted deception as "a fact of social life rather than an extraordinary or unusual event" (p. 1037). In the context of romantic partner deceptive affection, results indicate that Kashy and DePaulo's 
description is indeed accurate. In fact, the findings on the frequency of DAM expression elucidate how deception is a "fact of social life" for those in non-married romantic relationships, as they likely receive about three DAMs a week. Although this is not a particularly high number, it does suggest that romantic partners do routinely express deceptive affection. The frequency of DAMs is further supported by DePaulo and Kashy (1998), who found that individuals communicated deception to their romantic partners in one out of every three interactions. Viewing the present results with DePaulo and Kashy (1998) and Kashy and DePaulo (1996), deception appears to be a common message in romantic relationships.

The fact that individuals express about three DAMs a week has implications for truth biases. Recall that deception researchers argue that individuals in close relationships often assume honesty despite the frequent nature of deception (i.e., McCornack \& Parks, 1986). Given the intimate nature of affectionate messages within romantic relationships it is unlikely that individuals would question the authenticity of partners' affectionate messages. Accordingly, individuals in established romantic relationships may be especially prone to assuming that romantic partners' affectionate messages, compared to other messages, are honest. This speculation is supported by the vast majority of participants $(80.39 \%)$ indicating their partners did not discover they expressed deceptive affection. This suggests that partners did not question the honesty of affectionate messages. Regardless of their authenticity, affectionate messages signal feelings of affection and closeness, and are related to enhanced relational perceptions (e.g., Horan \& Booth-Butterfield, in press). As a result, both honest and deceptive affectionate messages may similarly enhance relational bonds. Thus, DAMs may serve to enhance perceptions of closeness and intimacy, and consequently, enhance truth-biased perceptions that 
relational partners are consistently honest. However, in order to fully understand the influence of DAMs, it was necessary to examine the feelings and messages that composed this process. Feelings, Messages, and Deceptive Affection

Given that deceptive affection represents a discrepancy between feelings of affection and expressions of affection, research question two asked participants about their feelings and subsequent affectionate messages. Six themes describe the feelings that individuals use affection to lie about: negative feelings, desire for interaction, reflecting on a transgression, neutral/baseline, sexual interest, and positive affect.

The majority of participants reported that, when communicating deceptive affection, they were feeling some sort of negative affect or physiology. This finding has both positive and negative aspects. The positive aspect of this finding is that individuals in romantic relationships appear to shield their partners from the brutal honesty of their negative feelings. This suggests that individuals maintain an awareness of and respect for their partners' feelings, and importantly, consciously engage in emotion management. Conversely, results suggest that, when expressing deceptive affection, some individuals feel negatively and, frequently, the negative feelings were about their partners. This is indicative of a larger tension that partners may experience, namely, that communicators maintain an overall love and commitment for their partner, yet during the time of deceptive affection, communicators were bothered by their partners. Potentially then, partners may have elected to communicate deceptive affection to avoid conflict or hurtful messages and, ultimately, to maintain the quality of their relationships.

What is perhaps most interesting about the finding that individuals most often lie about their negative feelings is that individuals elected to communicate affectionate messages to mask their feelings. When communicators experience these negative states, they have a variety of 
messages to choose from, ranging from no communication to a topic change. However, within the constraints of this study, individuals elected to communicate affection while feeling negatively. This is quite paradoxical, as the affectionate messages are not only deceptive, but signaled to partners the complete opposite of what sources felt. Potentially, communicating affection while with-holding negative feelings may have reinforced irritating partner behaviors and further increased the deceiver's negative feelings. Regardless, the fact that individuals communicated affection rather than partner frustration is consistent with prior research revealing that individuals sometimes withhold partner complaints (e.g., Solomon, Knobloch, \& Fitzpatrick, 2003).

In response to research question 2-b, three themes were discovered that describe the affectionate messages used to communicate DAMs: verbal, nonverbal, and supportive affectionate messages. Although Floyd and Morman's (1998) three factor consideration of verbal, nonverbal, and supportive affection was not adopted a-priori as a coding scheme, the emergence of affectionate messages occurring in these three forms supports their view of affectionate messages. Floyd and Morman argued that a comprehensive and valid measure of affectionate communication was needed, and consequently, conducted a series of studies to develop such a measure. Using an inductive approach, they asked participants to list ways in which they communicated affection. Next, 34 coders reviewed those descriptions to eliminate responses that did not constitute affection. The resulting referents were used in multiple studies in which participants rated their affectionate communication in their closest relationships (with the majority of participants identifying romantic partners), platonic friends, and father-son relationships. Results of Floyd and Morman's research indicated that descriptions of affection are best represented using a three factor verbal, nonverbal, and supportive solution. Further, their 
results indicated this three-factor measure is a reliable, stable, and valid way to measure affection. The diary results independently confirm their three-dimensional treatment of affection.

Although verbal and nonverbal descriptions of affectionate communication are logical, given that they are the primary modes in which individuals communicate, supportive affection was initially thought to be a muddied view of affectionate communication. That is, because supportive affection appears to share conceptual overlap with existing conceptualizations of social support (see Burleson \& MacGeorge, 2002; Sarason \& Sarason, 2006), study one did not propose research question 2-b as a hypothesis predicting that romantic partners would communicate DAMs using verbal, nonverbal, and supportive messages. This same concern pertaining to the overlap between supportive affection and social support was maintained by Horan and Booth-Butterfield (in press), who partially based their decision to use competing measures of affectionate communication because of the ACI's supportive affection factor. Nevertheless, and consistent with Floyd and Morman's (1998) studies, results of study one indicate that individuals do record expressing verbal, nonverbal, and supportive messages.

Given that supportive affection was recorded by study one's participants, an important question to explore is how supportive affection differs from verbal and nonverbal affection. After all, the distinctions between verbal and nonverbal are apparent; yet, could supportive affection be classified more succinctly as verbal or nonverbal? Floyd (2006a) argued that there are two key characteristics that make supportive affection unique. First, supportive affectionate messages offer some assistance to receivers, and second, supportive affectionate messages are indirect ways of expressing affection. Examples of supportive affection include advice, money, and bringing someone food. Importantly, because of the indirect nature of supportive affection, Floyd argues that researchers often ignore it when examining affectionate communication. Viewing 
Floyd (Floyd, 2006a; Floyd \& Morman, 1998), Horan and Booth-Butterfield (in press), and study one together, it appears that supportive affection is a mode in which individuals indicate they express affectionate messages; yet, it is the task of future research to further elucidate how supportive affection is a unique mode of affection.

Collectively, viewing both the feelings and messages that are part of the deceptive affection process together provides support for display rules (Ekman \& Friesen, 1975). Ekman and Friesen proposed that individuals can inhibit, simulate, intensify, deintensify, and mask their feelings. Since individuals largely felt negatively when expressing deceptive affection, many individuals simulated and inhibited their feelings. Viewing the wide range of feeling and message examples offered in response to research question two, individuals reported inhibiting, masking, and deintensifying negative feelings and/or intensifying positive feelings while also simulating affectionate feelings. Consistent with the recent work of Hayes and Metts (2008), romantic couples do utilize display rules to act deceptively with feelings.

Although understanding the feelings and messages that compose the deceptive affection process was important, it was equally essential to examine the motives for expressing such messages. That is, in order to fully understand DAMs, it is important to understand why communicators expressed deceptive affection.

\section{Motives for Deceptive Affection}

Based on calls from prior deception research arguing for the importance of examining motives for deception (e.g., Buller \& Burgoon, 1994; Seiter et al., 2002), research question three was posed to discover the motives that drive DAMs. Seven motives were identified: to induce affect in partner, avoidance, mask affect, routine/reciprocation, provide support, communicate affiliation, and to receive affection. O'Hair and Cody (1994) summarized deceptive motives by 
arguing they could be described based on target (self, relational, other) and valence. The identified motives in study one are consistent with this typology, in that the motives were self and relationship focused and prosocial in nature.

The motives that were most frequently cited were to induce affect in partner (e.g., to make their partner feel a certain way; typically positive feelings desired in partner), avoidance (e.g., to avoid partner, topic, and/or conflict), mask affect (e.g., minimize source's feelings; typically negative feelings minimized), and routine/reciprocation (e.g., affection was expressed as part of a habit or in response to partner initiated affection). It can be argued that these motives are largely prosocial in nature: individuals want to make their partners feel good, avoid a conflict with their partner, hide their negative feelings from their partner, and reciprocate affectionate communication to avoid hurting their partner. Even some of the less popular motives, such as providing support, can also be argued to be prosocial. This suggests that communicators may maintain a positivity bias when making sense of why they deceived their partners. Individuals may cite largely positive reasons for deception to avoid experiencing dissonance (Festinger, 1957) from two inconsistent thoughts: caring for their partner (closeness), yet deceiving their partner (distance).

Regardless of why individuals list positive motives for their DAMs, this trend is consistent with prior mate selection and deception research. In the context of evolutionary goals, communicators may report expressing deceptive affection for positive reasons because they are in a relationship with someone who they view as a valued mate. To keep this valued mate, thus enhancing their survival odds, communicators would want to make their partner feel positive, avoid certain topics, and reciprocate affection. Research on altruistic deception (e.g., Kaplar \& Gordon, 2004) and deceptive typologies with components acknowledging partner 
benefit/protection (O’Hair \& Cody, 1994) suggests that individuals make sense of some deceptive acts with their partner's well-being in mind. This proposed positivity bias is supported by the fact that none of the motives were overtly negative. Despite work on altruistic deception and positive deception motives, some deception research suggests that these prosocial deceptive aspects may actually be more myth than reality. Ekman (1985), for example, lamented that it is likely that few acts of deception are actually driven by altruistic reasons. In support of Ekman's claim, O'Hair and Cody (1994) found that the majority of their respondents expressed deception for self-serving motives. Thus, although individuals report expressing DAMs for positive reasons, this may not be entirely consistent with reality. Future deceptive affection research would be wise to adopt a dyadic approach and compare sources' motives for deception and receivers' perceived motives for source deception.

Within the second study, motives did not explain as much of the difference in factors following recollections of deceptive affection as originally predicted (e.g., differences in heart rate, blood pressure, guilt, and shame). These findings will be reviewed, in detail, in the subsequent sections addressing the remaining findings; however, there are two clear motiverelated methodological issues that must be first acknowledged to appropriately understand study two's motive findings. Study one used an inductive approach to identify seven motives for expressing deceptive affection, whereas study two used a four item forced-choice measure of motives. Thus, the first methodological issue with motives in study two relates to the motive question. Ideally, the motives identified in study one would function as the motive questionnaire in study two. However, both studies were conducted concurrently and, as a result, the motives identified in study one were unavailable while study two's participants participated in the experiment. A related second methodological issue relates to the size of the deceptive affection 
condition in study two. This condition had 34 participants. Analyzing for motive differences within such a small sample allows little room to discover any statistically significant differences. Combining this fact with the uneven breakdown of participants between the differing motives ( 2 self protection, 9 partner protection, 17 relationship protection, and 6 other) suggests that the non-significant motive findings do not indicate that motive plays little-to-no role in understanding deception; rather, it suggests an area for future research to replicate, improve, and further examine.

Within study two, it was argued that motives would explain differences in potential risk factors for DAMs. These risk factors included guilt, shame, and physiological changes. To fully understand findings, the physiological results will first be discussed.

\section{Deceptive Affection and Physiological Responses}

It was argued in study two that expressing deceptive affection represented a physiological risk to deceivers, thus recalling DAMs should increase arousal. Specifically, hypothesis one predicted that writing about deceptive affection would increase heart rate and blood pressure, but this was not supported. Research question one queried if there were physiological differences between written recalls of honest and deceptive affection, and research question two asked if deceivers experienced differing physiological changes based on the motive for their DAM. In response to these research questions, results indicated no physiological differences between honest and deceptive conditions and no physiological differences based on deceptive motives.

Viewing the physiological findings of study two collectively, results fail to replicate the physiological findings obtained in prior AET research. Thus it appears that recalling both honest and deceptive affectionate messages does not elicit physiological changes. These findings support prior considerations of deception as typical, routine, and normative (e.g., DePaulo \& 
Kashy, 1998; Kashy \& DePaulo, 1996). Potentially then, communicators in this sample were accustom to expressing routine levels of deception and, as a result, were not physiologically influenced by recalling their deceptive affection. If this study focused on less normative instances of deceptive affection, such as DAMs that communicators viewed as relational turning points, participants may have been physiologically aroused; however, priming respondents to recall such an important message would have likely skewed findings.

Results of the diaries in study one may further inform why individuals were not physiologically influenced by recalling DAMs. Results of the first study revealed that individuals were motivated by prosocial reasons to express deceptive affection while feeling negatively. A re-analysis of the written texts in study two further supports the prosocial nature of DAMs, finding that $91.17 \%$ of participants in study two described their deceptive affection as motivated for prosocial reasons. Thus, DAMs may be considered some sort of relational coping mechanism or maintenance behavior. That is, communicators expressed these messages to avoid conflict or expressing hurt/complaints in order to maintain relational stability. Based on this reasoning, it is unlikely that an individual would experience elevated heart rate or blood pressure while reflecting on a message he/she viewed as functional. This may be especially true given that the majority of couples remain together following deception detection (McCornack \& Levine, 1990; Planalp, Rutherford, \& Honeycutt, 1988). Future research should code the qualitative writing entries in study two to see if, in fact, the descriptions of deceptive affection were functional and maintenance based. This would also serve to validate the typologies of deceptive feelings, messages, and motives identified in study one.

Although study two indicated that participants were not differentially physiologically aroused when recalling honest or deceptive affectionate messages, physiological differences 
should have emerged between the affectionate communication conditions (honest and deceptive) and the control condition. This reasoning was based on prior affectionate communication research as well as AET; yet analyses revealed no such differences. This may be due to the differences between study two's control condition and prior control conditions. Floyd et al. (2007) conducted two studies adopting a similar method in which participants wrote about affectionate communication and randomly assigned participants to one of three control conditions: one in which participants wrote about activities during the past week, one in which participants described where they lived, and one in which participants wrote about a recent job. In contrast, here participants were asked to describe a recent time they made plans with their friends. This condition was created, as opposed to adopting the Floyd et al. control groups, so that study two's control condition would be conceptually similar to the affectionate communication conditions - that is, they all involved recalling communication in close relationships. This was an important methodological change so that comparisons in study two could be made between three communicative conditions, differing from Floyd et al.'s comparisons between communicative and non-communicative conditions. Although having a control condition that involved communication with a friend may have hurt the comparison of physiological differences, future research examining physiological differences based on affectionate communication would be wise to employ a control condition that encompasses communication to allow for accurate comparisons.

Collectively, study two's findings do not parallel prior physiological studies examining affectionate communication. Given this finding, it is necessary to review some methodological issues that may account for variance in findings. Thus, the following discussion will initially explore how study two's method differs from prior AET physiological research. Next, potential 
issues concerning the 20 minute time frame will be explored as well as concerns surrounding only two physiological assessments. Finally, potential issues with a wrist cuff will be discussed.

The lack of statistically significant findings regarding physiological changes may be attributable to differences in this study's design compared to prior physiological affection research. That is, study two predicted an increase in heart rate and blood pressure from writing about affectionate communication whereas prior studies examined decreases in blood pressure and heart rate from writing about affection. Prior work incorporating stress inductions, such as a mental arithmetic challenge and a cold pressor test, revealed that writing about affectionate messages enhanced physiological functioning post stress induction (Floyd, Mikkelson, Tafoya, Farinelli, LaValley, Judd, Davis et al., 2007; Floyd, Mikkelson, Tafoya, Farinelli, LaValley, Judd, Haynes et al., 2007). Study two did not include a formal stress induction, reasoning that the recollection of the DAM was a sufficiently stressful activity. Yet, it appears that recalling a DAM may not be a sufficiently stressful activity to elicit physiological changes. In order to further understand the influence of deceptive affection on physiological functioning, future research should combine the Floyd studies with study two's design.

An additional explanation for the lack of physiological differences may be the manner in which heart rate and blood pressure were assessed. Blood pressure and heart rate were measured two times: once at baseline, and once after participants wrote for 20 minutes. The 20 minute window, although used in past research (Floyd et al., 2007), may be problematic. It is unknown if individuals wrote for the entire 20 minutes and spent time reflecting on their communication. In the interest of privacy, participants were left alone in the laboratory to write for 20 minutes. When reviewing the written texts in study two, individuals in the deceptive affection condition wrote an average of 25.54 lines $(S D=8.56), 25.41$ lines $(S D=8.55)$ in the honest affection 
condition, and 30.56 lines $(S D=10.41)$ in the control condition (an ANOVA between the conditions was significant $(F(2,96)=3.29, p=.04)$, with an LSD post-hoc revealing individuals wrote significantly more in the control condition than the deceptive and honest affection conditions). Thus, it is possible that a participant spent the first few minutes trying to recall an affectionate interaction and then began to describe it, whereas plans with friends (control) were easier to recall and describe. Alternatively, participants may have written about their interaction for the first 5 minutes and spent the remaining time relaxing. This issue did manifest itself during data collection, when one participant walked out of the room and explained that he could not write for 20 minutes (this data was not included in the analysis). These situations would influence any physiological changes.

A related issue to the 20 minute time frame pertains to the frequency of physiological assessments. Researchers argue that it is important to select an appropriate frame in which to assess physiology (Burgoon \& Le Poire, 1992; Floyd, 2004). Specifically, "Measurement windows that are too narrow may result in oversampling, whereas windows that are too wide can mask important variation in the signal being measured" (Floyd, 2004, p. 304). Thus, participants' blood pressure and heart rate may have needed to be assessed multiple times to discover physiological changes from recalling DAMs. Potentially, assessing blood pressure and heart rate at the one minute mark followed by five minute intervals for 20 minutes would have been more revealing. This assessment method would have been more informative compared to the present analysis comparing two measurements that were taken 20 minutes apart.

Another measurement factor that may have influenced findings was the use of a wrist cuff. Based on prior affectionate communication research, an Omron wrist monitor was selected (Floyd, Mikkelson, Tafoya, Farinelli, LaValley, Judd, Davis et al., 2007). A recent essay on 
physiological measurement in communication research identified three main ways to assess heart rate: a chest band, an ear clip, or wrist cuff (Floyd, 2004). This essay acknowledged that key advantages of the wrist apparatus include its non-invasive nature and affordability; however, wrist cuffs were argued to be "less accurate" than chest bands (p. 304). Thus, physiological findings may be limited by using this method, compared to the chest band. However, recall that prior research has discovered correlations between manual heart rate assessments and an Omron wrist cuff (Floyd, Mikkelson, Tafoya, Farinelli, LaValley, Judd, Davis et al., 2007). Similarly, study two's baseline physiological means are similar to the resting heart rate and blood pressure means in a recent video game experiment (Ballard, Hambee, Panee, \& Nivens, 2006). Regardless, a more invasive measure would be more accurate, and importantly, allow for continuous physiological measures while participants described their affectionate and honest communication.

In sum, it appears that communicators are not physiologically influenced when recalling honest and deceptive affectionate messages. Given this unpredicted finding, it is necessary to return to this dissertation's main argument that expressing deceptive affection is a risk for sources. Is Deceptive Affection A Risk?

A main argument presented throughout this dissertation is that communicating DAMs represents a risk to sources. The risks associated with deceptive affection have been speculated throughout this research, ranging from detection to an alteration of relational qualities. Communicators likely take this "risk" to receive the benefits affectionate communication engenders, including increased health, conflict communication, and relational qualities (e.g., Floyd, 2006a). Thus, both studies one and two explored this possibility that deceptive affection is 
a risk. Results of study one inform this argument by identifying factors that influence perceptions of rumination and severity. Specifically, individuals forecasted higher levels of rumination after expressing supportive deceptive affection compared to nonverbal deceptive affection. Further, participants perceived verbal DAMs as more severe if detected than nonverbal detected DAMs. Based on these results, for example, it is likely an individual ruminates more over a supportive DAM, such as cooking dinner for a romantic partner, compared to a nonverbal DAM, such as rubbing a partner's back when not feeling affection. Further, an individual views a verbal DAM, such as "I love you," as having more severe implications if discovered than holding a partner's hand when not feeling affection. Consequently, it appears that communicators view nonverbal DAMs as the least problematic. This may be due to their ambiguous nature, compared to overt verbal messages or supportive behaviors. A communicator would likely spend less time ruminating or maintain less severity concerns over a nonverbal DAM because such messages warrant multiple interpretations. Thus, if a nonverbal DAM was discovered, a deceiver could explain it was intended in a different way than it was interpreted. Importantly, these results begin to identify what characteristics of DAMs influence rumination and severity concerns.

The second study examined deceptive affection as a risk by examining heart rate, blood pressure, and feelings of guilt and shame. There were no discovered physiological differences between the conditions in which participants wrote about honest affection, deceptive affection, or a control condition. This suggests that, physiologically, expressing deceptive affection may not be a risk for sources. Future research is needed to further understand the physiological implications of expressing deceptive affection. Similarly, in study two, there were no differences in feelings of guilt and shame following recollection of a DAM based on deceptive motive. These differences are potentially attributable to the nature of analyses, with a sample of 34 
individuals completing measures of guilt and shame and differences analyzed across four deceptive motives. Stepping away from motive differences and examining these scales overall, the guilt mean $(M=3.86)$ was above the midpoint whereas the shame $(M=3.34)$ mean was below the midpoint. This indicates that individuals experience minimal emotional reactions after expressing deceptive affection.

Viewing studies one and two together, it appears that expressing DAMs is not "risky" for sources of such messages. Two studies with very different methods confirm this finding by specifically exploring rumination, guilt, shame, blood pressure, and heart rate. As a result, it appears that communicators do not view their deceptive expressions as stressful or anxiety inducing. Prior deception research, as well as results of study one, inform why communicators may not be emotionally or physiologically stressed post-DAM expression. DePaulo, Kashy, and colleagues (DePaulo \& Kashy, 1998; DePaulo et al., 1996; Kashy \& DePaulo, 1996) found that individuals routinely express deception to romantic partners in about one out of every three interactions. Further, study one found that individuals often expressed deception for prosocial reasons to benefit their relationship or partner. Combined, the frequent nature of romantic partner deception and prosocial nature of DAMs indicates that such messages are normative and would not elicit emotional or physiological responses. This is consistent with DePaulo et al.'s finding that communicators reported little distress during deceptive communication.

Although counter to arguments proposed throughout this dissertation, it appears that expressing deceptive affection is not troubling for sources. In an effort to further understand the results in this dissertation, the subsequent section will discuss the overall implications of the findings. 


\section{Implications}

In concert, results of studies one and two present implications for theory, research, and practice. First, because this dissertation identified that individuals do express deceptive affection it is necessary to understand how DAMs fit into AET's existing predictions. This theory offers a comprehensive set of predictions about affectionate communication; yet, with the exception of the second postulate, it is implied that AET is a set of predictions pertaining to authentic affectionate messages. How then, do deceptive messages work within this theory? Consider postulate three-a, for example, which argues that affectionate messages enhance pair bonds. It is unknown if undetected DAMs enhance pair bonds in the same manner that honest affectionate messages are argued to enhance bonds. Potentially, a source expressing deceptive affection may actually tarnish his/her perception of the relationship, while simultaneously enhancing his/her relational partner's perceptions. Consequently, affection exchange theorists should continue to examine deceptive affection, and work to understand how these expressions operate within their existing set of predictions.

Some deception researchers have proposed that being able to successfully communicate undetected deception may be a competent communicative behavior (Buller \& Burgoon, 1994; Camden, Motley, \& Wilson, 1984). This claim has gathered mixed support (e.g., Burgoon \& Buller, 1995; Frank \& Vasilyeva, 2006), and Camden et al. (1984) were even conflicted in their proposal of such a view. Specifically, Camden et al. proposed that effectively communicating deception may be indicative of communication competence, or conversely, deception may reflect a lack of competence. Interestingly, they do not advocate one view over the other, writing "we are not going to argue for a position...for we are not in agreement ourselves" (p. 321). Although the view of deception as a skill has gathered mixed empirical support, this dissertation lends 
preliminary support to the argument that successfully communicating deception is a competent communication skill, or at the very least, is an important skill to have in romantic relationships. That is, because communicators in study one largely expressed deceptive affection for prosocial reasons while experiencing negative states, it appears that participants maintained an awareness that successfully communicating deception was important to avoid hurting their partners. Potentially, utilizing affectionate communication, compared to other deceptive messages, is an important message to express to romantic partners when attempting to competently and successfully deceive.

Results of this investigation suggest that DAMs are indicative of temporary dissatisfaction with one's partner or relationship. That is, a communicator may maintain an overall love and commitment for their partner, yet at the time of DAM expression, experience some frustration or similar negative affect. Yet, individuals in this research elected to communicate deceptive affection, rather than express their current negative feelings. Expressing their negative affect could, potentially, jeopardize their current relational state, and, given that these negative states were temporary, individuals likely communicated deceptive affection to preserve their overall relational commitment and satisfaction. This is consistent with prior work identifying affection as a relational maintenance behavior (Guerrero \& Bachman, 2006), introducing the possibility that deceptive affection may be expressed to maintain relationships or as a way to cope with difficult situations.

Although the present research adopted a source approach to understanding deceptive affection, there are implications for receivers of such messages in relationships. Because affectionate messages were often expressed to disguise some negative affect, receivers of such messages should not always assume that affectionate messages are positive and pleasant 
messages from romantic partners. Consequently, for those receiving affectionate messages within romantic relationships, an interesting quandary exists: these affectionate messages may be authentic, however, when deceptive, partners may be experiencing negative feelings. The discovered routine nature of deceptive affection only further exacerbates this unique situation. Affection researchers have described, based on the link between affectionate communication and relational qualities, that affectionate messages may be a thermometer indicating a partner's level of satisfaction with the relationship (Horan \& Booth-Butterfield, in press). Building off of this metaphorical argument, deceptive affection may signal temporary dissatisfaction; yet, given the benefits associated with affectionate communication, the deceptive affection should still benefit the receiver. Future research is needed to understand the relationships among deceptive affection and relational qualities.

\section{Limitations}

The results should be interpreted with the following limitations in mind. First, and as identified previously during the discussion of deceptive motives, study two should have measured deceptive motives using the typology discovered in study one. This was not possible because studies one and two were conducted concurrently. Second, it is very likely that social desirability influenced reporting of DAMs, the motive for the DAM, and self reports of affectionate communication and deception. Although this bias was measured in both studies, the measure was statistically unreliable in studies one $(\alpha=.44)$ and two $(\alpha=.47)$. Further, after dropping various combinations of items, a reliable version of the scale was not discovered. Therefore, it is unknown how social desirability impacted the results of the present investigation. Future studies examining deceptive affection should also assess social desirability using a different measure. 
Although some may consider the sample used in the first study small, it is relatively consistent with recent communication diary research. Recent studies used samples of 21 (Schrodt, Baxter, McBride, Braithwaite, \& Fine, 2006) and 22 parents (Braithwaite, McBride, \& Schrodt, 2003) and 15 teachers (McBride \& Wahl, 2005) who kept interaction logs over a twoweek period. Further, participants recorded their romantic partner interaction over a week long period yielding descriptions of 180 DAMs. However, a potential limitation worth noting with this sample is the key difference between those who completed only the initial phase of the study and those who completed all three phases. Analyses revealed that those who completed all phases reported communicating significantly less deception to romantic partners $(M=2.92)$ compared to those who completed only the initial phase $(M=3.45)$. Thus, because the initial sample reported communicating more deception, they also likely communicated more DAMs. Obtaining diary data from the entire sample would have provided many more DAMs for analysis, and consequently, informed research on the deceptive affection process.

A related limitation pertains to the frequency and manner in which participants reported their deceptive affection in study one. Participants were instructed to complete their diaries, when possible, immediately following their expressions of deceptive affection. Understanding that this was not always possible, participants were instructed that they should, at the very least, complete their diaries once a day. Despite these instructions, it is unknown what the actual length of time was between their expressed deception and their descriptions of the communication. It is probable that, as time passed between the actual communication and the recording of the communication, the accuracy of participants' recordings likely decreased such that diary entries immediately following deceptive affection were the most accurate. Thus, some descriptions of feelings, motives, and messages in the diaries are likely not as accurate if participants waited 
many hours, or even days, to describe their deceptive affection. The previously reviewed diary work by McAuliffe et al. (2007) would suggest that this is an accurate concern. To control for this potential limitation in future diary based deception studies, daily recording should prompt communicators to list the time of their communication and the time of their recording to offer insight into the accuracy of participants' descriptions.

Moreover, two diary related limitations warrant review. Given the interpretive nature of study one's design, is likely that two coders could review the diary data and develop different typologies describing the feelings, messages, and motives for deceptive affection. Further, it appears that participants were confused about the manner in which to record the number of interactions they had with their romantic partner. Based on prior work, interactions were described as communication lasting longer than 10 minutes (DePaulo \& Kashy, 1998; Wheeler $\&$ Nezlek, 1977). Many participants left these questions blank, and for those who did report interactions a wide range $(0.00-1690.00 ; M=105.69, S D=252.35)$ resulted indicating participants misunderstood directions. Thus, understanding participants' number of interactions does not appear interpretable. Given both the ever changing nature of technology and the prevalence of technology (social networking websites, instant messaging software, and text messaging), considering interactions as face-to-face communication lasting longer than 10 minutes may be a dated consideration of communication that could have skewed the reported number of interactions. Accordingly, future studies should modify the interaction definition to reflect technology and, when conducting diary research, explicitly define the constants of what constitutes an interaction. Potentially, ignoring technology when defining interactions inflated the mean number of interactions participants reported. 
A final limitation worth noting, across both studies, is the average age of participants (study $1 M=20.27$, study $2 M=20.54$ ). Given the mean age of participants, this study is rather informative as to how young, non-married adults communicate deceptive affection in their established (length of relationships in study $1 M=21.34$ months, study $2 M=19.26$ months) romantic relationships. This age group was purposively sampled, given that prior work indicates that individuals communicate the most deception to their non-married romantic partners (DePaulo \& Kashy, 1998). Regardless though, these findings do not speak to how individuals communicate deceptive affection across the life-span or in marital relationships. Given the potential differences between those who have dated for two years in their early 20s and individuals married for 10 years, future studies should examine how deceptive affection operates in married relationships. Likewise, because this research focused on geographically close relationships, future studies should examine deceptive affection within long-distance relationships.

\section{Future Research}

Deceptive affection is relatively under-researched, thus there are multiple directions for future research. Some of these ideas have previously been discussed, such as replicating study two while also inducing stress, and working toward understanding how DAMs fit into AET's existing predictions. This dissertation examined physiology, rumination, guilt, and shame as potential source implications of expressing deceptive affection. Although these factors are informative, future research should work to truly understand if and how expressing DAMs is problematic for sources. One avenue for future work in this area would be to collect other physiological assessments, including cortisol and cholesterol. Although blood pressure and heart rate did not vary in study two, likely attributable to methodological concerns, these more 
advanced physiological stress indicators may be better assessments of how deceptive affection is problematic for sources.

Evolutionary and AET theorists argue that affectionate communication engenders numerous pro-creation based benefits including enhanced mate value and closer pair bonds. Aside from these perspectives, affectionate communication results in numerous emotional, physical, and relational advantages (e.g., Floyd, 2006a). It is unknown if DAMs result in the same benefits, and consequently, future research should examine if honest and deceptive affection result in similar benefits. Working from this evolutionary perspective, affectionate communicators are further argued to be valued mates. This suggests that those skilled in deceptive affection may also be valued mates, offering them evolutionary advantages in the mate selection process. Thus, future studies should also explore whether skilled affectionate deceivers are privileged in mate selection.

Some scholars consider successfully communicating deception to be a skill (Buller \& Burgoon, 1994; Camden et al., 1984). Therefore, future research should discover how relational communication is impacted when deceptive affection is discovered. Potentially, these messages could be quite harmful to receivers given the intimate nature of affectionate messages. Conversely, because such messages are reported to be expressed for prosocial motives, discussions of why one's partner expressed deceptive affection may result in partners feeling closer to one another. As this is speculation, future affection research should examine what happens when deceptive affection is detected.

A number of factors have the potential to influence how often individuals communicate deceptive affection, and researchers should work to identify what factors influence the frequency of such messages. A relational factor that could influence such communication is dependence 
power (Cloven \& Roloff, 1993; Lawler \& Bacharach, 1987). The perception of dependence power is generated when an individual believes his/her romantic partner has high quality alternatives and low levels of commitment. Potentially, a partner who has high alternatives and low levels of commitment would likely express more deceptive affection. Understanding the relational and personality factors that influence DAMs would offer a richer understanding of the deceptive affection process.

\section{Conclusion}

O'Hair and Cody (1994) argued that "deceptive acts cannot be viewed in isolation" (p. 210). Consistent with this view, this dissertation examined the feelings, messages, motives, and emotional and physiological consequences of expressing deceptive affection to romantic partners. The results indicate that individuals actively communicate deceptive affection to romantic partners for a variety of, mostly, positive reasons. This deceptive affection was frequently communicated to mask negative feelings. Importantly, this suggests that DAMs may perform some sort of maintenance function in romantic relationships. Further, recollections of DAMs did not cause physiological changes or strong emotional reactions. Thus, DAMs elicited minimal reactions from sources, potentially because communicators may not view them as consequential messages. Future research is necessary to further understand the positive and negative aspects of deceptive affection. With the results of this research in mind, holding hands, hugs, and kisses are not always genuine manifestations of love and affection, rather these messages may be expressed to mask a source's negative feelings. 


\section{References}

Abdel-Khalek, A. M. (1998). The structure and measure of death obsession. Personality and Individual Differences, 24, 159-165.

Andersen, P. A., \& Guerrero, L. K. (1998). Principles of communication and emotion in social interaction. In P. A. Andersen \& L. K. Guerrero (Eds.), Handbook of communication and emotion: Research, theory, applications, and contexts (pp. 49-96). San Diego: Academic Press.

Anderson, C. M., \& Martin, M. M. (1995). Communication motives of assertive and responsive communicators. Communication Research Reports, 12, 186-191.

Andsager, J. L., Bernker, V., Choi, H. L., \& Torwel, V. (2006). Perceived similarity of exemplar traits and behavior: Effects on message evaluation. Communication Research, 33, 3-18.

Ballard, M. E., Hamby, R. H., Panee, C. D., \& Nivens, E. E. (2006). Repeated exposure to video game play results in decreased blood pressure responding. Media Psychology, 8, 323341.

Baumeister, R. F., Stillwell, A. M., \& Heatherton, T. F. (1995a). Guilt: An interpersonal approach. Psychological Bulletin, 115, 243-267.

Baumeister, R. F., Stillwell, A. M., \& Heatherton, T. F. (1995b). Personal narratives about guilt: Role in action control and interpersonal relationships. Basic and Applied Social Psychology, 17, 173-198.

Beatty M. J., \& Dobos, J. A. (1997). Physiological assessment. In J. A. Daly, J. C. McCroskey, J. Ayres, T. Hopf, and D. M. Ayres (Eds.), Avoiding communication (pp. 217-229). Creskill, NJ: Hampton Press.

Bevan, J. L., \& Hale, J. L. (2006). Negative jealousy-related emotion rumination as 
consequences of romantic partner, cross-sex friend, and sibling jealousy expression. Communication Studies, 57, 363-379.

Boon, S. D., \& McLeod, B. A. (2001). Deception in romantic relationships: Subjective assessments of success at deceiving and attitudes toward deception. Journal of Social and Personal Relationships, 18, 463-476.

Booth-Butterfield, M., \& Trotta M. R. (1994). Attributional patterns for expressions of love. Communication Reports, 7, 119-129.

Booth-Butterfield, S. (1987). Action Assembly Theory and communication apprehension: A psychophysiological study. Human Communication Research, 13, 386-398.

Braithwaite, D. O., McBride, M. C., \& Schrodt, P. (2003). "Parent teams" and the everyday interactions of coparenting stepfamilies. Communication Reports, 16, 93-111.

Brann, M., Horan, S. M., \& Sidelinger, R. J. (2008). How do we match up? An analysis of gender orientation and mate selection preferences. Paper presented at the annual meeting of the National Communication Association, San Diego, CA.

Brehm, M. L., Back, B. K., \& Bogdonoff, M. D. (1964). A physiological effect of cognitive dissonance under stress and deprivation. Journal of Abnormal and Social Psychology, 69, 303-310.

Buller, D. B., \& Burgoon, J. K. (1994). Deception: Strategic and nonstrategic communication. In J. A. Daly \& J. M. Wiemann (Eds.), Strategic interpersonal communication (pp. 191223). Hillsdale, NJ: Lawrence Erlbaum.

Burgoon, J. K. (1978). A communication model of personal space violations: Explication and an initial test. Human Communication Research, 4, 129-142.

Burgoon, J. K., \& Buller, D. B. (1995). Interpersonal deception. Journal of Language \& Social 
Psychology, 14, 289-312.

Burgoon, J. K., \& Le Poire, B. A. (1992). A reply from the heart: Who are Sparks and Greene and why are they saying all these horrible things? Human Communication Research, 18, $472-482$.

Burleson, B. R., \& MacGeorge, E. L. (2002). Supportive communication. In M. L. Knapp and J. A. Daly (Eds.), Handbook of interpersonal communication (pp. 374-424). Thousand Oaks, CA: Sage

Buss, D. M. (1985). Human mate selection. American Scientist, 73, 47-51.

Buss, D. M. (1988). The evolution of human intrasexual competition: Tactics of mate attraction. Journal of Personality and Social Psychology, 54, 616-628.

Buss, D. M. (2006). Sexual selection and human mating strategies. Science, 312, 690-691.

Buss, D. M., \& Barnes, M. (1986). Preferences in human mate selection. Journal of Personality and Social Psychology, 50, 559-570.

Camden, C., Motley, M. T., \& Wilson, A. (1984). White lies in interpersonal communication: A taxonomy and preliminary investigation of social motivations. Western Journal of Speech Communication, 48, 309-325.

Carson, C. L., \& Cupach, W. R. (2000). Fueling the flames of the green-eyed monster: The role of ruminative thought in reaction to romantic jealousy. Western Journal of Communication, 64, 308-329.

Charania, M., \& Ickes, W. J. (2006). Research methods for the study of personal relationships. In A. L. Vangelisti and D. Perlman (Eds.), Handbook of personal relationships (pp. 5171). New York: Cambridge.

Cloven, D. H., \& Roloff, M. E. (1991). Sense-making activities and interpersonal conflict: 
Communicative cures for the mulling blues. Western Journal of Communication, 55, 134158.

Cole, T. (2001). Lying to the one you love: The use of deception in romantic relationships. Journal of Social and Personal Relationships, 18, 107-129.

Crowne, D. P., \& Marlowe, D. (1960). A new scale of social desirability independent of psychopathology. Journal of Consulting Psychology, 24, 349-354.

Dainton, M. (1998). Everyday interaction in marital relationships: Variations in relative importance and event duration. Communication Reports, 11, 101-109.

Daly, M., \& Wilson, M. (1980). Discriminative parental solicitude: A biological perspective. Journal of Marriage and the Family, 42, 277-288.

Darwin, C. (1859). On the origin of species. London: J. Murray.

DePaulo, B. M., \& Kashy, D. A. (1998). Everyday lies in close and casual relationships. Journal of Personality and Social Psychology, 74, 63-79.

DePaulo, B. M., Kashy, D. A., Kirkendol, S. E., Wyer, M. M., \& Epstein, J. A. (1996). Lying in everyday life. Journal of Personality and Social Psychology, 74, 63-79.

Doss, B. D., Simpson, L. E., \& Christensen, A. (2004). Why do couples seek marital therapy? Professional Psychology, 35, 608-614.

Ekman, P. (1985). Telling lies. New York: Norton.

Ekman, P., \& Friesen, W. V. (1975). Unmasking the face: A guide to recognizing emotions from facial clues. Englewood, NJ: Prentice Hall.

Erbert, L. A., \& Floyd, K. (2004). Affectionate expressions as face-threatening acts: Receiver assessments. Communication Studies, 55, 230-246.

Festinger, L. (1957). A theory of cognitive dissonance. Stanford, CA: Stanford University Press. 
Fishbein, M., Hennessy, M., Yzer, M., \& Curtis, B. (2004). Romance and risk: Romantic attraction and health risks in the process of relationship formation. Psychology, Health, \& Medicine, 9, 273-285.

Fletcher, G. J. O., Tither, J. M., O’ Loughlin, C., Friesen, M., \& Overall, N. (2004). Warm and homely or cold and beautiful? Sex differences in trading off traits in mate selection. Personality and Social Psychology Bulletin, 36, 659-672.

Floyd, K. (1997a). Communicating affection in dyadic relationships: An assessment of behavior and expectancies. Communication Quarterly, 45, 68-80.

Floyd, K. (1997b). Knowing when to say "I love you": An expectancy approach to affectionate communication. Communication Research Reports, 14, 321-330.

Floyd, K. (2001). Human affection exchange: I. Reproductive probability as a predictor of men's affection with their sons. Journal of Men's Studies, 10, 39-50.

Floyd, K. (2002). Human affection exchange: V. Attributes of the highly affectionate. Communication Quarterly, 50, 135-152.

Floyd, K. (2004). An introduction to the uses and potential uses of physiological measurement in the study of family communication. The Journal of Family Communication, 4, 295-318.

Floyd, K. (2006a). Communicating affection: Interpersonal behavior and social context. Cambridge, England: Cambridge University Press.

Floyd, K. (2006b). Human affection exchange: XII. Affectionate communication is associated with diurnal variation in salivary free cortisol. Western Journal of Communication, 70, 47-63.

Floyd, K., Haynes, M. T., \& Mikkelson, A. C. (2005). The biology of human communication. Florence, KY: Thomson. 
Floyd, K., Hesse, C., \& Haynes M. T. (2007). Human affection exchange: XV. Metabolic and cardiovascular correlates of trait expressed affection. Communication Quarterly, 55, 7994.

Floyd, K., Hesse, J. A., Miczo, L. A., Halone, K., Mikkelson, A. C., \& Tusing, K. J. (2005). Human affection exchange: VIII. Further evidence of the benefits of expressed affection. Communication Quarterly, 53, 285-303.

Floyd, K., Mikkelson, A. C., \& Hesse, C. H. (2008). The biology of human communication. Mason, OH: Thomson.

Floyd, K., Mikkelson, A. C., Hesse, C., \& Pauley, P. M. (2007). Affectionate writing reduces total cholesterol: Two randomized controlled trials. Human Communication Research, 33, 119-142.

Floyd, K., Mikkelson, A. C., Tafoya, M. A., Farinelli, L., La Valley, A. G., Judd, J., Davis, K. L., Haynes, M. T., \& Wilson, J. (2007). Human affection exchange: XIV. Relational affection predicts resting heart rate and free cortisol secretion during acute stress. Behavioral Medicine, 32, 151-156.

Floyd, K., Mikkelson, A. C., Tafoya, M. A., Farinelli, L., La Valley, A. G., Judd, J., Haynes, M. T., Davis, K. L., \& Wilson, J. (2007). Human affection exchange: XIII. Affectionate communication accelerates neuroendocrine stress recovery. Health Communication, 22, 123-132.

Floyd, K., \& Morman, M. T. (1997). Affectionate communication in nonromantic relationships: The influences of communicator, relational, and contextual factors. Western Journal of Communication, 61, 279-298.

Floyd, K., \& Morman, M. T. (1998). The measurement of affectionate communication. 
Communication Quarterly, 46, 144-162.

Floyd, K., \& Morman, M. T. (2000). Affection received from fathers as a predictor of men's affection with their own sons: Tests of modeling and compensation hypotheses. Communication Monographs, 67, 347-361.

Floyd, K., \& Morman, M. T. (2001). Human affection exchange: III. Discriminative parental solicitude in men's affectionate communication with their biological and nonbiological sons. Communication Quarterly, 49, 310-327.

Floyd, K., \& Morman, M. T. (2003). Human affection exchange: II. Affectionate communication in father-son relationships. The Journal of Social Psychology, 143, 599-612.

Floyd, K., \& Morman, M. T. (2005). Fathers' and sons' reports of fathers' affectionate communication: Implications of a naïve theory of affection. Journal of Social and Personal Relationships, 22, 99-109.

Floyd, K., \& Morr, M. C. (2003). Human affection exchange: VII. Affectionate communication in the sibling/spouse/sibling-in-law triad. Communication Quarterly, 51, 247-261.

Floyd, K., \& Riforgiate, S. (2008). Affectionate communication received from spouses predicts stress hormone levels in healthy adults. Communication Monographs, 75, 351-368.

Floyd, K., Sargent, J. E., \& DiCorcia, M. (2004). Human affection exchange: VI. Further tests of the reproductive probability as a predictor of men's affection with their adult sons. The Journal of Social Psychology, 144, 191-206.

Floyd, K., \& Voloudakis, M. (1999). Affectionate behavior in adult platonic friendships. Human Communication Research, 25, 341-369.

Foa, U. G., \& Foa, E. B. (1972). Resource exchange: Toward a structural theory of interpersonal communication. In A. W. Siegman \& B. Pope (Eds.), Studies in dyadic communication 
(pp. 291-323). New York: Pergamon.

Frank, M., \& Vasilyeva, A. (2006). Testing Interpersonal Deception Theory: Strategic and nonstrategic behaviors of deceivers and truth tellers, communication skills, and the dynamic character of deception. Paper presented at the annual meeting of the International Communication Association, Dresden, Germany.

Glaser, B. G., \& Strauss, A. (1967). The discovery of grounded theory: Strategies for qualitative inquiry. Chicago, IL: Aldine.

Guerrero, L. K., \& Bachman, G. F. (2006). Associations among relational maintenance behaviors, attachment-style categories, and attachment dimensions. Communication Studies, 57, 341-361.

Gulledge, A. K., Gulledge, M. H., \& Stahmann, R. B. (2003). Romantic physical affection and types of relationship satisfaction. The American Journal of Family Therapy, 31, 233-242.

Hansen, S. (1977). Dating choices of high school students. The Family Coordinator, 26, 133138.

Harvey, J. H., \& Wenzel, A. (2006). Theoretical perspectives in the study of close relationshps. In A. L. Vangelisti and D. Perlman (Eds.), Handbook of personal relationships (pp. 3549). New York: Cambridge.

Hayes, J. G., \& Metts, S. (2008). Managing the expression of emotion. Western Journal of Communication, 72, 374-396.

Helmreich, R., \& Stapp, J. (1974). Short forms of the Texas Social Behavior Inventory measure of self-esteem. Bulletin of the Psychonomic Society, 4, 473-475.

Hesse, C., \& Floyd, K. (2008). Affectionate experience mediates the effects of alexithymia on mental health and interpersonal relationships. Journal of Social and Personal 
Relationships, 25, 793-810.

Holden, R. R.,\& Fekken, G. C. (1989). Three common social desirability strangers? Journal of Research in Personality, 23, 180-191.

Horan, S. M., \& Booth-Butterfield, M. (in press). Investing in affection: An investigation of Affection Exchange Theory and relational qualities. Communication Quarterly.

Horan, S. M., \& Dillow, M. R. (in press). Deceivers and emotion: The impact of relational commitment, satisfaction, and deceptive message type on feelings of guilt and shame. The Atlantic Journal of Communication.

Horan, S. M., \& Turner, L. H. (2009). Sibling transgressions: An application of Affection Exchange Theory. Paper presented at the annual meeting of the Eastern Communication Association, Philadelphia, PA.

Huston, T. L., Caughlin, J. P., Houts, R. M., Smith, S. F., \& George, L. J. (2002). The connubial crucible: Newlywed years as predictors of marital delight, distress, and divorce. Journal of Personality and Social Psychology, 80, 237-252.

Jones, W. H., \& Kugler, K. (1993). Interpersonal correlates of the guilt inventory. Journal of Personality Assessment, 61, 246-258.

Jorm, A. F., Dear, K. B. G., Rodgers, B., \& Christensen, H. (2003). Interaction between mother's and father's affection as a risk factor for anxiety and depression symptoms. Social Psychiatry and Psychiatry Epidemiology, 38, 173-179.

Kaplar, M. E., \& Gordon, A. K. (2004). The enigma of altruistic lying: Perspective differences in what motivates and justifies lie telling in romantic relationships. Personal Relationships, 11, 489-507.

Kashy, D. A., \& DePaulo, B. M. (1996). Who lies? Journal of Personality and Social 
Psychology, 70, 1037-1051.

Keicolt-Glaser, J. K., \& Newton, T. L. (2001). Marriage and health: His and hers. Psychological Bulletin, 127, 472-503.

Kerver, M. J., Van Son, M. J. M., \& De Groot, P. A. (1992). Predicting symptoms of depression from reports of early parenting: A one year prospective study in a community sample. Acta Psychiatrica Scandinavia, 86, 262-272.

Knapp, M. (2006). Lying and deception in close relationships. In A. L. Vangelisti and D. Perlman (Eds.), Handbook of personal relationships (pp. 517-532). New York: Cambridge.

Kugeares, S. L. (2002). Social anxiety in dating initiation: An experimental investigation of an evolved mating-specific anxiety mechanism. Unpublished doctoral dissertation, University of Texas at Austin, Austin, TX.

Lawler, E. J., \& Bacharach, B. (1987). Comparison of dependence and punitive forms of power. Social Forces, 66, 269-284.

Lewis, H. B. (1971). Shame and guilt in neurosis. New York: International Universities Press.

Martin, M. M., \& Anderson, C. M. (1995). The father-young adult relationship: Interpersonal motives, self disclosure, and satisfaction. Communication Quarterly, 43, 119-130.

McAuliffe, T. L., DiFranceisco, W., \& Reed, B. (2007). Effects of question format and collection mode on the accuracy of retrospective surveys of health risk behavior: A comparison with daily sexual activity diaries. Health Psychology, 26, 60-67.

McBride, M. C., \& Wahl, S. T. (2005). “To say or not to say:” Teachers' management of privacy boundaries in the classroom. Texas Speech Communication Journal, 30, 8-22.

McCornack, S. A., \& Levine, T. R. (1990). When loves become leery: The relationship between 
suspicion and accuracy in detecting deception. Communication Monographs, 57, 219230.

McCornack, S. A., \& Parks, M. R. (1986). Deception detection and relationship development: The other side of trust. Communication Yearbook, 9, 377-389.

McCroskey, J. C. (1970). Measures of communication bound anxiety. Speech Monographs, 37, 269-277.

McCullough, M .E. (2001). Forgiveness: Who does it and how do they do it? Current Directions in Psychological Science, 10, 194-197.

McCullough, M. E., Osulak, P., Brandon, A., \& Akers, L. (2007). Rumination, fear, and cortisol: An in vivo study of interpersonal transgressions. Health Psychology, 26, 126-132.

McGraw, K. M. (1987). Guilt following transgression: An attribution of responsibility approach. Journal of Personality and Social Psychology, 53, 247-256.

Medalie, J. H., Strange, K. C., Zyanski, S. J., \& Goldboart, U. (1992). The importance of biopsychosocial factors in the development of duodenal ulcer in a cohort of middle-aged men. American Journal of Epidemiology, 136, 1280-1287.

Messman, S. J., \& Mikesell, R. L. (2000). Competition and interpersonal conflict in dating relationships. Communication Reports, 13, 21-34.

Metts, S., \& Cupach, W. R. (2007). Responses to relational transgressions: Hurt, anger, and sometimes forgiveness. In B. H. Spitzberg and W. R. Cupach (Eds.), The dark side of interpersonal communication (pp. 243-274). Mahwah, NJ: Lawrence Earlbaum.

Morman, M. T., \& Floyd, K. (1998). “I love you man”: Overt expressions of affection male-male interaction. Sex Roles, 38, 872-881.

O’Hair, D., \& Cody, M. J. (1994). Deception. In W. R. Cupach and B. H. Spiztberg (Eds.), The 
dark side of interpersonal communication (pp. 181-214). Hillsdale, NJ: Lawrence Erlbaum.

Omron (2007). Omron instruction manual: Wrist blood pressure monitor with advanced position sensor (APS) model HEM-650. Bannockburn, IL.

Owen, W. F. (1987). The verbal expression of love by women and men as a critical communication event in personal relationships. Women's Studies in Communication, 10, $15-24$.

Pennebaker, J. W., \& Beall, S. (1986). Confronting a traumatic event: Toward an understanding of inhibition and disease. Journal of Abnormal Psychology, 95, 274-281.

Pennebaker, J. W., Colder, M., \& Sharp, L. K. (1990). Accelerating the coping process. Journal of Personality and Social Psychology, 58, 528-537.

Pennebaker, J., W., Kiecolt-Glaser, J. K., \& Glaser, R. (1988). Disclosure of trauma and immune function: Health implications for psychotherapy. Journal of Consulting and Clinical Psychology, 56, 239-245.

Peterson, C. (1996). Deception in intimate relationships. International Journal of Psychology, 6, 279-288.

Pines, A. M. (2001). The role of gender and culture in romantic attraction. European Psychologist, 6, 92-102.

Planalp, S., Rutherford, D., \& Honeycutt, J. M. (1988). Events that increase uncertainty in personal relationships II: Replication and extension. Human Communication Research, $14,516-547$.

Punyanunt-Carter, N. M. (2005). Father and daughter motives and satisfaction. Communication Research Reports, 22, 293-301. 
Roloff, M. E., Soule, K. P, \& Carey, C. M. (2001). Reasons for remaining in a relationship and responses to relational transgressions. Journal of Social and Personal Relationships, 18, $362-385$.

Rubin, R. B., Perse, E. M., \& Barbato, C. A. (1988). Conceptualization and measurement of interpersonal communication motives. Human Communication Research, 14, 602-628.

Sarason, B. R., \& Sarason, I. G. (2006). Close relationships and social support: Implications for the measurement of social support. In A. L. Vangelisti and D. Perlman (Eds.), Handbook of personal relationships (pp. 429-443). New York: Cambridge.

Scherer, K. R., \& Wallbott, H. T. (1994). Evidence for universality and cultural variation of differential emotional response patterning. Journal of Personality and Social Psychology, $66,310-328$.

Scholl, J. C., \& O’Hair, D. (2005). Uncovering beliefs about deceptive communication. Communication Quarterly, 53, 377-399.

Schrodt, P., Baxter, L. A., McBride, M. C., Braithwate, D. O., \& Fine, M. A. (2006). The divorce decree, communication, and the structuration of coparenting relationships in stepfamilies. Journal of Social \& Personal Relationships, 25, 741-759.

Schrodt, P., Ledbetter, A. M., \& Ohrt, J. K. (2007). Parental confirmation and affection as mediators of family communication patterns and children's mental well being. Journal of Family Communication, 7, 23-46.

Schutz, W. (1958). FIRO: A three-dimensional theory of interpersonal behavior. New York: Rinehart.

Scott, W. A. (1955). Reliability of content analysis: The case of nominal scale coding. Public Opinion Quarterly, 19, 321-325. 
Seiter, J. S., \& Bruschke, J. (2007). Deception and emotion: The effects of motivation, relationship type, and sex on expected feelings of guilt and shame following acts of deception in United States and Chinese samples. Communication Studies, 58, 1-16.

Seiter, J. S., Bruschke, J., \& Bai, C. (2002). The acceptability of deception as a function of perceivers' culture, deceivers' intention, and deceiver-deceived relationship. Western Journal of Communication, 66, 158-180.

Sidelinger, R. J., \& Booth-Butterfield, M. (2007). Mate value discrepancy as a predictor of forgiveness and jealousy in romantic relationships. Communication Quarterly, 55, 207223.

Sifneos, P. E. (1973). The prevalence of 'alexithymic' characteristics in psychosomatic patients. Psychotherapy and Psychosomatics, 22, 255-262.

Smith, R. H., Webster, J. M., Parrott, W. G., \& Eyre, H. L. (2002). The role of public exposure in moral and nonmoral shame and guilt. Journal of Personality and Social Psychology, 83, 138-159.

Soliz, J. (2008). Intergenerational support and the role of grandparents in post-divorce families: Retrospective accounts of young adult grandchildren. Qualitative Research Reports in Communication, 9, 72-80.

Solomon, D. H., Knobloch, L. K., \& Fitzpatrick, M. A. (2003). Relational power, marital schemas, and the decisions to withhold complaints: An investigation of the chilling effect on confrontation in marriage. Communication Studies, 55, 146-167.

Sprecher, S., Sullivan, Q., \& Hatfield, E. (1994). Mate selection preferences: Gender differences examined in a national sample. Journal of Personality and Social Psychology, 66, 10741080. 
Stewart, S., Stinnett, H., \& Rosenfeld, L. B. (2000). Sex differences in desired characteristics of short-term and long-term relationship partners. Journal of Social and Personal Relationships, 17, 843-853.

Strauss, A., \& Corbin, J. (1998). Basics of qualitative research: Techniques and procedures for developing grounded theory. Thousand Oaks, CA: Sage.

Strzyzewski, K. D., Buller, D. B., \& Aune, K. (1996). Display rule development in romantic relationships. Human Communication Research, 23, 115-146.

Tangney, J. P. (1992). Situational determinants of shame and guilt in young adulthood. Personality and Social Psychology Bulletin, 18, 199-206.

Tangney, J. P., Wagner, P., \& Gramzow, R. (1989). The test of self conscious affect inventory. Fairfax, VA: George Mason University.

Tangney, J. P., Wagner, P., \& Gramzow, R. (1992). Proneness to shame, proneness to guilt, and psychopathology. Journal of Abnormal Psychology, 101, 469-478.

Tangney, J. P., Wagner, P. E., Hill-Barlow, D., Marshall, D. E., \& Gramzow, R. (1996). Relation of shame and guilt to constructive versus destructive responses to anger across the lifespan. Journal of Personality and Social Psychology, 70, 797-809.

Trivers, R. L. (1972). Parental investment and sexual selection. In B. Campbell (Ed.), Sexual selection and the descent of man (pp. 136-179). Chicago: Aldine.

Wheeler, L., \& Nezlek, J. B. (1977). Sex differences in social interaction. Journal of Personality and Social Psychology, 35, 742-754. 


\section{Appendix A}

\section{Outline of Phase One Training}

I. Introduction \& thanks for coming

a. Sean Horan-dissertation

II. Review inclusion material

a. 18 years of age or older

b. In a romantic relationship that is not long distance

c. Dating, not married

d. Must define themselves as a couple for at least 3 months

III. Hand out phase one measures (Should take no more than 10-15 minutes to complete)

a. Have them write their code number on the top right. Explain that the code number is six digits: the first two numbers are the day you were born and the last four numbers are the last four numbers of your phone number.

IV. Going over content. What is deceptive affection?

a. Define deception

i. Deception occurs anytime you intentionally try to mislead someone

ii. Social desirability messages: not a good or bad thing, everyone does it, not judged for it, answers are confidential, one third of messages are deceptive to non-married romantic partner

b. Define affection

i. Feelings of affection

1. Internal feelings of fondness, liking, or love

ii. Communicating affection

1. Expressions of the internal feelings

2. Verbal \& Nonverbal

a. Saying I love you, I like you, holding hands, back rubs, compliments, cuddling, etc.

c. Define deceptive affection

i. The focus of this study is deceptive affection. It is very important that you all understand what this is, so please feel free to ask questions at any point.

ii. Deceptive affection occurs when you communicate affection that you are not genuinely feeling. So the expression of affection and feelings of affection are not the same. Basically, it is any affection you express that you do not completely feel.

iii. Examples:

1. You and your romantic partner are upset with one another. You rub his/her back, even though you are not feeling affection, to avoid a fight

2. You think someone is "checking out" your romantic partner. You then hold their hand to show that you two are a couple - not because you actually were feeling warmth and fondness toward your partner.

3. Your romantic partner had a bad day at school/work. You are feeling really tired and feel stressed with school. However, to make 
your partner feel better, you hug them and say "I'm sorry you had a bad day. You mean a lot to me.”

4. Another example would be communicating affection to obtain sex. You tell your partner how much you love and care for him/herthat is, you overstate your feelings - to elicit sex.

5. Maybe your partner asks: "Do you love me?" You may care about your partner very deeply, but not be sure it is love. To avoid hurting their feelings, you say "Yes, I do love you."

6. Do you have any examples?

7. Again, these are not good or bad. They are very common messages in romantic relationships.

V. Hand out diaries

a. Have them write code number.

b. Explain that the purpose of the diary is a 7-day log of deceptive affection expressed in your romantic relationship.

c. Explain that they should set aside a certain time each day that works best for them to fill this out (Right before dinner? Break between classes?). They should write this time on the front of the diary.

d. The second page of the diary reviews what we just talked about. It explains deception, affection, and deceptive affection. If you have questions over these things, please email/call/stop by.

e. At the end of each day they should record the total number of interactions they had with their romantic partner. An interaction is any communication lasting longer than 10 minutes. Record this on the second page.

f. Page three is where the diary begins. When filling it out...

i. You are first asked to describe what you were actually feeling. This is the internal experience.

ii. Then you are asked to describe the deceptive affection. This is the external affectionate message you told to your partner that was not consistent with what you were actually feeling.

iii. Next you are asked why you did this.

iv. There are 6 survey questions to fill out after that.

v. You are asked to fill out ONE page for EVERY incident of deceptive affection.

vi. You are welcome to use the back of each page if you need more room.

g. You should keep this diary confidential from their romantic partner.

h. If you remember deceptive affection after it happens (i.e., on Wednesday you remember a Monday instance, you can record it).

i. Not sure if what happened constitutes deceptive affection? Record it.

j. Do not worry about grammar, spelling, etc.

k. Completely confidential —no one will ever find out your answers

1. If they need extra pages or have any questions they can email/call me or come to my office hours.

VI. Turning in the diary 
a. You will begin the 7 day diary tomorrow. So you will keep this log from day to ___ day. The next day, you should come by my office and turn this in.

b. My office is Armstrong 113 and I will be in there In some instances, Colleen may take your diary.

c. You will be asked to fill out a one page survey 
Appendix B

Study 1 Survey Materials

Phase One Materials

DIRECTIONS: Below is a list of items describing your general communication behaviors. Using the scale below, please rate the frequency with which you enact these behaviors.

\begin{tabular}{ccccc}
1 & 2 & 3 & 4 & 5 \\
\hline Never & Rarely & Sometimes & Often & Always
\end{tabular}

1. I am courteous.

2. I deliberately hurt others.

3. I have felt the urge to tell someone off.

4. I hesitate to help others.

5. I am a good listener

\section{DIRECTIONS: Below is a list of items describing how you communicate with your} romantic relational partner. Using the scale below, please rate how accurately each item describes your communication.

\begin{tabular}{lcccccc}
1 & 2 & 3 & 4 & 5 & 6 & 7 \\
\hline $\begin{array}{llll}\text { Strongly } \\
\text { Disagree }\end{array}$ & Disagree & Moderately & Undecided & Moderately & Agree & Strongly \\
& & Disagree & & Agree & & Agree
\end{tabular}

1. I disclose everything to my partner, both good and bad.

2. I sometimes find myself lying to my partner about things I have done.

3. I sometimes lie to my partner.

4. I tell my partner the complete truth, even things that he/she does not want to hear.

5. I try to hide certain things that I have done from my partner.

6. There are certain issues that I try to conceal from my partner.

7. There are certain things I try to mislead my partner about.

8. When I don't live up to my partner's expectations, I always tell him/her what I've done.

9. In the blank to the left, please estimate the number of times you lie to your partner during the course of a week. 


\section{Affection consists of verbal and nonverbal messages that communicate positive regard, liking, fondness, and love.}

Examples of affection include, but are not limited to, the following: holding hands, kissing, massages, hugging, putting your arm around your partner, winking at each other, saying "I like you," saying "I love you," telling your partner how important the relationship is, complimenting your partner, sitting close to your partner, and deeply staring into your partner's eyes.

Below is a list of items describing affection IN YOUR CURRENT ROMANTIC RELATIONSHIP. Please use the scale to describe how accurately each statement describes affection in your relationship.

*The term "partner" refers to your dating partner, boyfriend, girlfriend, or fiancé.

\begin{tabular}{lcccccc}
1 & 2 & 3 & 4 & 5 & 6 & 7 \\
\hline Strongly & Disagree & Moderately & Undecided & Moderately & Agree & Strongly \\
Disagree & & Disagree & & Agree & & Agree
\end{tabular}

1. I consider myself to be very affectionate with my partner.

2. I am always telling my partner how much I care about him/her.

3. When I feel affection for my partner, I usually express it.

4. I have a hard time telling my partner that I love or care about him/her.

5. I am not very good at expressing affection.

6. I am not a very affectionate person.

7. I love giving my partner a hug or putting my arm around him/her.

8. I do not tend to express affection to my partner very much.

9. My partner would say that I am a pretty affectionate person.

10. Expressing affection to my partner makes me uncomfortable.

11. My partner hugs me quite a bit.

12. My partner is always telling me that they like me, love me, or care about me.

13. I do not get very much affection from my partner.

14. I get quite a bit of affection from my partner. 
15. My partner is quite affectionate with me.

16. My partner does not express affection to me very often.

Your sex: $\quad$ Male $\quad$ Female

Your age:

Your relational partner's sex: Male Female

Your relational partner's age:

Overall, how long have you known your relational partner? Months and Days

How long have you defined you and your partner as a "romantic couple?" Months and Days

Which of the following best describes your romantic relationship with your partner? (check one)

Casually dating Seriously dating

Engaged

Other

What is your prominent racial/ethnic background? (check one):

Asian
Black/African American
White/Caucasian

Native American
Hispanic/Latino
O_ther (please specify:___


Phase Two

\section{COMMUNICATION JOURNAL}

\section{My Survey \#}

(Remember: Your survey number is six digits long. The first two numbers are the day you were born and the last four numbers are the last four numbers of your phone number. So if you were born on March 9 and your phone number was 297-1947, your survey number would be 091947.)

The best time for me to fill this out each day is: a.m./p.m.

(It is easier to do this journal if you make it part of your daily routine. For example, if you complete it after dinner every day or right before bed every night.)

If at any time when filling out this diary you have questions, please do not hesitate to contact Sean Horan (Shoran1 @ mix.wvu.edu, 304-293-3905). 
Two common messages we communicate in romantic relationships are deception and affection.

Lying occurs frequently in romantic relationships and it is quite normal to lie from time to time. In fact, $92 \%$ of people have admitted to lying to their romantic partner about something. About one out of every three interactions between romantic partners involves a lie. These lies range from minor to major topics.

Affection is defined as feelings of liking, fondness, and/or love for another person. This comes in many forms, including verbal, nonverbal, and supportive. Examples include, but are not limited to, the following: holding hands, kissing, massages, hugging, putting your arm around your partner, winking at each other, saying "I like you," saying "I love you," telling your partner how important the relationship is, complimenting your partner, sitting close to your partner, and deeply staring into your partner's eyes.

Sometimes we communicate deceptive affection - that is, we communicate feelings we are not genuinely feeling. For example, we may tell our romantic partner that we think he/she looks "pretty" when we do not actually feel that. Other times we may tell our partner we "love" him/her when we really do not feel like we do.

On the pages that follow in this journal, you are asked to record any time you lie about your feelings of affection to your romantic partner. Whenever you have lied about your affection, you are asked the following:

To fill out this journal as soon as possible

To record the date, time, and location

$>$ To describe how you were feeling toward your romantic partner

$>$ To describe how you communicated what you felt (which is different than how you were feeling)

Your reason/motive for why you lied about your affection

Remember - all of your answers are completely confidential. If you need more pages, please contact Sean Horan (304-293-3905; Shoran1@ mix.wvu.edu)

At the conclusion of each day, please write below how many interactions you had with your romantic partner. An interaction is considered any communication lasting longer than 10 minutes.

Day 1

Day 2

Day 3

Day 4

Day 5

Day 6 interactions interactions interactions interactions interactions interactions 
Day 7

Date: Time: interactions

a.m./p.m. Location (apartment, phone, IM, etc.):

What were you feeling (internal)? [use the back if you need more space]

What affection did you express (communicated verbally or nonverbally)? [use the back if you need more space]

Why did you choose to express something different than how you felt? [use the back if you need more space]

If discovered, how much do you think this deceptive message would impact your relationship?

1 No Impact
2

A small impact
3

A moderate impact
4

A big impact
5

A huge impact

Below are a number of statements that describe how much you think will reflect on the lie you just told. Based on that interaction, please rate how much you agree with each statement. The closer the number is to a statement, the more certain you are of your evaluation.

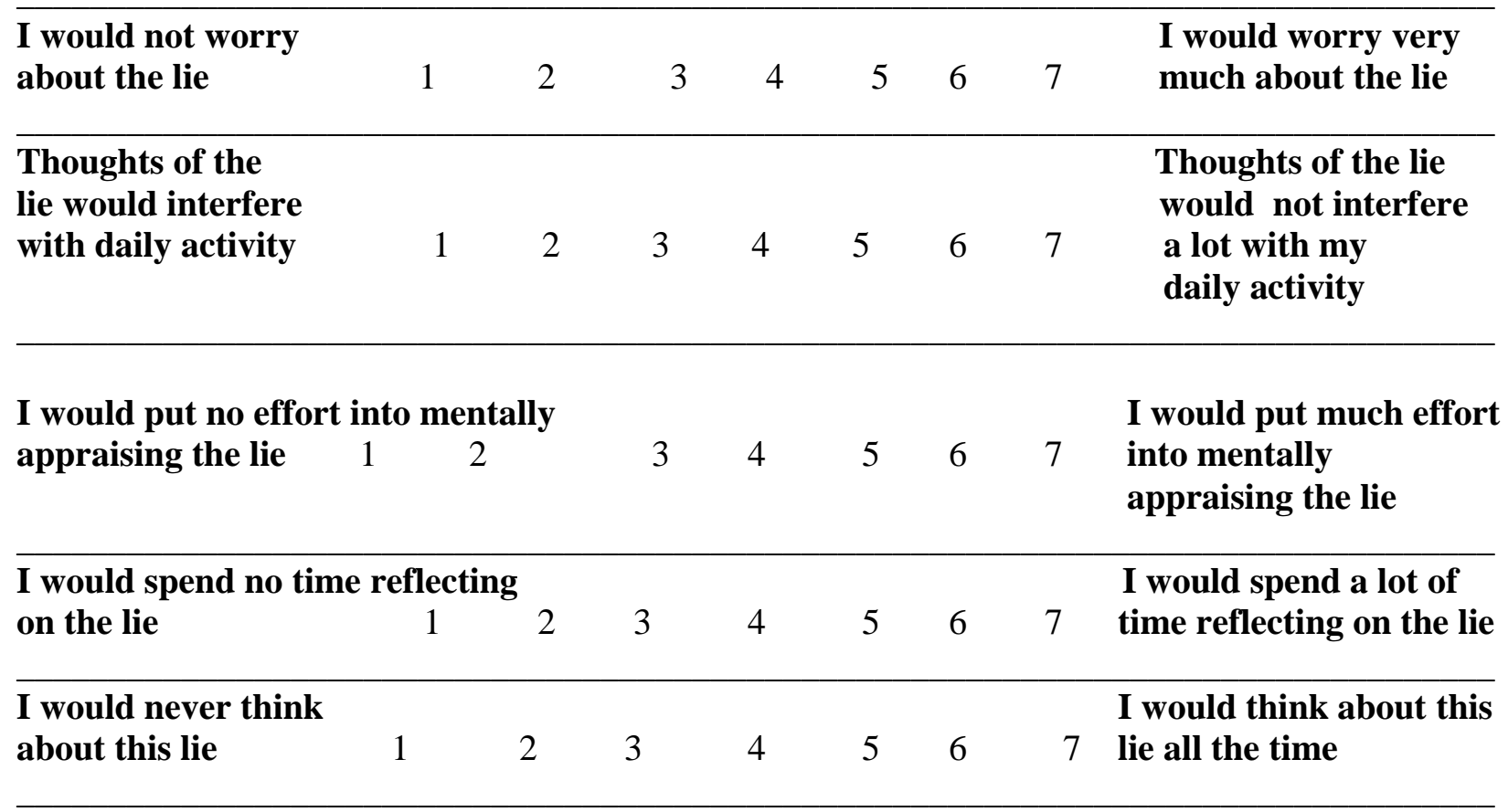




\section{Phase Three Items}

\section{My survey ID number is}

(Remember: Your survey number is six digits long. The first two numbers are the day you were born and the last four numbers are the last four numbers of your phone number. So if you were born on March 9 and your phone number was 297-1947, your survey number would be 091947).

2. Of all the deceptive affection communicated, which instance of deceptive affection did you think about the most?

3. How often did you think about that deceptive affection you communicated (i.e., the response to question 2)?

Not often Somewhat Often Often $\quad$ Very Often

4. Why did you think of this instance of deceptive affection the most?

5. Did your partner ever find out you lied about your affection? If yes, how did he/she react?

6. If you chose NOT to communicate deceptive affection your romantic partner at all this week, why did you make that choice?

7. You spent this week describing your communication with your romantic partner. How typical is this week compared to other weeks with your partner?

Not typical Somewhat Typical Typical $\quad$ Very typical

8. How successful do you think you are at lying?

Not successful Somewhat successful Successful $\quad$ Very successful

9. Compared to other people your age in romantic relationships, you lie: 
As much as they do Less than they do More than they do Undecided

10. Are you still dating the same person? Yes No

11. If no, was lying about your affection a factor in your break-up?

Yes No We are still dating 


\section{Appendix C}

Writing Instructions for Study Two

\section{Deceptive Affection Prompt}

Two common messages we communicate in romantic relationships are deception and affection.

Deception occurs frequently in romantic relationships and it is quite normal to deceive from time to time. In fact, $92 \%$ of people have admitted to deceiving their romantic partner about something. About one out of every three interactions between romantic partners involves a deception. These messages range from both minor to major topics.

Affection is defined as feelings of liking, fondness, and/or love for another person. This comes in many forms, including verbal, nonverbal, and supportive. Examples include, but are not limited to, the following: holding hands, kissing, massages, hugging, putting your arm around your partner, winking at each other, saying "I like you," saying "I love you," telling your partner how important the relationship is, complimenting your partner, sitting close to your partner, and deeply staring into your partner's eyes.

Sometimes we communicate deceptive affection-that is, we communicate feelings we are not genuinely feeling. For example, we may tell our romantic partner that we think he/she looks "pretty" when we do not actually feel that. Other times we may tell our partner we "love" him/her when we really do not feel like we do. Essentially, the external expression of affection verbally or nonverbally is not consistent with what one is actually feeling internally.

In the space below, please write about a recent memorable/important time when you communicated deceptive affection to your romantic partner. That is, explain a time when you communicated affection to your partner that you were not actually feeling. Please be as honest as possible and provide a complete and vivid description of the event. It may help for you to replay the event in your mind. Remember, your answers are completely confidential. No one will find out what you wrote, and the researcher understands deception is a common practice and, therefore, does not judge anyone for the act of deception.

Please describe what took place in this interaction as honestly and clearly as possible. Also, please write for the entire time you are asked to.

Before describing the event, please answer the following questions. Do not worry about grammar, spelling, or punctuation; rather, write freely about what comes to mind.

Approximately how long ago did this happen? 
Where did this happen (apartment, restaurant, phone, Facebook/Myspace, text message, etc.)?

What affection did you express (communicated verbally or nonverbally)?

What were you feeling (internal)?

Why did you choose to express something different than how you felt? (Circle one)

a) For self protection (i.e., to avoid looking bad)

b) To protect my partner (i.e., to avoid hurting his/her feelings)

c) To protect the relationship (i.e., to avoid conflict or relational problems)

d) Other: Please write in:

Please describe, in further detail, why you chose to express something different than how you felt?

Did your romantic partner find out that you were being dishonest?

If so, how did he/she react?

How did you feel after you expressed this dishonest affection? 
In the space below, please describe the interaction from start to finish. To capture all the details, please describe the event as if you were telling someone a story about it. Please use as much detail as possible.

\section{Honest Affection Prompt}

Affection is defined as feelings of liking, fondness, and/or love for another person. This comes in many forms, including verbal, nonverbal, and supportive. Examples include, but are not limited to, the following: holding hands, kissing, massages, hugging, putting your arm around your partner, winking at each other, saying "I like you," saying "I love you," telling your partner how important the relationship is, complimenting your partner, sitting close to your partner, and deeply staring into your partner's eyes.

In the space below, please write about a recent memorable/important time when you communicated affection to your romantic partner. That is, you expressed affection through verbal and/or nonverbal messages that matched how you actually felt. Please be as honest as possible and provide a complete and vivid description of the event. It may help for you to replay the event in your mind. Remember, your answers are completely confidential. No one will find out what you wrote. Take as much time as you need. Please describe what took place in this interaction as honestly and clearly as possible.

Please describe what took place in this interaction as honestly and clearly as possible. Also, please write for the entire time you are asked to.

Before describing the event, please answer the following questions. Do not worry about grammar, spelling, or punctuation; rather, write freely about what comes to mind. 
When did this happen (i.e., how long ago)?

Where did this happen (apartment, restaurant, phone, Facebook/Myspace, text message, etc.)?

What affection were you feeling (internal)?

What affection did you express (communicated verbally or nonverbally)?

Why did you express this affection?

How did your romantic partner react?

How did you feel after expressing the affection? 
In the space below, please describe the interaction from start to finish. To capture all the details, please describe the event as if you were telling someone a story about it. Please use as much detail as possible.

\section{Control Prompt:}

Think of a time you recently spent making plans with a friend. What did you two talk about? How did you make plans? Where did you all plan to go and/or what did you plan on doing? Please describe what took place in this interaction as honestly and clearly as possible.

Please be as honest as possible and provide a complete and vivid description of the event. It may help for you to replay the event in your mind. Remember, your answers are completely confidential. No one will find out what you wrote. Take as much time as you need.

Please describe what took place in this interaction as honestly and clearly as possible. Also, please write for the entire time you are asked to.

While writing, please describe the event as clearly as possible.

Before describing the event, please answer the following questions. Do not worry about grammar, spelling, or punctuation; rather, write freely about what comes to mind.

When did this happen (i.e., how long ago)? 
Where did this happen (apartment, restaurant, phone, Facebook/Myspace, text message, etc.)?

What did you two talk about?

What plans did you make?

Were these difficult plans to make? Why or why not?

How did you feel about these plans? Why?

In the space below, please describe the interaction from start to finish. To capture all the details, please describe the event as if you were telling someone a story about it. Please use as much detail as possible. 


\section{Appendix D}

Guilt and Shame Measures (Horan \& Dillow, in press)

\section{Below is a list of items that describe how you may have felt after communicating with your romantic partner. Using the scale below, please rate (1-7) how accurately each item below described how you felt after telling your lie.}

\begin{tabular}{lcccccc}
1 & 2 & 3 & 4 & 5 & 6 & 7 \\
\hline $\begin{array}{l}\text { Strongly } \\
\text { Disagree }\end{array}$ & Disagree & Moderately & Undecided & Moderately & Agree & Strongly \\
& & Disagree & & Agree & & Agree
\end{tabular}

1. I felt ashamed and wanted to avoid my partner after telling the lie.

2. I thought about the lie several times and different ways I could have avoided telling it.

3. I felt stupid after telling the lie.

4. I regret that I lied to my relational partner.

5. I felt incompetent after telling the lie.

6. I should have known that telling lies to my partner is not acceptable.

7. I felt disgusted at what I had done.

8. I felt like I needed to be a better relational partner.

9. I felt immature because I had lied to my partner.

10. I wanted to make it up to my partner as soon as possible.

11. I felt like a bad relational partner because I had lied to my partner.

12. I wanted to apologize for telling the lie and make sure my relational partner felt good.

13. I felt inadequate because I could not be honest with my partner.

14. I felt unhappy because I lied and wanted to do something to remedy the situation.

15. I felt like a coward because I was not honest with my partner.

16. I planned to do something to make up for telling the lie.

17. I felt small, like a rat, because I lied to my partner. 
18. I deserved to be reprimanded for telling the lie.

19. I felt anxious, like I needed to confess that I had lied.

20. I should have been more aware of my partner's feelings when I lied. 
Appendix E

Codebook

\author{
Feelings lied about \\ Negative thoughts about a partner's appearance/behavior \\ Wanting/not wanting to be with partner \\ Negative self affect/physiology \\ Disinterest in partner \\ Disguising sexual interest \\ Neutral feelings \\ Concern over a transgression \\ Other
}

\title{
Expressed affection \\ Verbal affection \\ Nonverbal affection \\ Supportive affection \\ Playful teasing \\ Commitment for a future together \\ Sex \\ Minimized affectionate feelings
}

\section{Deceptive affection motives}

Avoid hurting partner's feelings

Save partner's face

To receive affection

Avoid affection

Avoid conflict

Avoid topic

Show affiliation

Induce affect in partner

Habit/routine/reciprocation

To end an interaction

Avoid partner

Provide support

Mask affect

Other 